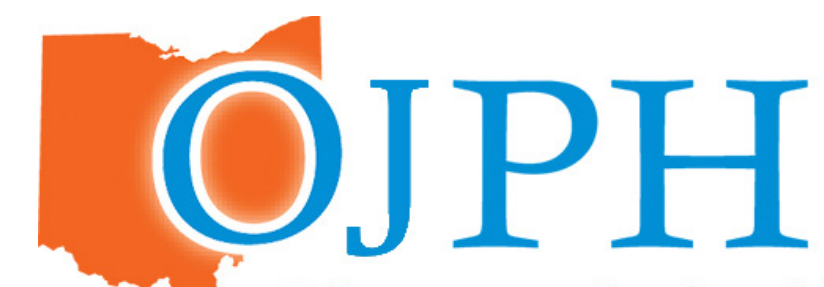

Vol. 4, Issue 1

June 2021

Ohio Journal of Public Health

Ohio Public Health Association

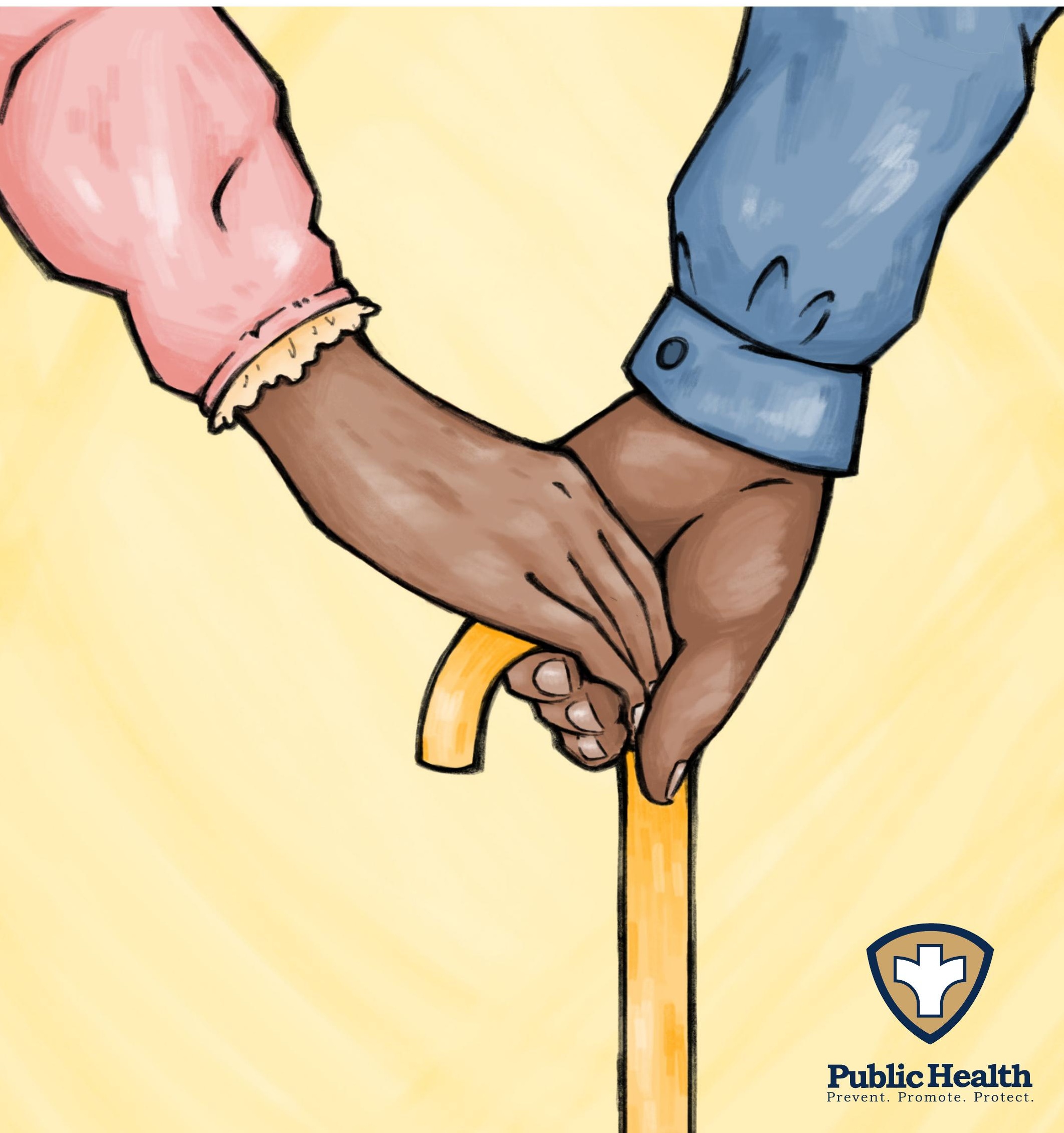




\section{TABLE OF CONTENTS}

\section{Editorial}

1 Keeping the Public Healthy During a Pandemic

Amy Ferketich

\section{COVID-19 Special Section}

3 Unintended Consequences: Social Isolation in the Elderly During COVID-19

Geoffrey Carney-Knisely

5 The Design and Methodology of the Ohio COVID-19 Survey

Marcus E. Berzofsky, Naomi Freedner, Caroline Scruggs, Robert Ashmead, Timothy Sahr, Bo Lu, Michael Nau, Eric Seiber, Hilary Rosebrook, Tom Duffy

11 The Ohio COVID-19 Survey: Preliminary Findings and Their Use During the Pandemic Lisa A. Frazier, Eric Seiber, Kristin J. Harlow, Selasi Attipoe, Brian O'Rourke, Ohio COVID-19 Survey Team

\section{Research Articles}

23

Sexually Transmitted Diseases Among Residents in Nursing Homes: The Nurses'

Perspective

Lauren N. Maziarz, Nikki Sorgi, Nicole Fischer

31 A Geographic Perspective on Opioid Misuse: Substance Abuse Treatment Deserts in Southwestern Ohio

Linnea Lowe, Cole Brokamp, Erika Rasnick, Eric S. Hall, Shauna Acquavita

\section{Public Health Practice}

38 Using Social Determinants Screening/Mapping Tools to Identify Needs and Resources for Student-Run Free Clinic Patients

Akanksha Dadlani, Cooper T. Johnson, Rebecca Fischbein, Stacey L. Gardner-Buckshaw, Amy Lee, John M. Boltri

45 Leveraging Local and Regional Partners to Implement Hospital Closed Point of Dispensing Sites

Daniel Baker, Sara Paton

53 Toledo Naloxone Outreach Program: Patient and Health Care Professional Student Education

Alex Petrak, Luke Zona, Jeni Ten Eyck, Manish Karamchandani, Tanvir Singh

60 Sight for All United: Five Year Impact of a Vison Foundation on its Community

Ankur Parikh, Meredith Spitz, Cooper T. Johnson, S.A. Erzurum 


\section{EDITORIAL}

\section{Keeping the Public Healthy During a Global Pandemic}

\section{Amy Ferketich}

The Ohio State University, College of Public Health, Columbus, $\mathrm{OH}$

Published June 21, 2021 https://doi.org/10.18061/ojph.v4i1.8365

I welcome you to the June 2021 issue of the Ohio Journal of Public Health (OJPH). Some of you may be reading this issue while working from home, still, after 16 months. For others, work may have resumed outside the home or, perhaps, your work setting did not change at all during the pandemic. No matter where you are working, or what you do in the field of public health, you have probably been told by someone not in the field that "everyone knows what public health is now!" as a result of COVID-19 and the public health response that it demanded. Awareness of public health as a profession has indeed increased considerably during the pandemic. ${ }^{1}$ Perhaps as a direct result, applications to public health education programs increased $20 \%$ to $30 \%$ during the pandemic. ${ }^{2,3}$ This is certainly good news for the profession. However, we all know that the work we do to keep the public healthy goes way beyond pandemic preparedness and infectious disease control and the Journal continues to be a means for communicating this important work to colleagues.

The current issue of OJPH features a special COVID-19 section that includes two research articles and one Op-Ed, two additional research articles, and four public health practice articles. Most of the work presented in these papers took place during the pandemic, which demonstrates a strong commitment not only to continuing the work to keep the public healthy in Ohio, but also to writing up the findings for this issue. This issue again features a cover design by Whitney Baxter and Gad Owusu, undergraduate students in the Department of Design at The Ohio State University. The design was inspired by several articles in this issue.

The two COVID-19 articles report on the Ohio COVID-19 Survey (OCS), which is a weekly survey of adults in Ohio that started in April 2020 and continues today. The OCS is used by Governor DeWine and his staff to make decisions about how to respond to the pandemic from a public health and economic recovery perspective. The article by Berzofsky et al describes the methodology and implementation of the survey. The OCS is the result of a longstanding partnership between State agencies, public colleges in Ohio, and a survey research firm. Frazier and colleagues report on some of the preliminary OCS findings related to the health and economic impact of the pandemic. The Op-Ed by Carney-Knisley, focused on social isolation among the elderly, was motivated by his grandmother's unfortunate experience in a hospital during the pandemic. It ends with a call to do better for the elderly, a group already vulnerable to the negative impact of social isolation.

The research article by Lowe et al maps substance abuse treatment deserts (defined as no treatment within a 15-minute drive) in a 13-county region in Southwest Ohio. Unfortunately, over half of individuals live in a methadone treatment desert and nearly 1 in 5 live in other substance use treatment deserts. Maziarz and colleagues report on the results from a survey with nursing home directors in Northwest Ohio to examine their support for, and behaviors associated with, educating nursing home 
residents about sexually transmitted diseases. Overall, support for such education remains high but delivery is low.

The four public health practice articles touch on different issues related to public health programs in the state. Two of the articles are focused on professional students in Ohio. In one, Dadlani and colleagues report on their social determinants of health screening tool and community resource referral process that were incorporated into their student-run free clinic in Northeast Ohio. This project allows the authors to determine the resources that are in greatest need among patients who seek care at the clinic. In the second paper, Petrak et al reported on the Toledo Naloxone Outreach Program's student education training on naloxone distribution. The results suggest that training is effective in increasing confidence in discussing substance abuse, and its treatment, with patients and family members.

The other two public health practice articles report on two important programs in Ohio. One is Sight for All United, a program in Mahoning County with a goal of providing care for underserved individuals. In the paper, Parikh et al summarize the types of services provided to individuals between 2016 and 2020. The second program involves the development and delivery of a toolkit that contains information about medical treatments, such as vaccines, that need to be delivered rapidly during emergencies. The toolkit was designed for local public health agencies and the article by Baker and Paton describes the feasibility assessment performed with local public health professionals.

This issue marks my last as Editor. As I noted in December, Professor Sheryl Chatfield, of Kent State University, is the new Editor of OJPH. I feel honored to have been asked by Lois Hall and Joe Ebel to serve as the Founding Editor of OJPH. It was a wonderful opportunity to meet other scholars, educators, and practitioners in Ohio. Serving as Founding Editor also taught me a lot about how to start a journal and manage the process that leads to a full issue. I have truly enjoyed working with the Associate Editors, Editorial Board, and the wonderful copy editor, Darlene Bowers. We can all agree that Darlene's articles are beautifully formatted! As I say farewell, know that I will continue to advocate for the important work that you do in Ohio to keep the public healthy. And I will support the Ohio Public Health Association in other ways as it serves to be the "voice" of public health in Ohio.

\section{REFERENCES}

1. Brisolara KF, Smith DG. Preparing students for a more public health-aware market in response to COVID-19. Prev Chronic Dis. 2020;17:200251. https://doi.org/10.5888/pcd17.200251

2. Maxouris C. Student interest in this field soared since the pandemic's start. Experts hope this is a turning point. May 9, 2021: Accessed May 29, 2021. https://www.cnn.com/2021/05/09/us/public-healthpandemic-student-applications/index.html
3. Smith MR and Young K. Public health programs see surge in students amid pandemic. November 17, 2020. Accessed May 29, 2021.

https://abcnews.go.com/Health/wireStory/public-health -programs-surge-students-amid-pandemic-74246218 


\section{Unintended Consequences: Social Isolation in the Elderly During COVID-19}

\section{Geoffrey Carney-Knisely ${ }^{1}$}

${ }^{1}$ College of Public Health, The Ohio State University, Columbus, $\mathrm{OH}$

Corresponding Author: Geoffrey Carney-Knisely, 1841 Neil Avenue, Columbus, OH 43210, (802)578-8503, geoffrey.carney-knisely@osumc.edu

Submitted December 14, 2020 Accepted May 6, 2021 Published June 21, 2021 https://doi.org/10.18061/ojph.v4i1.8066

My mother's face paused on the screen-again. As our call reconnected, the beeping EKG machine filled the silence. I sat in the surgical intensive care unit at The Ohio State University Wexner Medical Center trying to help my mother say goodbye to her mother over a video call. My grandmother fell, breaking her hip and suffering a heart attack during surgery. Hospital policy did not allow additional visitors; today might be my mother's last chance to say goodbye.

As of February 19, 2021, nearly 500000 Americans have died from (coronavirus disease 2019) COVID-19,1 many without family members in their final moments. In Ohio, 52\% of COVID-19 related deaths occurred in long-term care facilities, exceeding the national median of $37 \% .^{2}$ Policies restricting nursing home access were adopted to protect some of the country's most vulnerable populations. These policies have come at a great cost. It does not have to be this way.

Though my grandmother survived her visit to the SICU, her recovery was uphill. My visits were phone calls while peering through her nursing home window. I witnessed her slow daily decline. Her dementia worsened. She lost weight until she weighed just 90 pounds.

Her challenges are not unique. Social isolation has harmed elderly Americans; it is associated with an increased risk of all-cause mortality, a risk that may rival or exceed that posed by smoking or obesity. ${ }^{3}$ Further, loneliness has been associated with higher rates of depression and a 50\% increased risk of developing dementia. ${ }^{3}$ Prior to the pandemic, one-quarter of community-dwelling adults were considered socially isolated. ${ }^{3}$ Lockdown policies exacerbate this challenge.

What can we do differently? What can we do to protect the most vulnerable from both coronavirus and social isolation? Part of the answer is following public health guidelines: universal mask wearing, proper hand hygiene, and maintaining social distancing. Despite the US Centers for Medicare and Medicaid Services guidance for long-term care facilities in March 2020 restricting visitor access, many outbreaks still occurred, ${ }^{4}$ suggesting introduction of coronavirus into facilities by staff. This is compounded by low adherence to infection control practices among staff, with nearly one-third failing to wear a mask. ${ }^{5}$ Enforcement of guidelines will help to reduce community spread of COVID-19 and allow nursing homes to safely loosen some restrictions.

Another part of the answer is for long-term care facilities to promote social interactions for residents, whether physically distanced activities with other residents or through technological venues. Programming that encourages physical activity while maintaining distance can improve physical and mental health. This pandemic highlighted challenges for mental health services for older adults, and we must emphasize routine and crisis psychiatric services. Increased use of screening tools and of online psychological services could benefit our elders.

We have devastated an already marginalized elderly population. Our response to the pandemic should not render lives devoid of human interaction. We need to alter our policies so that we can continue to protect elderly Americans and prevent rising rates of physical and mental health conditions in nursing homes across the country.

\section{REFERENCES}

1. Centers for Disease Control and Prevention. COVID data tracker. Accessed February 21, 2021.

https://covid.cdc.gov/covid-data-tracker

2. Kaiser Family Foundation. State COVID-19 data and policy actions. Accessed February 21, 2021. 
https://www.kff.org/coronavirus-covid-19/issue-brief/state-covid-19data-and-policy-actions/\#longtermcare

3. National Academies of Sciences, Engineering, and Medicine. The National Academies Press; Washington, D.C.: 2020. Social isolation and loneliness in older adults: opportunities for the health care system.

4. Chen MK, Chevalier JA, Long EF. Nursing home staff networks and COVID-19. Proc Natl Acad SCI U S A. 2021;118(1).

https://doi.org/10.1073/pnas.2015455118

5. Au JKL, Suen LKP, Lam SC. Observational study of compliance with infection control practices among healthcare workers in subsidized and private residential care homes. BMC Infect Dis. 2021;21(1):75.

https://doi.org/10.1186/s12879-021-05767-8 


\section{The Design and Methodology of the Ohio COVID-19 Survey}

\section{Marcus E. Berzofsky ${ }^{1}$; Naomi Freedner ${ }^{1}$; Caroline Scruggs ${ }^{1}$; Robert Ashmead ${ }^{2}$; Timothy Sahrr ; Bo Lü; Michael Nau; Eric Seiber ${ }^{4}$; Hilary Rosebrook ${ }^{2}$; Tom Duffy ${ }^{1}$}

${ }^{1} \mathrm{RTI}$ International, Research Triangle Park, NC

${ }^{2}$ Ohio Colleges of Medicine Government Resource Center, Columbus, $\mathrm{OH}$

${ }^{3}$ Division of Biostatistics, The Ohio State University, Columbus, OH

${ }^{4}$ Division of Health Service and Management Policy, The Ohio State University, Columbus, $\mathrm{OH}$

Corresponding Author: Robert Ashmead, 150 Pressey Hall, 1070 Carmack Road, Columbus, OH 43210, (614) 685-6817, robert.ashmead@osumc.edu Submitted December 14, 2020 Accepted February 11, 2021 Published June 21, 2021 https://doi.org/10.18061/ojph.v4i1.8068

\section{ABSTRACT}

Background: Governments worldwide are balancing contrasting needs to curtail the toll that coronavirus disease 2019 (COVID-19) takes on lives and health care systems and to preserve their economies. To support decisions, data that simultaneously measure the health status of the population and the economic impact of COVID-19 mitigation strategies are needed. In the United States, prior to the onset of COVID-19, surveys or tracking systems usually focused on public health or economic indicators, but not both. However, tracking public health and economic measures together allow policy makers and epidemiologists to understand how policy and program decisions are associated. The Ohio COVID-19 Survey (OCS) attempts to track both measures in Ohio as one of the first statewide population surveys on COVID-19. To achieve this there are several methodological challenges which need to be overcome.

Methods: The OCS utilizes a representative panel offering both cross-sectional and longitudinal analyses. It targets 700 to 1000 respondents per week for a total of 12600 to 18000 respondents over an 18 -week period. Leveraging a sample of 24000 adult Ohioans developed from a statewide population health survey conducted in fall 2019, the OCS produces weekly economic and health measures that can be compared to baseline measures obtained before the COVID-19 pandemic began.

Results: The OCS was able to quickly launch and achieve high participation (45.2\%) and retention across waves.

Conclusion: The OCS demonstrates how it is possible to leverage an existing health-based survey in Ohio to generate a panel which can be used to quickly track fast-breaking health issues like COVID-19.

Keywords: COVID-19; Panel survey; Survey design; Ohio COVID-19 survey

\section{INTRODUCTION}

\section{Understanding the Problem}

Governments worldwide are balancing contrasting needs to curtail the toll that coronavirus disease 2019 (COVID-19) takes on lives and health care systems and to preserve their economies. In the United States (US), the federal government has instructed each state to determine the best time to implement its suggested guide- lines for either the entire state or regions of the state. ${ }^{1}$ To make an informed determination, states need detailed regional information about COVID-19 health and economic impacts. However, existing information at the state or county levels is consigned to tracking COVID-19 prevalence (eg, the Johns Hopkins Coronavirus Resources Center) or economic impact data (eg, the US Current Population Survey). Although these individual sources are useful, having health and economic data from a single source would help 
states to determine the potential impact of any policy or program on health and economic well-being. Furthermore, because the pandemic is dynamic and changes quickly, data on population risks are outdated in less than a week. To understand the impacts of policy and program decisions, governments must be able to measure change before, during, and after new policies and programs are implemented.

To help inform these decisions and understand how they impact Ohioans, the state of Ohio launched the Ohio COVID-19 Survey (OCS). The OCS leverages a prior Ohio, statewide population survey from which a panel of prospective survey participants was built. The OCS is a weekly web- and telephone-based tracking survey that is representative of Ohio residents and is designed to provide information on health and behavioral measures such as the respondent's COVID-19 testing status and compliance with social distancing and economic measures such as employment status and consumer confidence. This paper explains the OCS methods, which ensure it is generalizable to the Ohio population, and provides paradata from each wave of implementation.

\section{Panel Surveys}

Studies measuring emergent public health related topics such as COVID-19 face a challenge in trying to quickly recruit representative respondents who are willing to participate. This is especially true of studies which track health measures over time. To overcome this challenge, survey methodologists can turn to an existing panel to recruit study participants. Panels come in 2 varieties: (1) opt-in or voluntary panel, and (2) probability-based panel.

Opt-in or voluntary panels consist of a collection of persons who chose to be part of a panel and subsequently choose which surveys they participate in. Opt-in panels are not representative of the population for 2 reasons: (1) they skew toward high internet users, and (2) they usually suffer from low (ie, single digit) response rates. $^{2}$ For these reasons, opt-in panels were not considered for the OCS.

Probability-based panels are sets of persons randomly recruited to be a part of a panel. A non-web-based method is used for the recruitment (eg, a random digit dial (RDD) or address-based sample) in order to ensure non-internet users are included. Therefore, these panels are generally representative of the entire population. Probability-based panels require a 2-stage process to conduct a survey. The recruitment stage is first, and the participation stage follows where panel members are invited to take a particular survey. Because of this multi-stage process, response rates are presented for recruitment and participation. The recruitment response rate is the product of the recruitment stage and participation stage. These rates can be low and survey weights are required at each stage to correct for potential biases. ${ }^{3,4}$ However, the participation stage response rates can be high depending on the survey topic. 5 National probability-panels such as the Understanding America Study (UAS) have been used to quickly pivot and study emergent topics such as COVID-19.5 However, these national panels are relatively small (between 10000 and 60000 members spread across all 50 states). Therefore, at the state level, it is difficult for the national panels to obtain a large enough sample to produce reliable estimates. The OCS used a probability-based panel approach, but, to generate reliable estimates, developed its own panel in order to ensure adequate coverage of the entire state.

\section{METHODS}

\section{Setting}

The OCS is a general population survey of residents of Ohio. The survey was conducted via web and telephone by RTI International.

\section{Design}

The OCS has 3 overall analytic objectives: (1) estimate Ohio statewide and regional health and economic indicators related to COVID-19, concentrating on how they change over the progression of the pandemic; (2) understand how individual health and economic statuses and behaviors change over time; and (3) compare current health and economic statuses to prepandemic statuses. To achieve these analytic objectives, the OCS employed a rotating panel design with a 10-minute web-/telephone-based survey.

Panel construction. The OCS sampling frame is a statewide representative panel of Ohioans developed from respondents to the 2019 Ohio Medicaid Assessment Survey (OMAS). The OMAS is a biannual survey of Ohio residents that collects data on health insurance status, health statuses, access to care, determinants of health, and demographics. 6 The 2019 OMAS, conducted from September to December 2019, obtained 30068 adult interviews using a dual cell phone and landline RDD frame. The OMAS is weighted to be representative at the statewide and Ohio regional levels. At the end of the OMAS survey, respondents were asked if they were willing to be recontacted. Among the respondents, 24029 (79.9\%) agreed to be recontacted; of these, 16438 (68.4\%) provided telephone and email contact information and 7591 (31.6\%) provided only a telephone number. Because not all OMAS respondents agreed to be recontacted, analysts adjusted survey weights for the panel members using a generalized exponential model (GEM) with key demographic and health characteristics to correct for potential panel selection bias. ${ }^{7}$ After this panel inclusion adjustment, the design-based weights for each panel member in OCS fully represent the state and subdomain populations within the state.

Sample design. To achieve the 3 analytic goals, we used a rotating panel design which allowed the OCS to obtain 18 weekly, statewide, cross-sectional estimates and up to 3 repeated interviews with panel members. ${ }^{8}$ Under this design, the full panel was randomly split into 6 rotation groups of approximately 4000 panel members each. Each rotation group was further randomly split into 20 replicates of 200 panel members each. The weights for each replicate were adjusted to represent the full population by multiplying the design-based weights by 120 (the total number of replicates created). Each week for the first 6 weeks a set of repli- 
cates (up to 20) from a new rotation group was released to the field. After the first 6 weeks of data collection the rotation groups were released again. This process was repeated over 3 panel waves. Figure 1 illustrates the rotating panel design for the OCS. The number of replicates released for a weekly rotation group week was the amount anticipated to achieve 700 to 1000 interviews. The design allows for a floor response rate of $17.5 \%$ to achieve the minimum collection of 700 weekly interviews. If some replicates were not released, they were held in reserve for future waves to account for possible attrition in the cross-sectional response rates. In waves 2 and 3 all replicates released in wave 1 were released plus any additional replicates needed to achieve the weekly target sample size, estimating for attrition. Therefore, the wave 1 sample release was the set of possible longitudinal respondents that were used for the second analytic objective.

\section{Participants}

The OCS target was 700 to 1000 interviews over a 7-day period (weekly) for 18 weeks of data collection split across 3 waves. A rotation group sample was released each Monday. ${ }^{\text {a }}$ The rotation groups did not overlap in the field. An initial invitation was sent by text and email (if available). Three text/email reminders were sent between Tuesday and Wednesday morning. Telephone calling began on Wednesday for all sample members who had not yet responded via web. Up to 3 call attempts per sample member were made through Sunday evening. All panel members who indicated they still lived in the state of Ohio were eligible to take the survey. All respondents were offered a $\$ 5$ incentive for completing the survey. Wave 1 was collected from April 20, 2020, until May 31, 2020; wave 2 was collected from June 1, 2020, to July 19, 2020; and wave 3 was collected from July 20, 2020, to August 30, 2020.

\section{Measures/Outcomes}

The OCS instrument was a 10-minute survey that obtained critical health, behavioral, and economic indicators. Table 1 details the topics covered in the OCS. To achieve the third analytic objective, the OCS included 5 items from the 2019 OMAS. These items, itali- cized in Table 1, include health and economic indicators such as self-rated health statuses and food insecurity. In wave 1, the experience of symptoms reference period for the OCS was March 1, 2020 . Note that the reference period for time associated questions was modified to "in the past 30 days" for fielding waves 2 and 3.

\section{Statistical Analysis}

Two types of analytic weights were created to allow for generalizable inference to the Ohio population: (1) cross-sectional weights, and (2) longitudinal weights.

The cross-sectional weights were produced after each weekly rotation group release. The design-based weights had 3 adjustments made. First, a rotation group and replicate release adjustment was implemented. Because each replicate has weights that represent the full state, the initial replicate weights for each weekly release were adjusted by dividing the weights by the number of replicates released that week. Second, a nonresponse adjustment was made. Because the OCS panel was constructed from the 2019 OMAS, a rich set of characteristics exists and was used to adjust for potential nonresponse biases, including demographic, geographic, financial (income), employment, and health characteristics. Third, a post-stratification adjustment was made for any potential coverage error caused in the creation of the panel rotation groups. Because the design-based weights were not equal (although the expectation was that each randomly created rotation group represents the full population), some variation in the weight totals may exist. Therefore, the weights adjusted for nonresponse were poststratified to the Ohio population using 2018 American Community Survey estimates. ${ }^{\text {b }}$ The nonresponse adjustment and poststratification adjustment was conducted using GEM, an iterative raking procedure.

The longitudinal weights were produced after wave 3 was completed among the set of respondents who participated in all 3 waves. The base longitudinal weight was the wave 1 weight for each rotation group because they are the set of sampled persons eligible for the longitudinal analysis. Within each rotation group, a

\begin{tabular}{|c|c|c|c|c|c|c|c|c|c|c|c|c|c|c|c|c|c|}
\hline & & & & & & & & & & ve 2 & & & & & & & \\
\hline & 1 & 2 & 3 & 4 & 5 & 6 & 7 & 8 & 9 & 10 & 11 & 12 & 13 & 14 & 15 & 16 & 17 \\
\hline Rotation group 1 & $\mathrm{x}$ & & & & & & $\mathrm{x}$ & & & & & & $\mathrm{x}$ & & & & \\
\hline Rotation group 2 & & $\mathrm{x}$ & & & & & & $x$ & & & & & & $\mathrm{x}$ & & & \\
\hline Rotation group 3 & & & $x$ & & & & & & $x$ & & & & & & $x$ & & \\
\hline Rotation group 4 & & & & $x$ & & & & & & $x$ & & & & & & $x$ & \\
\hline Rotation group 5 & & & & & $x$ & & & & & & $x$ & & & & & & $x$ \\
\hline Rotation group 6 & & & & & & $\mathrm{x}$ & & & & & & $\mathrm{x}$ & & & & & \\
\hline
\end{tabular}

\section{Figure 1. Rotating Panel Design for the OCS by Wave and Week}

an wave 2 and wave 3 sampled persons who opt out of the study or refuse to participate in an earlier wave will not be contacted again ${ }^{\mathrm{b}}$ The year 2018 is the most recently available year for American Community Survey data. 
Table 1. Topics Covered in the OCS

\begin{tabular}{|c|c|}
\hline Topic & Subtopic(s) \\
\hline Illness & $\begin{array}{l}\text { Self-rated health status; experiencing cough, shortness of breath, chest pain, nausea, vomiting, diar- } \\
\text { rhea, headache, sore throat, fatigue, difficulty sleeping, unexplained aches and pains, runny or con- } \\
\text { gested nose, loss of smell/taste, dizziness, eye pain, or fever }\end{array}$ \\
\hline Mental health & Self-rated interest in doing things; self-rated feeling down or depressed \\
\hline $\begin{array}{l}\text { COVID-19 health-seeking } \\
\text { behaviors and testing }\end{array}$ & $\begin{array}{l}\text { Question asks: Because you thought you had COVID-19, have you: had an appointment with health } \\
\text { care provider at office or by phone or computer; gone to a testing site or urgent care/ER/hospital; } \\
\text { been tested for COVID-19? If tested: date, type, and result of test }\end{array}$ \\
\hline Household risk & Anyone in household tested positive for COVID-19 \\
\hline $\begin{array}{l}\text { Employment and health } \\
\text { insurance }\end{array}$ & $\begin{array}{l}\text { Loss of job because of COVID-19; being paid for work or while staying at home (excluding unem- } \\
\text { ployment insurance); employment situation if employed, including working at home or working away } \\
\text { from home, concern about losing job; currently covered by any health insurance; currently covered } \\
\text { by Medicaid }\end{array}$ \\
\hline Social behaviors & $\begin{array}{l}\text { Are you: staying home; avoiding visiting neighbors, friends, or relatives who don't live with you; } \\
\text { avoiding letting neighbors, friends or relatives who don't live with you come to your house; staying } 6 \\
\text { feet away from people you don't live with; wearing a face covering when inside a store; wearing a } \\
\text { face covering when outside; attending gatherings (other than work) with } 10 \text { or more people? }\end{array}$ \\
\hline Consumer confidence & $\begin{array}{l}\text { Concern for you or your family about: physical health; mental health; personal finances; paying mort- } \\
\text { gage rent or utilities; worried about running out of food in past } 30 \text { days; run out of food (in past } 30 \\
\text { days); gotten take-out from a restaurant (since March 15); how you think you and your family will be } \\
\text { financially in next } 6 \text { months; how COVID- } 19 \text { has affected you (open ended) }\end{array}$ \\
\hline
\end{tabular}

nonresponse and post-stratification adjustment was applied to each set of wave 1 sample members who remained in the study at waves 2 and 3.

In this paper, to evaluate the methods, the statistical analysis utilized paradata. Paradata are data about the process by which the data was collected. ${ }^{9}$ Paradata are useful in assessing the quality and representativeness of the sample. In our case, we evaluated the methods through 5 paradata measures. First, response rates (both the participation response rate and recruitment response rate) were calculated. Second, the attrition rate (the percentage of respondents in a wave that also responded in the subsequent wave) were used to evaluate the power of the longitudinal analysis weights. Third, the distribution of respondents by interview mode (web or telephone) was assessed across waves. Fourth, the refusal rate (the percentage of persons who explicitly declined to take the survey) was used to assess bias in terms of who participated. Fifth, the ineligibility rate (the percentage of the sample who moved out of Ohio since the prior interview wave) was used to determine whether the panel, as time went on, still represented the state of Ohio.

\section{RESULTS}

The OCS was launched on April 20, 2020, and completed on August 30, 2020. Across the 3 waves the OCS obtained 17032 interviews. Table 2 presents the disposition across all 18 weeks and by wave (all rotation groups combined). The overall participation stage response rate was $45.2 \%$ yielding a recruitment response rate of $10.0 \%$ (ie, $=22.2 \% \times 45.2$ ) ${ }^{\text {c }}{ }^{10}$ By wave, the participation stage response rate was the highest in wave 1 (53.9\%) and decreased in

'The response rate in the 2019 OMAS was $22.2 \%{ }^{6}$ wave 2 and wave 3 to $42.4 \%$ and $39.2 \%$, respectively, due to panel attrition. The wave specific conditional response rates were consistent within each wave's rotation groups. The attrition rate was $66.7 \%$ between wave 1 and wave 2 and $75 \%$ between wave 2 and wave 3 .

The majority of respondents chose to answer via the web mode with an average $58.0 \%$ of respondents selecting this mode across the 3 waves. The percentage of web respondents increased in waves 2 and 3 compared to wave 1 (54.1\% in wave 1 compared to $60.1 \%$ in wave 2 and $61.2 \%$ in wave 3 ).

The refusal rate, the percentage of sample who explicitly indicated they did not want to take the survey, was consistent across the waves, averaging $34.6 \%$ and varying by less than $1.2 \%$ in any given wave. However, the ineligibility rate increased across waves from $3.0 \%$ to $5.5 \%$ to $7.1 \%$. This increase in the ineligibility rate is likely due to sample members moving out of Ohio during the 4-month data collection window.

\section{DISCUSSION}

The OCS is an example of how prior statewide surveys can be leveraged to develop a panel to track and measure the impact of COVID-19 on health, behavioral, and economic indicators. Three benefits worth highlighting are that: (1) with a panel who recently agreed to participate in a survey and the high saliency of COVID-19 as the topic, the response rate for the study is much higher compared to other statewide surveys; (2) our methodology allows for both a cross-sectional time series and longitudinal analyses; and (3) this survey can be linked to the 2019 OMAS allowing for health and economic comparisons to a prepandemic period estimate. 
For rapidly emergent health topics, like COVID-19, where quick collection of data is critical to understanding and tracking how an event impacts the population of interest, having access to an available panel can be very important to the success of a study. If no panel were available and a new sample needed to be recruited the data collection time would be prohibitive to tracking analyses. For example, the 2019 OMAS, which is the source of the panel used in the OCS, took 5 months to recruit 30000 participants. ${ }^{6}$ Therefore, what made the OCS successful was the inclusion of a question asking OMAS participants if they could be recontacted in the future. Having that agreed upon in advance allowed for the OMAS respondents to be used as a panel, which facilitated OCS data collection within 3 weeks of study inception.

Another key issue in the design is how to best mitigate attrition rates. We utilized 2 methods, reducing the number of recontacts and capping the number of waves. Our study chose to recontact persons every 6 weeks. We believed this time interval would allow us to understand how the pandemic's impact changed for each panel wave without overly burdening the respondents, which can accelerate attrition. Additionally, we capped the panel at 3 waves. While the panel could have been maintained for longer than 4 months, attrition rates would have continued to accelerate making the representativeness of the panel less useful.

As the COVID-19 pandemic continues through the fall of 2020 and into 2021, the OCS has continued with a second panel. Because of the high participation stage response rate, only 13214 of the 24000 panel members were invited (Table 2). Therefore, there are approximately 11000 panel members who could participate in a second OCS iteration without concern of prior panel fatigue.
The main limitation of the design is the low recruitment response rates. While these rates are in line with or slightly higher than national probability-based panels, the rates are still considered low by most survey standards. To mitigate the impact of this limitation we implemented a robust weighting methodology which utilized several correlated outcomes from the OMAS instrument to better calibrate the survey weights. Having health and socioeconomic measures which are typically not available for weighting models, and which are highly correlated to the severity of COVID19 and its economic impact, can greatly reduce the impact of nonresponse bias. ${ }^{11}$

\section{PUBLIC HEALTH IMPLICATIONS}

The OCS is providing Ohio the data it needs to understand how COVID-19 is affecting its residents' health and economic welfare. The study continues to produce statewide and sub-state estimates over time, allowing state officials to factor for how policy changes may affect residents in different parts of the state during a pandemic. The OCS maintained a high participation stage response rate (over $45 \%$ ) across the 3-wave period, demonstrating that a panel can be quickly constructed to conduct a survey on a salient topic like the COVID-19 epidemic to produce estimates that can be immediately operationalized for policy and resource decisions.

\section{REFERENCES}

1. White House Coronavirus Task Force. Guidelines opening up America again. 2020. Accessed April 26, 2020.

https://www.whitehouse.gov/openingamerica/

2. Baker R, Blumberg SJ Brick JM, et al. Research synthesis: AAPOR report on online panels. Public Opin Q. 2010;74(4):711-781.

https://doi.org/10.1093/poq/nfq048

Table 2. Disposition Status and Response Rates for the OCS by Wave

\begin{tabular}{|lllll|}
\hline Disposition & Total & Wave 1 & Wave 2 & Wave 3 \\
\hline Released sample & 35700 & 13214 & 11676 & 10810 \\
\hline Total completes & 17032 & 6894 & 5299 & 4839 \\
Web & 9879 & 3732 & 3187 & 2960 \\
Telephone & 7153 & 3162 & 2112 & 1879 \\
\hline Breakoffs & 807 & 388 & 246 & 173 \\
Web & 161 & 95 & 41 & 25 \\
Telephone & 646 & 293 & 205 & 148 \\
\hline Nonrespondent (refusal) & 12351 & 4468 & 4185 & 3698 \\
Web & 370 & 189 & 105 & 76 \\
Telephone & 11981 & 4279 & 4080 & 3622 \\
\hline Nonrespondent (unknown eligibility) & 3699 & 1069 & 1299 & 1331 \\
\hline Ineligible & 1811 & 395 & 647 & 769 \\
\hline Participation stage response rate & $45.2 \%$ & $53.9 \%$ & $42.4 \%$ & $39.2 \%$ \\
\hline Recruitment response rate & $10.0 \%$ & $12.0 \%$ & $9.4 \%$ & $8.7 \%$ \\
\hline
\end{tabular}

Note. The total counts are cumulative across the 3 waves and do not represent unique persons. 
3. DiSogra C, Callegaro M. Metrics and design tool for building and evaluating probability-based online panels. Soc Sci Comput Rev. 2016;34 (1):26-40. https://doi.org/10.1177/0894439315573925

4. Fahimi M. Recruitment-level nonresponse bias analysis for online panels. Paper presented at CIPHER 2020, Washington, DC. Accessed from https://cesr.usc.edu/cipher_2020_agenda

5. Kapteyn A, Angrisani M, Bennett D, et al. Tracking the effects of the COVID-19 pandemic on American households. Surv Res Methods. 2020;14(2):179-186.

https://doi.org/10.18148/srm/2020.v14i2.7737

6. Berzofsky ME, Duffy T, Johnson K. 2019 Ohio Medicaid assessment survey: methodology report. 2020. Accessed on December 11, 2020 https://grc.osu.edu/sites/default/files/inlinefiles/2019_OMAS_MethodsReport_final_combined_21Sept20.pdf

7. Folsom, RE, Singh AC. The generalized exponential model for sampling weight calibration for extreme values, nonresponse, and poststratification. In Proceedings of the 2000 Joint Statistical Meetings, American Statistical Association, Survey Research Methods Section, Indianapolis, IN. 2000; 598-603. Alexandria, VA: American Statistical Association.

8. Lavrakas, PJ. Rotating panel design. Encyclopedia of survey research methods. Sage Publications. 2008. https://doi.org/10.4135/9781412963947.n500

9. Groves RM, Heeringa SG. Responsive design for household surveys: tools for actively controlling survey errors and costs. JR Stat Soc Ser A Stat Soc. 2006;169(3):439-457. https://doi.org/10.1111/j.1467-985X.2006.00423.x

10. The American Association for Public Opinion Research. Standard definitions: Final dispositions of case codes and outcome Rates for Surveys. 9th edition. AAPOR. 2016

11. Groves R, Peytcheva E. The impact of nonresponse rates on nonresponse bias: a meta-analysis. Public Opin Q. 2008;72(2):167-189. https://doi.org/10.1093/poq/nfn011 


\title{
The Ohio COVID-19 Survey: Preliminary Findings and Their Use During the Pandemic
}

\author{
Lisa A. Frazier'; Eric Seiber ${ }^{1,2}$; Kristin J. Harlow'; Selasi Attipoe ${ }^{2}$; Brian O'Rourke ${ }^{2}$; \\ Ohio COVID-19 Survey Team \\ ${ }^{1}$ Center for Health Outcomes and Policy Evaluation Studies, The Ohio State University, Columbus, OH \\ ${ }^{2}$ College of Public Health, The Ohio State University, Columbus, $\mathrm{OH}$ \\ Corresponding Author: Lisa Frazier, 381 Cunz Hall, 1841 Neil Avenue, Columbus, OH 43210, (614)688-2073, frazier.202@osu.edu \\ Submitted December 18, 2020 Accepted March 15, 2021 Published June 21, 2021 https://doi.org/10.18061/ojph.v4i1.8067
}

\section{ABSTRACT}

Background: The coronavirus disease 2019 (COVID-19) pandemic has created exceptional health and economic uncertainty for Ohioans in 2020. In the spring of 2020, the state commissioned the Ohio COVID-19 Survey (OCS) to ask residential Ohio adults about how the pandemic was affecting them. The purpose of this research is to provide state leadership with real-time information about the effects of the pandemic and concurrent recession on Ohio households.

Methods: The OCS is a special supplement to the Ohio Medicaid Assessment Survey (OMAS), a stratified random digit dial, cell phone and landline telephone survey. This study includes data collected weekly between April 20, 2020, and August 24,2020 . We conducted descriptive time-series analysis of the survey data and provided updates to the state's COVID-19 Response Team throughout the survey period.

Results: Preliminary findings from the OCS reflect 3 themes among respondents: 1 ) elevated levels of concern over health and household economics; 2) disproportionate effects that exacerbate existing inequities; and 3) majority adjustment to "new normal" and acceptance of public health guidelines .

Conclusion: Preliminary findings indicate that groups that were struggling before the pandemic have faced the biggest challenges with regard to health and household economics since it began. Data from the OCS enabled us to provide real-time analysis to state leadership regarding Ohioans' experience during the first 6 months of the COVID-19 pandemic. Further analysis and integration of additional data will allow us to provide deeper insights as Ohio seeks to move into recovery.

Keywords: Ohio; COVID-19; Economic stress; Survey; Inequities

\section{INTRODUCTION}

In the earliest weeks of the coronavirus disease 2019 (COVID-19) pandemic, Ohio's elected leadership quickly moved to address data gaps that could hinder the response and recovery efforts. All states built online dashboards tracking COVID-19 cases, hospitalizations, and deaths. Ohio made the additional step of commissioning a weekly survey, the Ohio COVID-19 Survey (OCS) to track economic, risk mitigation, and health indicators of Ohio households.
All states have struggled with data needs during the pandemic. Existing health behavior and economic surveys produced by the federal and state governments routinely release final estimates 9 to 15 months after data collection. Administrative data such as tax collections often update quarterly or monthly. Even the fastest administrative data sources such as unemployment insurance claims still require weeks before final adjudicated totals are available.

Ohio's leadership's need for near real-time feedback from Ohio households led to their commissioning the Ohio COVID-19 Survey. 
The effort was led by the Ohio Department of Health and Ohio Department of Medicaid with technical expertise from The Ohio State University (OSU) and the RTI International (RTI). Envisioned as a near real-time tracking survey to monitor household impacts, Ohio had its first estimates of the pandemic's health, behavioral, and economic impacts on Ohio residents just 17 days after its initial conception ( 7 days for design, 7 days of data collection, and 3 days of data preparation). The initial iteration of the OCS covered in this paper ran weekly from April 2020 through August 2020, with subsequent iterations expected to continue through June 2021. The Center for Health Outcomes and Policy Evaluation Studies (HOPES) at OSU College of Public Health has been analyzing the survey data and providing updates to Ohio's COVID-19 Response Team throughout the survey period. A complete methodological description of the survey, including sample questions from the survey instrument, can be found in Berzofsky et al. ${ }^{1}$

This paper will report the key findings from the first 18 weeks of the OCS. Specifically, the OCS produced important initial estimates and the subsequent changes in the elevated levels of concern/ stress over health and household economics, disproportionate effects that exacerbate existing inequities, and majority adjustment to a "new normal" and acceptance of public health guidelines.

\section{METHODS}

\section{Setting}

The Ohio COVID-19 Survey (OCS) is a mixed-mode telephone and web-assisted survey conducted by the Ohio Colleges of Medicine Government Resource Center (GRC), a center for applied health policy research and technical assistance, and its contractor RTI. The GRC is housed at OSU.

\section{Design}

The OCS is a special supplement to the Ohio Medicaid Assessment Survey (OMAS). Both the OCS and the OMAS produce representative estimates for the entire Ohio population. The OCS uses the OMAS respondent set, which came from a stratified, random digit dial, dual-frame sample of Ohioans to conduct a telephone and web-assisted design. This study reports findings from data collected weekly between April 20, 2020, and August 24, 2020. Stratification and oversampling ensure survey responses are representative of the overall population, capturing geographic, racial, and generational diversity at the state level. However, the survey is not designed to consistently conduct robust subgroup analyses (eg, by race, ethnicity, county). A demographic description of survey respondents can be found in Appendix A.

\section{Participants}

Consistent with the OMAS, Ohio adults aged 19 years and older are eligible to respond to the OCS. Participants were randomly selected from stratified groups designed to ensure a representative sample of Ohio's adult population. Respondents provided informed consent to participate and confirmed eligibility as a current Ohio resident who previously completed the OMAS.

\section{Procedures}

Both this study and the survey itself were determined exempt by OSU's institutional review board. The GRC is responsible for survey design, management, and data storage as part of a work for hire agreement with the Ohio Department of Medicaid. A research team made up of GRC staff and OSU College of Public Health faculty selected COVID-19-specific questions. All interviews were conducted in English. The survey contractor, RTI International, conducted data collection over 18 weeks between April 20 and August 24, 2020, yielding 17032 total responses (average $n=946 /$ week). No data were collected during the Fourth of July holiday week. The sampling frame was randomly divided into 6 subframes that were recontacted every 6 weeks, resulting in 3 waves of survey responses among 6 samples $(\mathrm{n} \times 6894$ in wave $1, \mathrm{n} \times 5299$ in wave 2, $\mathrm{n} \times 4839$ in wave 3 ). The OCS is unique in its setting, scope, and procedure; no other COVID-19-related surveys have a such a robust sample of Ohioans or provide so much detail on household conditions over time.

\section{Measures}

This paper will focus on primary measures related to disease control or public health behaviors (eg, staying at home, avoiding visiting others outside of the home, wearing a face covering in public) and those related to employment and personal economy (eg, job loss due to COVID-19, concerns about ability to pay rent or utility bills). The OCS includes additional measures that allow the research team to identify patterns in behavior and personal economy in terms of geography, race and ethnicity, age, health status, and household income. ${ }^{1}$

\section{Statistical Analysis}

To serve the State of Ohio's need for real-time data on the impact of the COVID-19 pandemic on Ohio households, the study team used descriptive statistics and data visualizations to characterize trends in health, disease control behaviors, and household economics. In addition to state-level proportional responses, the team stratified analyses by demographic variables of interest to the state-including gender, age, race, household income, dependent children in the home, and health status-whenever possible. This allowed state leadership to track variation in how behaviors and attitudes changed as the first 6 months of the pandemic and response unfolded.

The OCS research team designed and executed weighting procedures on raw survey data to enable representative interpretation of the results for all noninstitutional Ohio residents and corresponding subgroups as appropriate. ${ }^{1}$ Therefore, all analyses shared with the State of Ohio were conducted as weighted proportional responses from each weekly period. We report only statistically significant findings in this paper. All analyses were 
performed using R statistical software version 4.0.2 (R Foundation for Statistical Computing).

\section{RESULTS}

\section{Health Status and Concerns}

Racial disparities are evident in self-reported overall health status among OCS respondents. Across the survey period, $27 \%$ of Black respondents rated their health as fair or poor compared to $15 \%$ of White respondents. Conversely, 55\% of White respondents rated their health as very good or excellent compared to $43 \%$ of Black respondents (Appendix B).

Survey respondents' concerns about physical and mental health were steady, but high, throughout the period in which the OCS was in the field. Extreme concern for physical health was inversely related to income; as income rises, levels of extreme concern fall. Ohioans with incomes from $139 \%$ to $206 \%$ federal poverty level (FPL) were most likely to report being moderately to extremely concerned about physical health (45\%), followed by those with incomes from $101 \%$ to $138 \%$ FPL (44\%), at or below $100 \%$ FPL (40\%), from $207 \%$ to $399 \%$ FPL (39\%), and at or above $400 \%$ FPL (34\%) (Figure 1). A similar pattern exists for mental health concerns (Appendix C).

\section{Infection Control Behaviors}

During the statewide stay-at-home (SAH) order (March 23, 2020, to May 1, 2020), 86\% to $90 \%$ of respondents reported avoiding unnecessary trips outside of the house. While that proportion fell as businesses and facilities opened back up, 61\% of respondents continued to largely stay at home in August 2020. Fewer than 8\% of respondents reported attending gatherings of 10 or more people during the SAH period; $27 \%$ to $38 \%$ of respondents attended such gatherings between June 15, 2020, and August 24, 2020 (Figure 2).

Respondents in fair or poor health avoided unnecessary trips out of the home slightly more than their healthier peers $(93 \%$ versus $87 \%$, on average). By the end of August 2020,87\% of those in fair or poor health reported staying at home compared to $59 \%$ of those in good to excellent health (Appendix D). Black respondents consistently reported staying home at higher levels than their White peers (eg, 96\% versus 85\% the first week of May), but most weeks the differences were not statistically significant.

Mask wearing in indoor, public places was already relatively prevalent by the time the first county-level mandates went into effect in mid-July. Within the first 3 weeks of Ohio's phased reopening (May 1, 2020), 71\% of respondents reported wearing masks in-

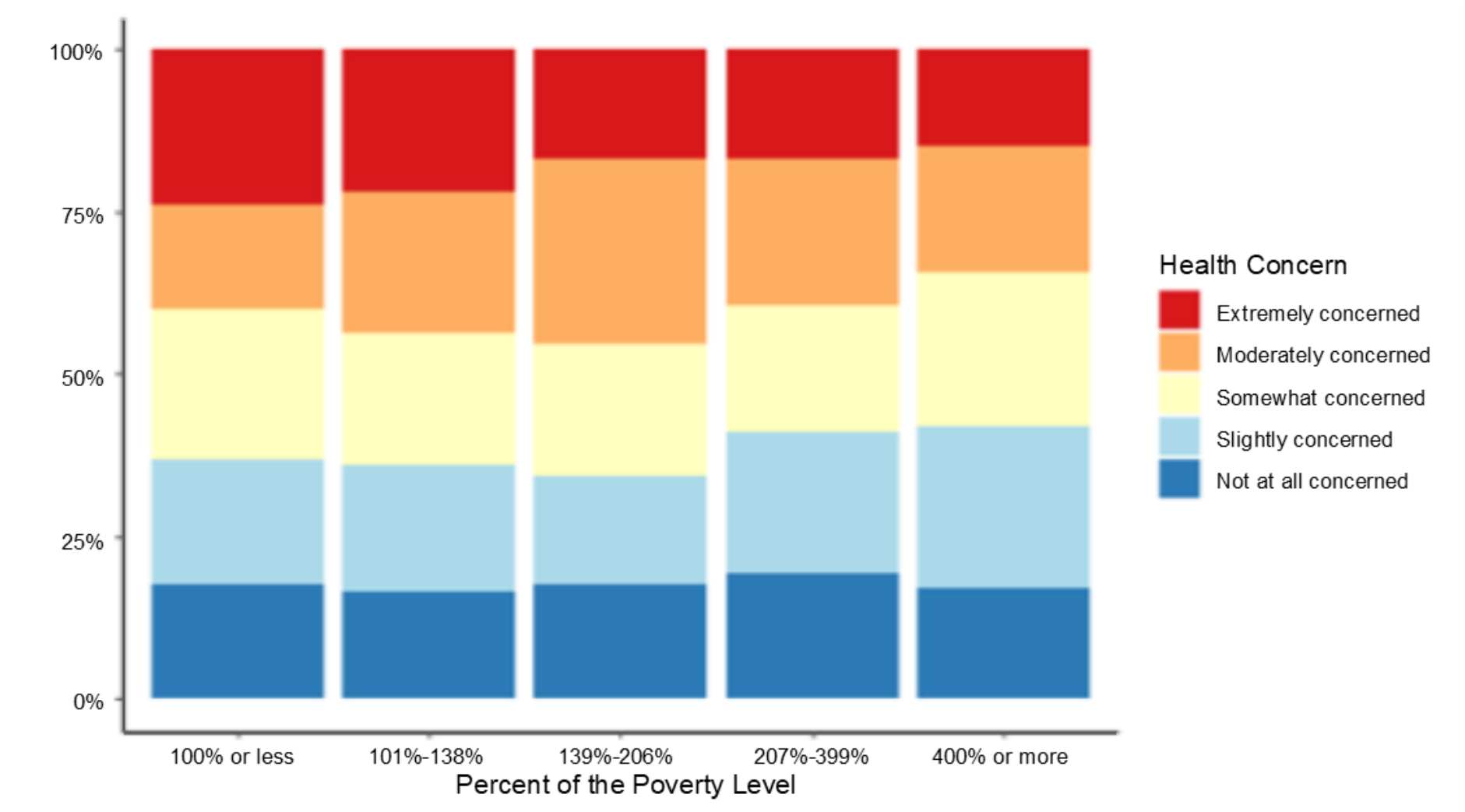

Figure 1. Concern for Physical Health by Income 


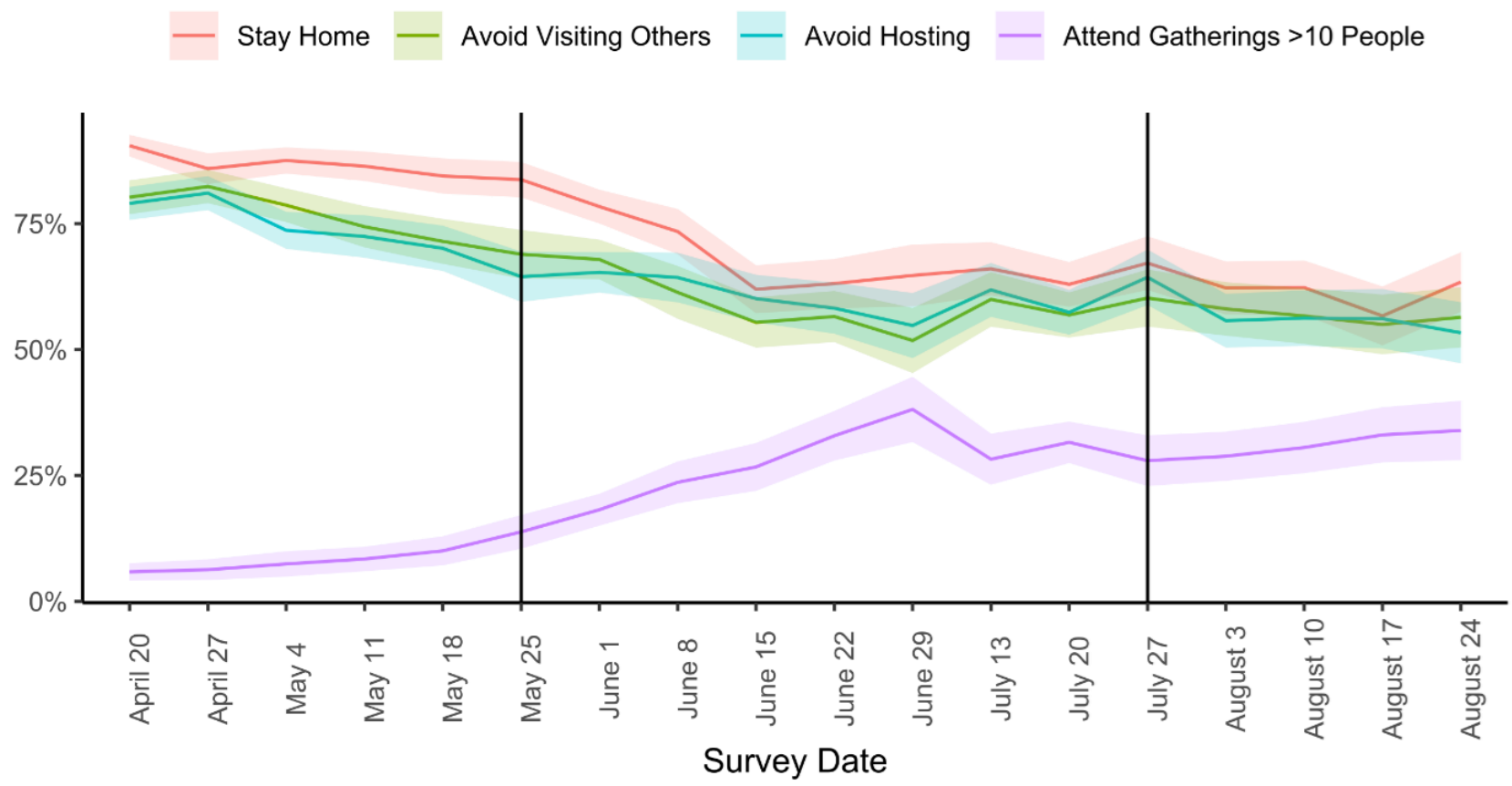

By May 25, 2020 (Memorial Day), restaurant dining, personal care services, campgrounds, and recreational centers were permitted to open, marking an important phase of Responsible Restart Ohio. By July 27, 2020, the entire state was operating under a mask mandate (issued July 23, 2020). Shaded bands represent $95 \%$ confidence intervals around central estimates, marked in solid lines.

Figure 2. Trends in Social Distancing Practices

doors. Close to $88 \%$ reported wearing masks after the first mandates went into effect in hard-hit counties (July 8-17, 2020). Once the statewide mandate went into effect (July 23,2020) that number rose slightly (about 92\%). Wearing a mask outdoors is much less prevalent, hovering around 22\% (Figure 3).

While respondents aged 65 years and older were slightly more likely than those aged 19 to 64 years to wear masks indoors initially, significant differences among age groups disappeared by the middle of June 2020-before any mask mandates went into effect. While Black respondents consistently reported wearing masks (both indoors and outdoors) at higher levels than their White peers, the confidence intervals for those estimates are too large for us to report those differences as statistically significant.

Throughout the 3 waves of the survey, respondents in fair or poor health were more likely to get tested for COVID-19 (6\% to 27\%) than those in good, very good, or excellent health (2\% to $17 \%)$. As testing at locations other than state-run sites has expanded, uninsured respondents have been getting tested at lower rates, and with slower growth, than their insured peers (Figure 4).

\section{Employment}

Between April 2020 and August 2020, roughly 1 in 7 respondents aged 19 to 64 years reported losing a job due to COVID-19, and 4 in 10 respondents reported being employed (Appendix E). A higher percentage of adults in more urban counties reported working compared to the rest of the state (Appendix F). The pro- portion of respondents working from home fell from nearly 15\% in wave 1 to $10 \%$ in wave 3 . Conversely, working outside the home and working both inside and outside increased respectively from $18 \%$ and $6 \%$ in wave 1 to $23 \%$ and $8 \%$ in wave 3 (Appendix G).

Employment and job loss varied by age, race, health, and income. Employment was highest among Ohioans aged 19 to 44 years (54\%); this group also experienced more job loss due to COVID-19 (19\%). In comparison, $45 \%$ of Ohioans aged 45 to 64 years reported being employed while $11 \%$ reported losing a job due to COVID-19 (Appendix H). More Ohioans of color reported losing a job due to COVID-19 (19\%) compared to their White peers (12\%) Appendix I). Employment is positively correlated with health as $56 \%$ of those in excellent health reported being employed compared to $48 \%$ of those in very good health, $36 \%$ of those in good health, $20 \%$ of those in fair health, and just $6 \%$ of those in poor health (Appendix J).

Employment is also positively correlated with income as more than half (56\%) of respondents with incomes at or above $400 \%$ FPL reported being employed throughout the survey period compared to less than one-fourth (24\%) of respondents living below the poverty line. Furthermore, low-income workers have been more susceptible to job loss due to COVID-19; 16\%, 23\%, 13.5\%, and $12.5 \%$ of Ohioans in the lower income categories reported job loss compared to $9 \%$ of those with incomes at or above $400 \%$ FPL (Figure 5). 


\section{Face Covering Outdoors — Face Covering Indoors}

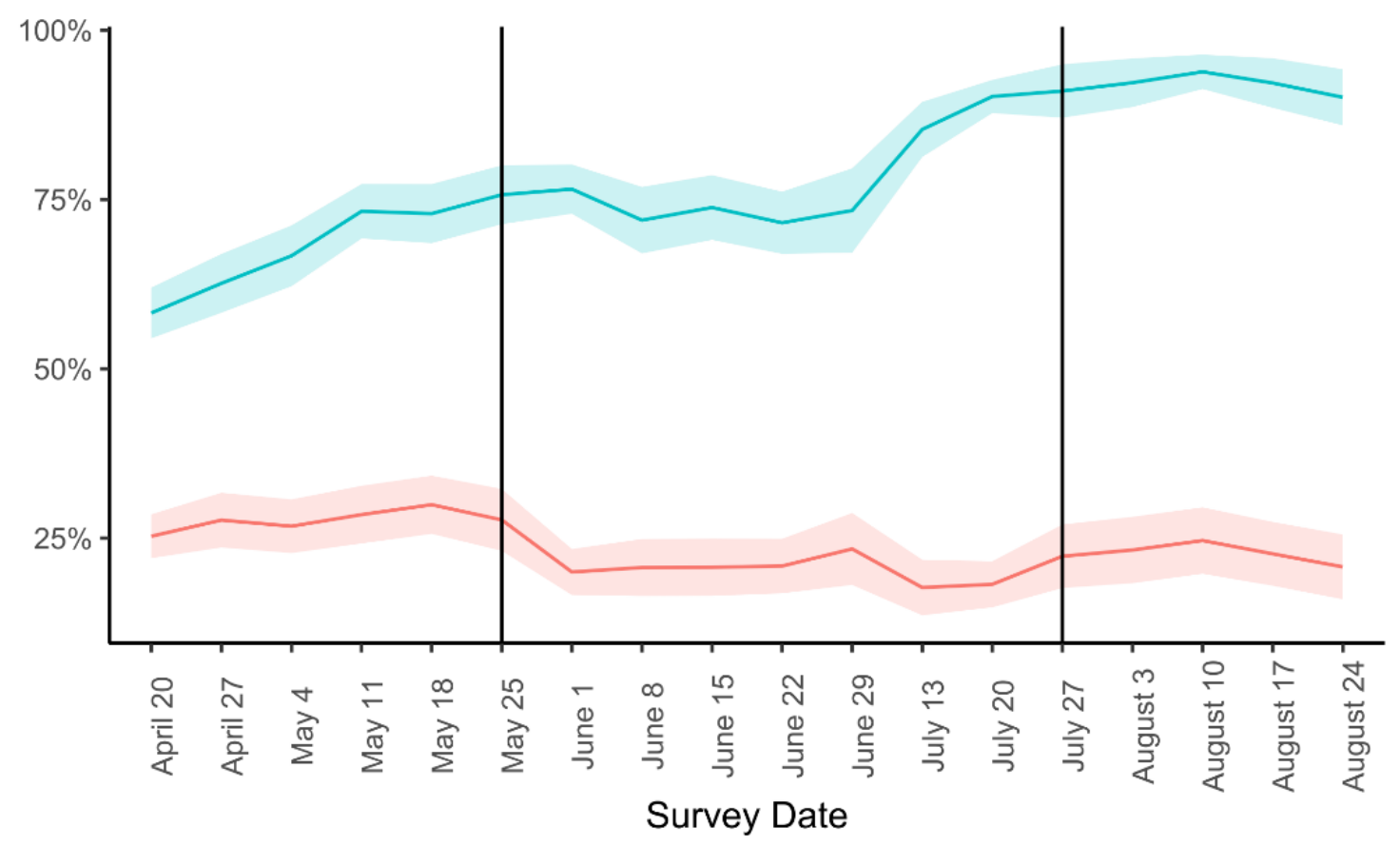

Figure 3. Mask Wearing Indoors Versus Outdoors
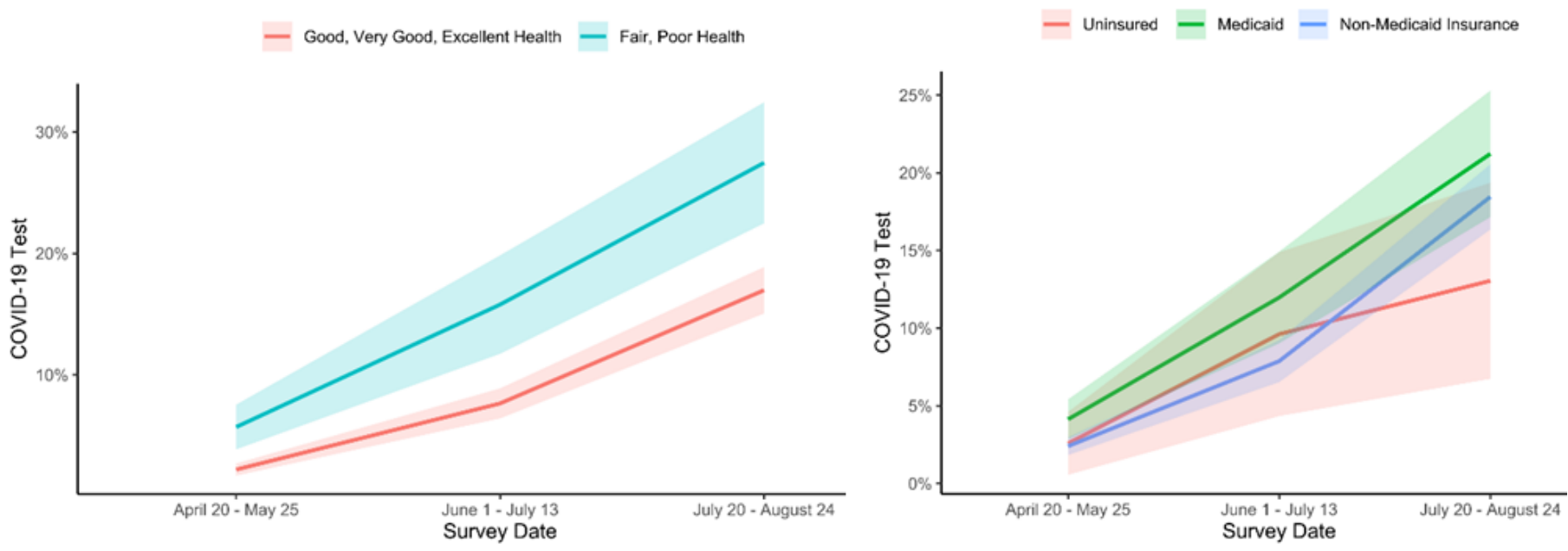


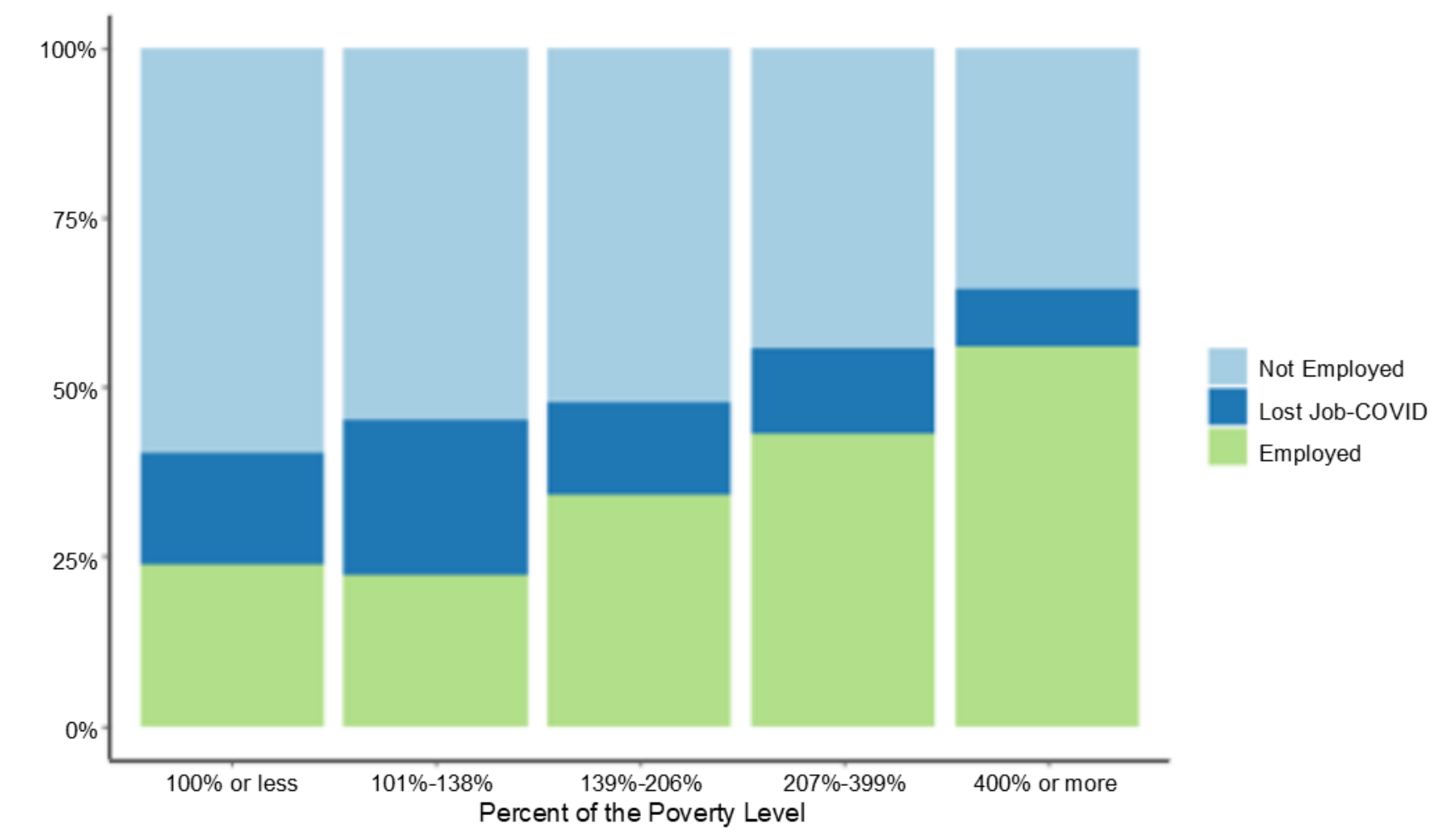

\section{Figure 5. Employment Status by Income}

\section{Economic Concerns}

Ohioans of color were more likely to report food insecurity than their White peers. For example, 35\% of Black respondents reported worrying about running out of food in the last 30 days compared to $15 \%$ of White respondents (Appendix K).

There was a strong relationship between health and financial security. Compared to $25 \%$ of those in good, very good, or excellent health, $36 \%$ of those in fair or poor health reported being moderately or extremely concerned about being able to pay rent, mortgage, or utility bills for themselves or their family. Conversely, $49 \%$ of those in good, very good, or excellent health reported not being at all concerned about paying bills compared to $36 \%$ of those in fair or poor health (Appendix L).

Those with at least one child dependent in the home reported slightly higher but significant levels of concern for their personal finances than adult-only households; $21 \%$ of those with dependents reported extreme concern compared to $17 \%$ of those without, and $32 \%$ of those without dependents reported no concern at all compared to $25 \%$ of those with dependents (Appendix M).

\section{DISCUSSION}

These preliminary results provide valuable framing and data to the State about the pandemic and concurrent recession. One con- sistent, if unsurprising, result from the OCS is that COVID-19 has put stress on people's health and financial well-being. Respondents expressed high levels of concern for their physical and mental health as well as that of their families. We cannot make inferences about how much of that concern is attributable to the pandemic because the OCS went into the field in April 2020. However, a Kaiser Family Foundation poll from mid-July found that $53 \%$ of adults reported that worry and stress about the coronavirus specifically were harming their mental health. ${ }^{2}$

The National Bureau of Economic Research determined that the current recession began in the United States in February 2020 as COVID-19 began to spread but before issuance of public health orders and business closures. ${ }^{3}$ In addition to job losses and reduction in work hours, respondents reported diminished consumer confidence and increased concern for their personal financial outlook. It has been useful to state leadership to see direct evidence of the connection between personal economic and health effects. One respondent made it quite clear: "The loss of my job has impacted my family financially and left us uncertain about the future. This has also impacted our family's mental health."

A second theme of the survey results is that the pandemic has exacerbated existing health and economic disparities and inequities. Historically marginalized, low-income, and medically vulnerable respondents were more likely to struggle with health- 
related issues before the emergence of COVID-19 and are disproportionately experiencing mental and physical health stresses associated with the pandemic. These same groups are shouldering the disease burden of COVID-19. For example, Black and Latinx Ohioans are overrepresented in the state's caseload, hospitalizations, and deaths. ${ }^{4}$ Low-income individuals, who are generally more likely to rate their overall health status as fair or poor, ${ }^{5}$ also experience higher rates of COVID-19 infection and illness than their higher-income peers. ${ }^{6}$

These disparities and inequities are mirrored in economic indicators. Non-White, low-income, and Ohioans in poor health are more likely to report job loss (and therefore loss of income and perhaps health insurance) than their White, healthier, wealthier peers, reinforcing existing economic disparities. Black employment has been especially hard-hit. Ohioans of color, in poor health, or with low incomes are more likely to report concern about their food security, paying their bills, and personal financial outlook.

Consistent with national findings, ${ }^{7}$ results from the OCS also suggest that marginalized and vulnerable groups have been somewhat more compliant with public health recommendations, despite being more likely to encounter barriers to compliance. For example, Ohioans in poor health generally report higher levels of mask wearing, staying at home, and physical distancing; they have also been more likely to get tested for COVID-19. However, these same groups face structural barriers; for example, Black (and Latinx) workers are more likely to have jobs in essential services that cannot be done from home, ${ }^{8}$ and costs associated with testing can make it less accessible to low-income workers. ${ }^{9}$

Finally, findings from the OCS indicate that, despite wellpublicized pushback among some, the majority of Ohioans are listening to public health advice and adjusting to a "new normal" of public behavior. Ohioans consistently reported maintaining 6 feet of distance between themselves and others since such measures were recommended in March 2020 (about 90\%).

During the stay-at-home period (March 23, 2020, to May 1, 2020), Ohioans generally stayed home and avoided interacting closely with people outside their household. As the order ended and the summer holidays arrived, people mingled more. However, the majority of respondents continued to report staying home and avoiding gatherings throughout the survey period, noting the change from their normal behavior. "I'm staying home more than I ever have in my entire life," and, "[i]t's definitely been a change in lifestyle," are representative responses.

Wearing masks in indoor, public places gained traction relatively early in the pandemic period and steadily increased over time. Despite being the target of continued political discussion, recommendations and formal policy actions from state leadership appear to have played an important role in increasing mask wearing. On April 4, 2020, state leadership recommended to all Ohioans that they wear masks when in indoor, public places or in outdoor spaces where proper social distancing cannot be maintained. On July 5 , the State announced mask mandates would go into effect in counties with very high or severe exposure. ${ }^{10}$ On July 23, 2020,a statewide mask mandate went into effect. Each of these events correlate with increases in reported mask wearing.

The OCS shares the standard survey limitations; namely, the results are sensitive to self-report issues, particularly with regard to infection control behaviors. For example, it is likely that social desirability bias is in play regarding mask wearing and avoiding gatherings, resulting in overreporting of those behaviors. However, such a pattern would also reflect that people are aware of what behaviors are recommended and see value in reporting their compliance.

\section{PUBLIC HEALTH IMPLICATIONS}

This work raises 3 broad public health implications for Ohio. First, the need for near real-time tracking of the pandemic's effects remains. Tracking through the OCS is expected to continue through at least the middle of 2021 as Ohio rolls out its COVID-19 vaccination efforts. The second iteration of the survey (fall 2020) piloted approaches to track COVID-19 testing and influenza vaccinations that will be refined to produce estimates of COVID-19 vaccination uptake in Ohio.

Second, the smaller sample sizes used for rapid, weekly estimates produce limited precision for county-level estimates. In March and April of 2020, data were limited to a few, outdated federal surveys while case counts escalated daily. The OCS filled this void and created ongoing statewide and regional estimates. However, local health departments faced the same problem as state decision makers in the early days of the pandemic. Surveys are too expensive to produce rapidly updated estimates for all counties, but the pandemic has accentuated the need for developing a low cost, dynamic data source for local public health decision makers.

Third, the same data challenge that prevents county-level estimates from the OCS also hinders monitoring of public health disparities. The differential health and economic impacts of the pandemic are a key finding emerging across the pandemic-related literature. Historically marginalized populations have faced both the greatest mortality and economic losses. Healing the health and economic wounds left by the pandemic will first require efforts monitoring the recovery to include specific mechanisms to measure the long-term impacts of the pandemic on disadvantaged groups.

This paper summarized and highlighted some key findings from the OCS regarding Ohioans' health, health behaviors, and household economics in the initial months of the pandemic and concurrent recession. Ohioans are struggling with what the pandemic and recession mean for themselves and their families, expressing intersecting concerns about their physical, mental, and financial health and highlighting the connection between public health and the economy. While headlines have largely perpetuated a narrative 
about political resistance to public health orders, results from the OCS indicate that most Ohioans have adapted to a new normal in which social distancing, mask wearing, and sensitivity to public health issues are everyday practices.

In contrast to other states that were not among the first epicenters of the COVID-19 pandemic, Ohio's leadership emphasized the role of individual infection control behaviors early on. State leadership recommended maintaining at least 6 feet of distance and increasing hygiene practices on March 8, 2020. Several infection control behaviors, such as mask wearing and distancing, were included as requirements for businesses and other facilities to reopen under the Responsible Restart Ohio plan. These requirements remain in place at the time of this report's publication. Public health recommendations and requirements are an important part of the picture of Ohioans' infection control behaviors during the pandemic. (See Appendix $\mathrm{N}$ for a timeline of important ordinances and events in Ohio's COVID-19 response.) Although Ohio continues to grapple with pandemic response, the long-term impacts of the pandemic are beginning to emerge and will loom large as increased attention shifts to recovery.

\section{ACKNOWLEDGMENTS}

The authors would like to thank the Ohio COVID-19 Survey research team, including Thomas Albani, Robert Ashmead, Michael Nau, Alicia Rooney, Hilary Rosebrook, Tim Sahr (GRC); Marcus Berzofsky, Meagan Brackin, Tom Duffy, Naomi Freedner, TJ Nesius, Dain Palmer, Jean Robinson, Dave Schultz, and Caroline Scruggs; and Dr. Bo Lu (OSU College of Public Health). Additionally, we thank Francis Anagbonu for his additional research support.

Funding. The OCS data collection is funded by the Ohio Department of Health and Ohio Department of Medicaid.

Disclosures. The authors declare that they have no conflict of interest.

\section{REFERENCES}

1. Berzofsky ME, Freedner N, Scruggs C, et al. The design and methodology of the Ohio COVID-19 Survey. Ohio J Public Health. 2021;4(1)5-10. https://doi.org/10.18061/ojph.v4i1.8068

2. Panchal N, Kamal R, Orgera K, et al. The implications of COVID-19 for mental health and substance abuse. Kaiser Family Foundation. Published August 21, 2020. Accessed December 4, 2020. https://www.kff.org/report-section/the-implications-of-covid-19-formental-health-and-substance-use-issue-brief/\#: :text=In\%20a\% 20KFF\%20Tracking\%20Poll,was\%20included\%20in\%20KFF\% 20 polling

3. Determination of the February 2020 Peak in US Economic Activity. NBER Business Cycle Dating Committee. Published June 8, 2020. Accessed December 4, 2020. https://www.nber.org/cycles/june2020.html

4. Schroeder KR. Black, Hispanic Ohioans face outsized COVID-19 risk. Dayton Daily News. Published September 6, 2020. Accessed November 10, 2020. https://www.daytondailynews.com/news/black-hispanic-ohioans-face -outsized-covid-19-risk/MCXLJ2E2WJDWXPJX774UBB4PRY/
5. Adeline A, Delattre E. Some microeconometric evidence on the relationship between health and income. Health Econ Rev. 2017;7(1):27. https://doi.org/10.1186/s13561-017-0163-5

6. Blundell R, Costa Dias M, Joyce R, et al. COVID-19 and inequalities. Fisc Stud. 2020;41(2):291-319. https://doi.org/10.1111/1475-5890.12232

7. Igielnik, R. Most Americans say they regularly wore a mask in stores in the past month; fewer see others doing it. Pew Research Center. Published June 23, 2020. Accessed February 24, 2021.

https://www.pewresearch.org/fact-tank/2020/06/23/mostamericans-say-they-regularly-wore-a-mask-in-stores-in-the-pastmonth-fewer-see-others-doing-it/

8. Gould E, Wilson V. Black workers face two of the most lethal preexisting conditions for coronavirus - racism and economic inequality. Economic Policy Institute. Published June 1, 2020. Accessed December 4, 2020.

https://www.epi.org/publication/black-workers-covid/

9. Ohio Department of Health. COVID-19 testing guidance: Protecting against COVID-19. ODH. Updated December 4, 2020. Accessed December 4,2020

https://coronavirus.ohio.gov/static/MHSF/COVID-19-Ohio-TestingFAQ.pdf

10. Ohio Department of Health. Ohio Public Health Advisory System. Columbus, OH: ODH; 2020

https://coronavirus.ohio.gov/wps/portal/gov/covid-19/public-health -advisory-system/ 


\section{APPENDIX A. Respondent Demographics}

\begin{tabular}{|c|c|c|}
\hline Category & Total Responses & $\begin{array}{l}\text { \% of Total } \\
\text { Responses }\end{array}$ \\
\hline & 17032 & $\begin{array}{l}\text { may not total } \\
100 \% \text { due to } \\
\text { rounding }\end{array}$ \\
\hline $\begin{array}{c}19-44 \\
45-64 \\
65+\end{array}$ & $\begin{array}{l}4530 \\
6779 \\
5723\end{array}$ & $\begin{array}{l}26.6 \% \\
39.8 \% \\
33.6 \%\end{array}$ \\
\hline $\begin{array}{r}\text { Race } \\
\text { Black } \\
\text { White } \\
\text { Asian } \\
\text { Other } \\
\text { Missing, don't } \\
\text { know, refuse }\end{array}$ & $\begin{array}{l}1843 \\
14479 \\
185 \\
304 \\
221\end{array}$ & $\begin{array}{l}10.8 \% \\
85 \% \\
1.1 \% \\
1.8 \% \\
1.3 \%\end{array}$ \\
\hline $\begin{array}{r}\text { Ethnicity } \\
\text { Hispanic } \\
\text { Not Hispanic } \\
\text { Missing, don't } \\
\text { know, refuse }\end{array}$ & $\begin{array}{l}334 \\
16636 \\
62\end{array}$ & $\begin{array}{l}2.0 \% \\
97.7 \% \\
0.3 \%\end{array}$ \\
\hline $\begin{array}{r}\text { Income } \\
<101 \% \\
101-138 \% \\
139-206 \% \\
207-400 \% \\
>400 \%\end{array}$ & $\begin{array}{l}2553 \\
1058 \\
2036 \\
4526 \\
6859\end{array}$ & $\begin{array}{l}15.0 \% \\
6.2 \% \\
12.0 \% \\
26.6 \% \\
40.3 \%\end{array}$ \\
\hline $\begin{array}{cc}\text { Gender } & \\
& \begin{array}{c}\text { Female } \\
\text { Male }\end{array}\end{array}$ & $\begin{array}{l}9580 \\
7452\end{array}$ & $\begin{array}{l}56.2 \% \\
43.8 \%\end{array}$ \\
\hline $\begin{array}{r}\text { Child Depend- } \\
\text { ent in Home } \\
\text { Yes } \\
\text { No }\end{array}$ & $\begin{array}{l}12238 \\
4794 \\
\end{array}$ & $\begin{array}{l}71.9 \% \\
28.1 \% \\
\end{array}$ \\
\hline
\end{tabular}

\section{APPENDIX B. Health Status by Race}

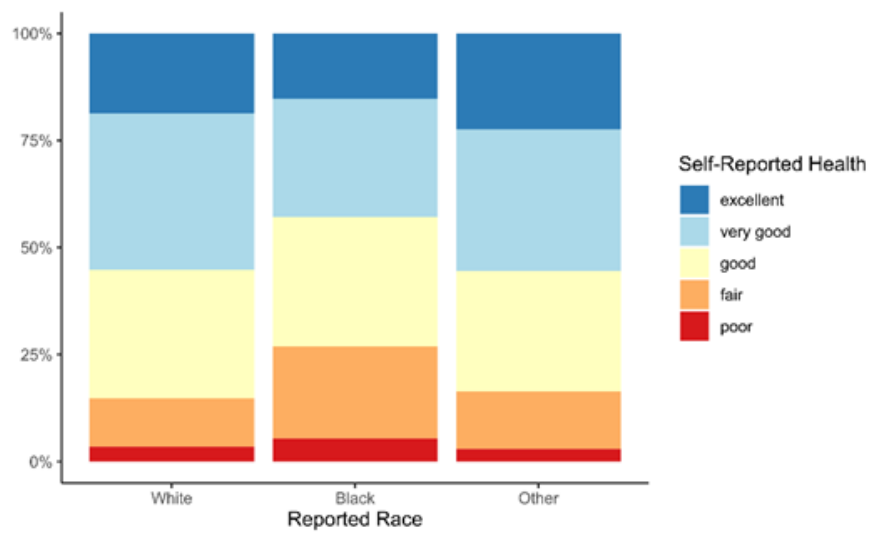

Federal Poverty Guidelines

\begin{tabular}{|l|l|l|}
\hline \multicolumn{3}{|c|}{ Table 2. Federal Poverty Guidelines, 2020 } \\
\hline $\begin{array}{l}\text { Household size } \\
\% \text { FPL }\end{array}$ & $\mathbf{1}$ & $\mathbf{4}$ \\
\hline $100 \%$ & $\$ 12760$ & $\$ 26200$ \\
\hline $138 \%$ & $\$ 17609$ & $\$ 36156$ \\
\hline $206 \%$ & $\$ 26286$ & $\$ 53972$ \\
\hline $400 \%$ & $\$ 51040$ & $\$ 104800$ \\
\hline
\end{tabular}

Source: Federal Registrar
APPENDIX C. Mental Health Concerns by Income

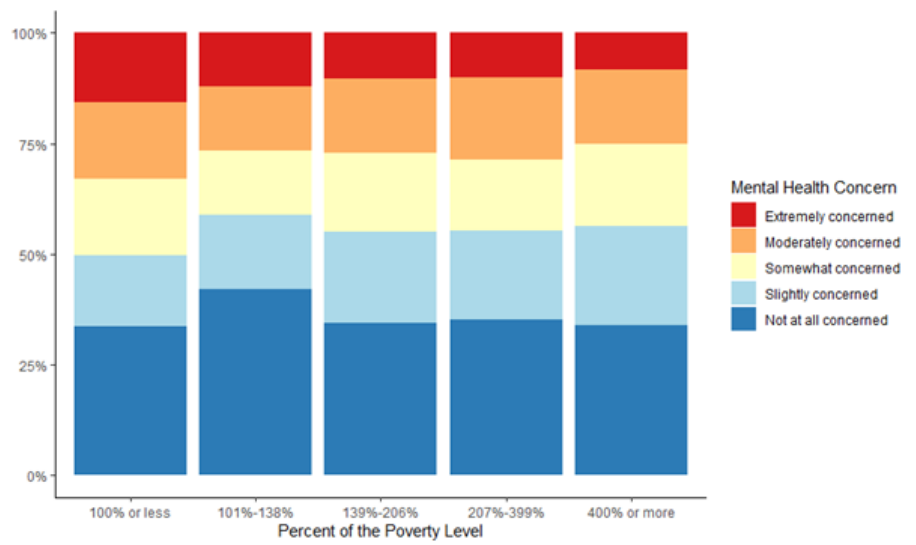

APPENDIX D. Staying at Home by Health Status

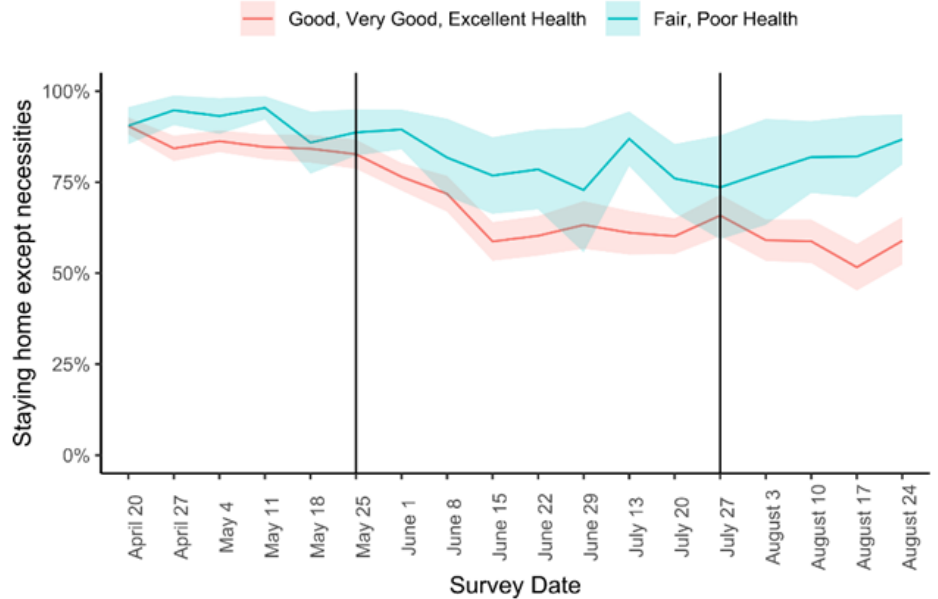

APPENDIX E. Employment and Job Loss Due to COVID-19, Adults 19-64

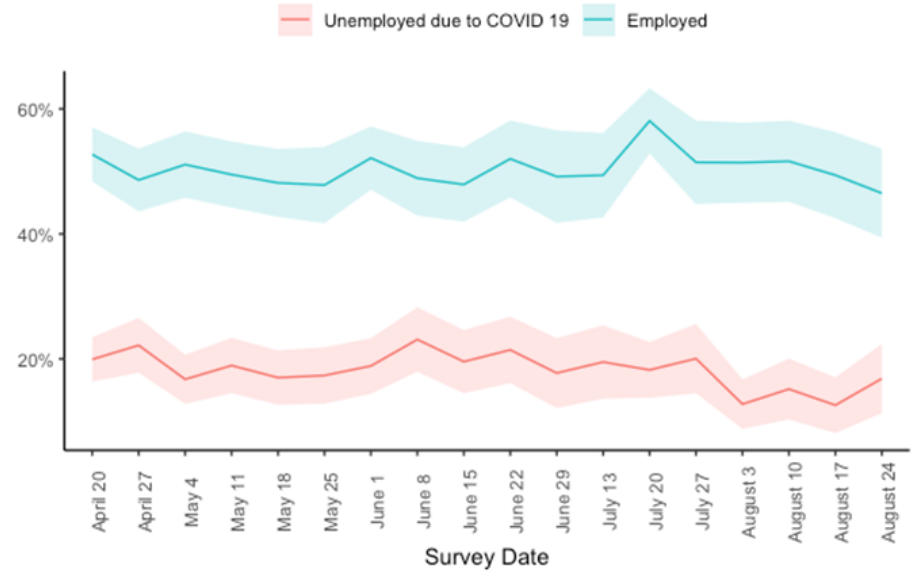




\section{APPENDIX F. Regional Employment}

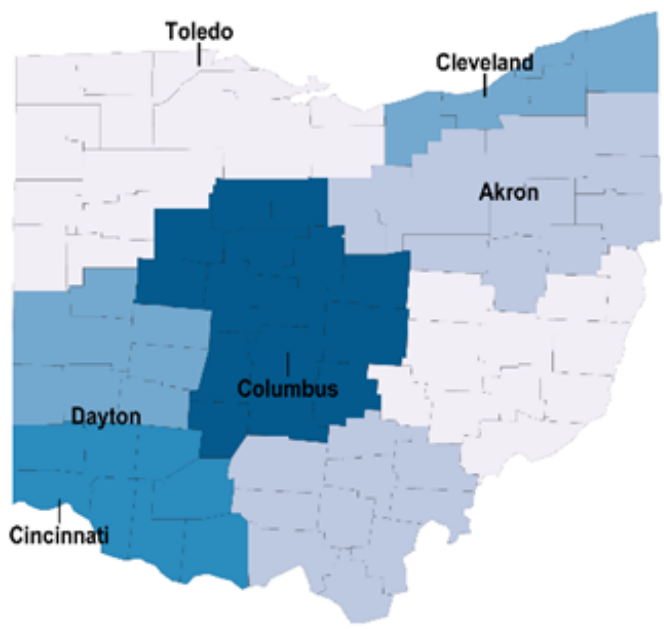

Ohio's regions: Central (Columbus), Northeast (Cleveland), Northeast Central (Akron), Northwest (Toledo), Southeast (Zanesville), Southeast Central (Portsmouth, Athens), Southwest (Cincinnati), West Central (Dayton).

\section{APPENDIX G. Working Location}

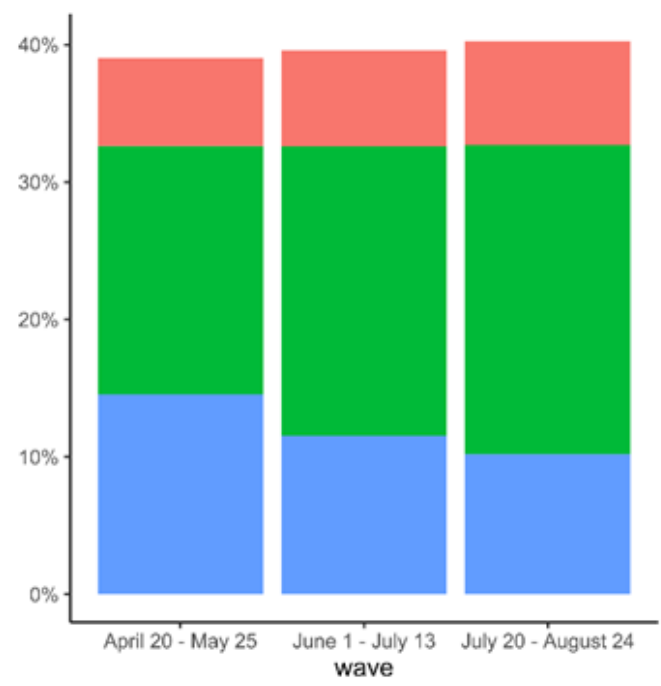

APPENDIX H. Employment Status by Age

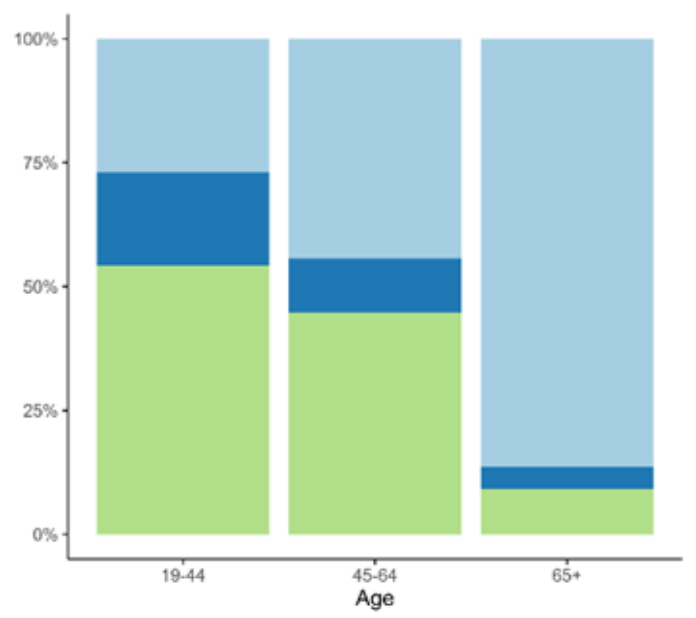

$45 \%$

$50 \%$

$33 \% \cdot 35 \%$

$36 \% .37 \%$

$38 \%-40 \%$

Both

Outside Home

From Home

Not Employed

Lost Job-COVID

Employed

\section{APPENDIX I. Employment Status by Race}

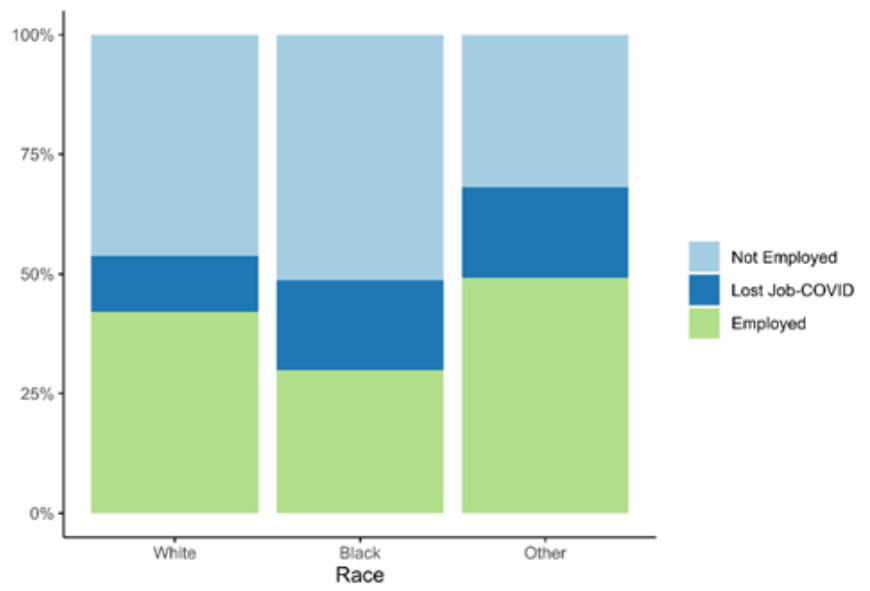

APPENDIX J. Employment Status by Health

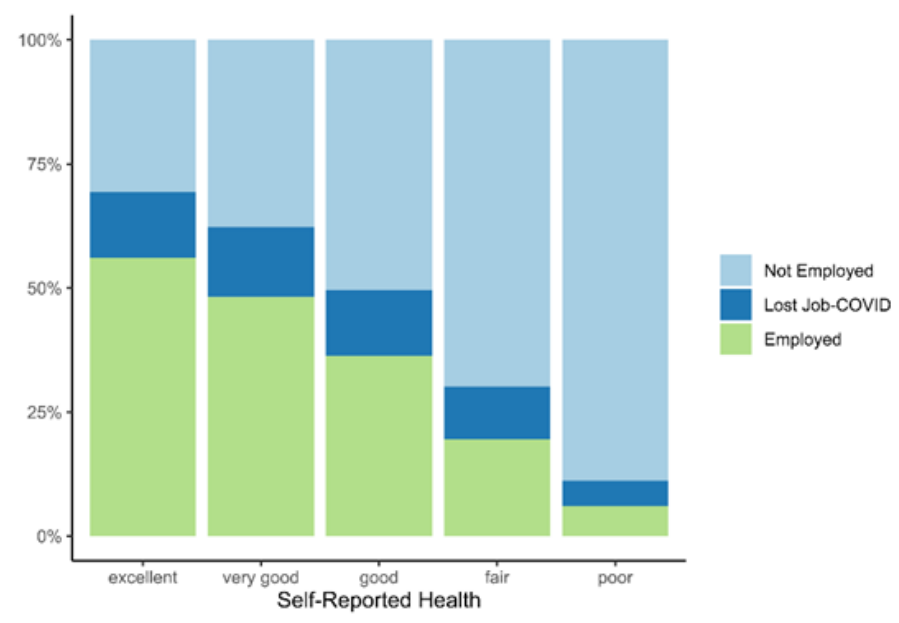


APPENDIX K. In the Last 30 Days Worried That Food Would Run Out by Race

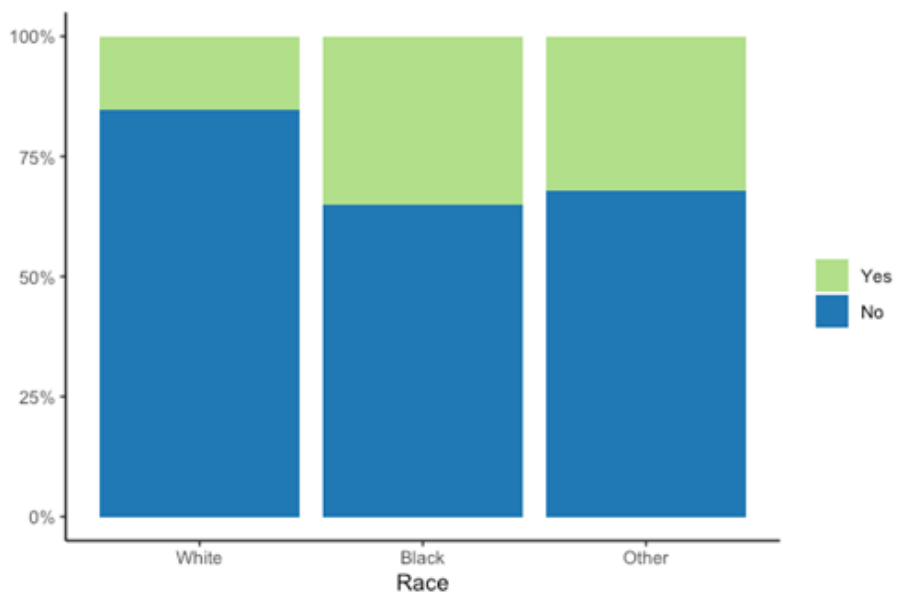

APPENDIX L. Concerns About Paying Bills by Health Status
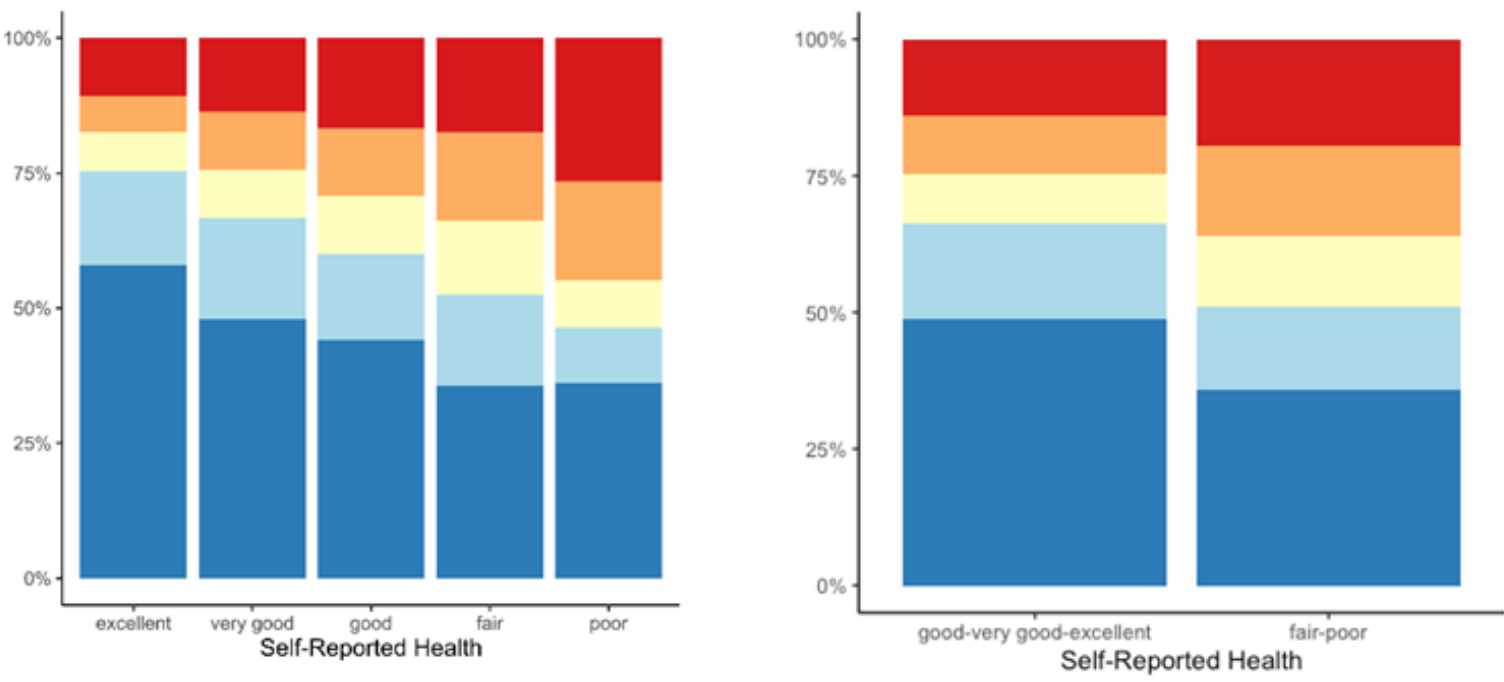

Extremely concemed

Moderately concerned Somewhat concerned Slightly concerned

Not at all concerned

APPENDIX M. Concern About Personal Finances

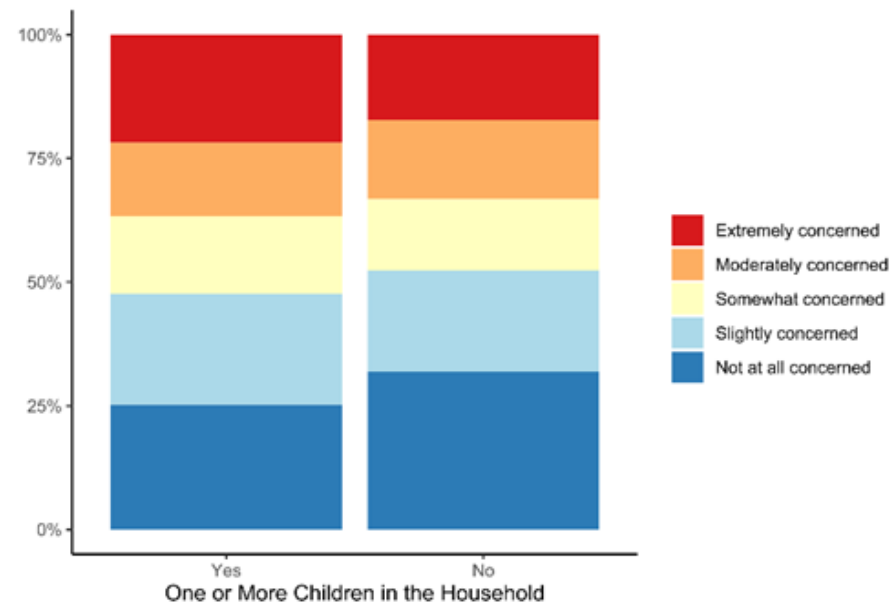


APPENDIX N. Timeline of Selected Public Health Orders, 2020

\begin{tabular}{|c|c|}
\hline February 12 & First Ohio case reported \\
\hline March 8 & Recommendation: Social distancing and enhanced hygiene \\
\hline March 9 & State of Emergency (ongoing) \\
\hline March 14 & Closure of K-12 schools \\
\hline March 15 & Closure of bars, restaurants (dine-in and patio) \\
\hline March 17 & First confirmed Ohio death \\
\hline March 17 & Prohibition on mass gatherings (50 or more people) (ongoing) \\
\hline March 20 & Closure of personal care services \\
\hline March 23 & $\begin{array}{l}\text { Stay-at-home order goes into effect } \\
\text { Closure of campgrounds } \\
\text { Closure of recreational centers }\end{array}$ \\
\hline March 25 & Closure of child care facilities \\
\hline April 4 & Recommendation: masks in public places \\
\hline May 1 & Responsible Restart Ohio / phased reopening begins \\
\hline May 15 & $\begin{array}{l}\text { Patio dining may resume * } \\
\text { Personal care services may resume * }\end{array}$ \\
\hline May 21 & $\begin{array}{l}\text { Dine-in service may resume * } \\
\text { Campgrounds may reopen * }\end{array}$ \\
\hline May 25 & Memorial Day \\
\hline May 26 & Recreational centers may reopen * \\
\hline May 31 & Child care facilities may reopen * \\
\hline June 5 & Bars may reopen * \\
\hline June 11 & Dr. Acton resigns as Director of Ohio Department of Health \\
\hline June 30 & Reopening of K-12 schools (end of school year) \\
\hline July 4 & Independence Day \\
\hline July 8 & Mask orders go into effect in Butler, Cuyahoga, Franklin, Hamilton, Huron, Montgomery, Trumbull Counties \\
\hline July 10 & Mask orders go into effect in Clermont, Fairfield, Lorain, Pickaway, Summit, Wood Counties \\
\hline July 17 & Mask orders go into effect in Allen, Athens, Delaware, Licking, Lucas, Richland, Scioto, Union Counties \\
\hline July 23 & Statewide mask order goes into effect (ongoing) \\
\hline September 7 & Labor Day \\
\hline
\end{tabular}




\title{
Sexually Transmitted Diseases Among Residents in Nursing Homes: The Nurses' Perspective
}

\author{
Lauren N. Maziarz'; Nikki Sorgi ; Nicole Fischer ${ }^{1}$ \\ ${ }^{1}$ Department of Public and Allied Health, Bowling Green State University, Bowling Green, $\mathrm{OH}$ \\ Corresponding Author: Lauren Maziarz, Department of Public and Allied Health, Bowling Green State University, Bowling Green, OH 43403, \\ Imaziar@bgsu.edu
}

Submitted November 9, 2020 Accepted April 8, 2021 Published June 21, 2021 https://doi.org/10.18061/ojph.v4i1.8069

\begin{abstract}
Background: Examining registered nurses' perceptions of sexually transmitted disease (STD) education among residents in nursing homes allows for broader insight into why STDs continue to increase among older adults.

Methods: A 4-page pilot survey was mailed to nursing home directors of nursing in Northwest Ohio $(n=99)$ with a response rate of $32 \%$. Directors of nursing were the target population as they are the most likely employee to hold registered nurse licensure. The health belief model formed the basis for the survey.
\end{abstract}

Results: Most nurses did not see STDs or human immunodeficiency virus (HIV) as problems among their residents (100\% and 96\%, respectively) yet support for sex among residents was high. All (100\%) agreed sex among married residents should be supported, while $77 \%$ agreed sex among nonmarried residents should be supported. Most nurses stated they were comfortable discussing HIV risk (84\%), STD risk (84\%), erectile dysfunction (75\%), sexual desire and intimacy (72\%), and correct condom use (66\%). The most commonly reported perceived barriers to STD education were family opposition (63\%), resident embarrassment (56\%), and lack of education regarding the prevalence of STDs in older adults (53\%). The most commonly reported perceived benefits to STD education were being seen as a leading facility for healthy initiatives (66\%) and promotion of healthy sexual relationships among residents (56\%).

Conclusion: There was strong support for STD education among nurses though implementation remains rare. Addressing the most commonly perceived barriers and benefits may prove beneficial in increasing the number of LTCFs that provide STD education to residents.

Keywords: Sexually transmitted disease education; STDs; Nursing homes; Nurses' perceptions

\section{INTRODUCTION}

Many older adults in the United States (US) aged 65 to 80 years are sexually active $(40 \%)^{1}$ yet report less condom use, fewer sexually transmitted disease (STD) screenings, and lower risk perceptions of STDs than their younger counterparts. ${ }^{2}$ While STD burden in the US remains highest during adolescence, STDs are on the rise among older adults. ${ }^{3}$ Rates for herpes, gonorrhea, syphilis, chlamydia, hepatitis B, and trichomoniasis rose 23\% between 2014 and 2017 for those over age 60.3 Unfortunately, discussions with care providers about sexual health remain rare. The majority of older adults (62\%) say they would talk to their health care provid- er if they were concerned about their sexual health, yet only $17 \%$ have done so in the last 2 years. ${ }^{1}$

Nurses who work in long-term care facilities (LTCFs) represent a unique population for studying barriers to STD education among older adults. Elderly individuals who reside in LTCFs tend to have higher dependency on care staff than the rest of the population, potentially hindering opportunities for sex and sexual expression. 4,5 Moreover, an increased prevalence of chronic illnesses compared to the general population coupled with prescription medications that limit sexual drive also contribute to limited opportunities for sexual intimacy.4 This does not mean that individu- 
als in LTCFs are asexual, however, as research has shown that sexual intimacy, while possibly becoming more difficult in older age, is still an important aspect of life.5,6 Since more than 1.5 million nurse employees (ie, registered nurses [RNs], licensed practical nurses [LPNs], and licensed vocational nurses [LVNs]) work in LTCFs in the US,7 examining barriers to STD education from the nurses' perspective allows for insight into why STD education and screening in nursing homes remains rare among this vulnerable population.

Although sexual activity decreases with age, interest in sex remains strong with $65 \%$ of adults aged 65 to 80 years reporting that sex is important to their overall quality of life. ${ }^{1}$ While these findings do not specify whether the adults are living in LTCFs, older men and women who self-report being in fair or poor health still acknowledge having regular sex at least 2 to 3 times per month (46\% versus $56 \%$, respectively). ${ }^{8}$ Several studies have also documented the assumption among LTCF staff that sexual expression over a certain age is inappropriate, ${ }^{4,9}$ which is alarming given that sexual activity does not decrease in older adulthood to the extent to which is commonly perceived. Nurses and other health care personnel are typically seen as being responsible for sex education for the elderly, although training is routinely focused on the physical aspects of sex as opposed to the psychological or emotional issues of intimacy. ${ }^{10}$ Staff regularly report either seeing sexual activity in LTCFs as distracting or even disturbing to younger family members and staff.4,9 Care providers may also feel as though sexual education is low on a long list of priorities, as comorbidities are common and dependence on staff is high. ${ }^{9}$

Negative staff attitudes regarding sexual expression also contribute to a lack of open dialogue among residents, as older adults are less likely to talk about sex if their health care providers do not broach the subject first. ${ }^{8}$ Active listening during conversations and connecting with patients to better understand the appropriate times when sexual health may be explained openly are important skills all health care professionals should acquire.4,9,11,12 It can be argued that the nature of longer and more meaningful encounters between a medical provider and their elderly resident may prove more effective for discussing sexual health than briefly visiting with shallow conversations, ${ }^{13}$ making LTCFs a place to engage in meaningful dialogue with residents regarding their sexual expression.

Previous research has demonstrated that there is a significant gap in knowledge and self-efficacy among care providers when it comes to addressing STDs in the elderly.4,14-19 One well-shared viewpoint, however, expresses the notion that more education on sexual health may yield more on-the-job confidence thereby reducing hesitation when approaching a person of any age concerning the topic.4,9,10,12,17-19 Knowing and understanding the sexual health needs of older adults makes care providers more likely to introduce the topic of sex into their everyday conversations. In a recent Australian study, nurse training has been found to be effec- tive at improving LTCF nurse knowledge and attitudes regarding older adult's sexuality, ${ }^{20}$ pointing to the need to expand knowledge and training for US-based LTCF nurses.

Facility policies can also either hinder or enhance communication regarding sexual health. ${ }^{12}$ Just $23 \%$ of LTCFs in the US have policies related to sexual expression, and even fewer (13\%) provide staff training on intimacy and sexual behavior. ${ }^{19}$ Without policies to guide the residents, there are no strict rules to govern the health care staff and to shape their perspectives when it comes to sexual expression. ${ }^{12}$ Several studies have also discussed how the lack of privacy among residents, family member involvement in decision making, as well as a lack of a partnercan all hinder sexuality among residents. ${ }^{4,5}$ Unfortunately, there is no published data on the percentage of LTCFs that provide STD education or screening, making it difficult to ascertain how common the practice is.

Nurses and care providers in LTCFs play an integral role in shaping the day-to-day lives of residents. Since resident dependency is high and autonomy is limited, this study represents an important step to understanding how nursing homes may differ from other populations in terms of STD prevention campaigns. As one of the first systematic quantitative explorations of RNs to examine perceptions of STD education in LTCFs, gaining insight into the barriers to and benefits of STD education will inform targeted education campaigns and aid in the development of evidence-based training programs for nurses in the future.

\section{METHODS}

\section{Setting and Design}

This study used a cross-sectional study design to explore nurses' beliefs and attitudes towards sexual relationships and STDs in nursing home residents. The health belief model ${ }^{21,22}$ formed the theoretical basis to explore nurses' perceived barriers, perceived benefits, and beliefs regarding both sexual intimacy and STDs among residents. The Health Belief Model was chosen to guide this study as other research has demonstrated the theory's applicability to examining perceptions, barriers, and benefits at the systems level.23,24 The 21-item instrument included 13 close-ended questions, 7 demographic items, and 1 open-ended question for additional insights. To ensure content validity, literature in the areas of sexual health, STD prevention, and health care provider knowledge provided the basis for question development. $2,4-6,9,12,17,18,20$

\section{Participants}

The subjects used for this study consisted of directors of nursing working in nursing homes in Northwest Ohio. Directors of nursing were the target population as they are the most likely employee to hold RN licensure, and, in fact, may be one of the only RNs in the facility. Thus, targeting directors of nursing was the most effective way of gathering RN perceptions. Furthermore, directors of nursing can help shape and direct policies and procedures within LTCFs, meaning their opinions can either support or hinder 
change within an agency. ${ }^{12}$ All 99 nursing homes in the 10 counties within Northwest Ohio received surveys. Facility names and locations were compiled from the Medicare Nursing Home Compare website and cross-referenced with the local Area Office on Aging (AOA) database. It should be noted that the term LTCF can encompass all long-term care options, including independent living facilities with minimal to no nurse support but can also encompass nursing homes with complete resident dependence. Since assisted living facilities are not well-defined by the State of Ohio, agencies listed only as an assisted living facility according to the AOA were excluded from this study.

\section{Procedures}

This research study was approved by the primary investigator's institutional review board. Mailed surveys were sent over 3 waves, all 2 weeks apart. Starting in June 2019, the initial wave included a hand-signed cover letter with an explanation of the research, a \$1 bill as an incentive, and a stamped return envelope sent through first-class mail. The second wave included a postcard requesting participants who had not already done so to complete the survey.

The third and final wave included another copy of the survey with a cover letter sent to the participants who had not yet completed the form.

\section{Data Analysis}

Data were analyzed using IBM SPSS Statistics 24.0 for Mac. We used descriptive analyses to examine the percentage of participants who responded to given survey items. Chi-square analyses were used to compare responders and nonresponders on several variables to determine sample representativeness.

\section{RESULTS}

\section{Demographics}

Out of 99 mailed surveys, a total of 32 surveys were returned for a response rate of $32 \%$. The majority of respondents identified as female (94\%), aged 40 and over (76\%), White (81\%), with an associate's degree as the highest level of education (53\%), 1 to 5 years of experience at their current facility (47\%), and came from midsized facilities with 50 to 99 beds (47\%). Most respondents also identified their current job title as the director of nursing (88\%) (Table 1). The 2 respondents who did not identify as a

\section{Table 1. Demographic and Background Characteristics of Respondents}

\begin{tabular}{|c|c|}
\hline Item & $\mathbf{N}(\%)$ \\
\hline \multicolumn{2}{|c|}{ Number of beds in the facility } \\
\hline$<50$ & $5(16)$ \\
\hline $50-99$ & $15(47)$ \\
\hline 100-199 & $11(34)$ \\
\hline \multicolumn{2}{|l|}{ Gender } \\
\hline Female & $30(94)$ \\
\hline Male & $1(3)$ \\
\hline \multicolumn{2}{|l|}{ Age } \\
\hline $20-29$ & $2(6)$ \\
\hline $30-39$ & $5(16)$ \\
\hline $40-49$ & $12(38)$ \\
\hline $50+$ & $12(38)$ \\
\hline \multicolumn{2}{|l|}{ Race/ethnicity } \\
\hline White & $26(81)$ \\
\hline Non-white & $5(16)$ \\
\hline \multicolumn{2}{|c|}{ Highest level of education } \\
\hline Diploma program & $1(3)$ \\
\hline Associate's degree & $16(53)$ \\
\hline Bachelor's degree & $13(41)$ \\
\hline Master's degree & $1(3)$ \\
\hline \multicolumn{2}{|l|}{ Years at current facility } \\
\hline $1-5$ & $15(47)$ \\
\hline $6-10$ & $6(19)$ \\
\hline $11-15$ & $2(6)$ \\
\hline $16-20$ & $1(3)$ \\
\hline $20+$ & $7(22)$ \\
\hline \multicolumn{2}{|l|}{ Current job title } \\
\hline Director of nursing & $28(88)$ \\
\hline Other & $2(6)$ \\
\hline
\end{tabular}

Note: Percentages may not equal $100 \%$ due to rounding and/or nonreported answers. 
director of nursing identified their positions as administrative in nature ("regional resource nurse manager" and "administrator") and were included in the results.

Additionally, to assess sample representativeness, responders and nonresponders were compared based on several variables reported in the skilled nursing facility provider catalog which includes publicly available data reported by nursing homes. ${ }^{25}$ Pearson chisquare results indicate no significant difference between responders and nonresponders depending on which county the facility was located in (Pearson $\left.\chi^{2}(9, N=99)=15.77, p=.072\right)$, the number of beds in the facility (Pearson $\chi^{2}(3, \mathrm{~N}=90)=1.50, \mathrm{p}=.682$ ), and the Centers for Medicare and Medicaid Services (CMS) RN staffing rating, which rates the number of adjusted RN hours per resident per day (Pearson $\left.\chi^{2}(4, \mathrm{~N}=76)=1.39, \mathrm{p}=.845\right)$. Table 2 provides a comparison of these variables among both responders and nonresponders as well as all nursing homes in Ohio.

\section{Sex Education Practices, Condom Availability, and Training}

The vast majority of respondents (94\%) stated there is no sex education provided to residents at their facility, while only $13 \%$ stated condoms are provided to residents who are sexually active. When asked if they had been trained on how to address STDs among residents, $87 \%$ said they had no formal training. Among those that had been trained $(n=4)$, education had occurred through either their nursing education $(n=2)$, employee education $(n=1)$, or continuing education $(n=1)$.

Interestingly, when asked whether STDs were a significant health problem among residents in their facility, all (100\%) respondents disagreed with this statement. In contrast, when asked if STDs were a significant problem among older adults in the US, only 53\% disagreed with this statement. Disparities also existed in perceptions of HIV burden. Most (97\%) disagreed HIV was a significant problem among residents at their facility, while only $38 \%$ disagreed HIV was a significant problem among older adults in the US.

\section{Facilitation of Sex and Sexual Relationships}

Respondents were unanimously supportive (100\%) of sex among married residents at their facility, while slightly fewer (77\%) agreed sex among nonmarried residents should be supported. The majority (78\%) also agreed sex among LGBTQ+ residents should be supported. Moreover, most (87\%) believed their facilities should provide private spaces for intimate partner visits, but fewer (52\%) believed condoms or lubricants (52\%) should be provided for residents who are having sex.

\section{Table 2. Comparison of Responders to Nonresponders/Ohio Nursing Homes}

\begin{tabular}{|c|c|c|c|}
\hline Characteristic & Responders N (\%) & Nonresponders N (\%) & Ohio nursing homes $\mathrm{N}(\%)^{\mathrm{a}}$ \\
\hline \multicolumn{4}{|c|}{ Number of beds in facility } \\
\hline$<50$ & $5(16)$ & $18(20)$ & $157(17)$ \\
\hline $50-99$ & $15(47)$ & $51(57)$ & $504(53)$ \\
\hline $100-199$ & $11(34)$ & $20(22)$ & $280(29)$ \\
\hline$>199$ & $0(0)$ & $1(1)$ & $11(1)$ \\
\hline \multicolumn{4}{|c|}{ Registered nurse (RN) staffing rating ${ }^{b}$} \\
\hline 1 star & $2(8)$ & $3(6)$ & $77(9)$ \\
\hline 2 stars & $9(35)$ & $19(37)$ & $289(35)$ \\
\hline 3 stars & $10(39)$ & $19(37)$ & $268(32)$ \\
\hline 4 stars & $4(15)$ & $5(10)$ & $139(17)$ \\
\hline 5 stars & $1(4)$ & $5(10)$ & $64(8)$ \\
\hline \multicolumn{4}{|c|}{ County of facility } \\
\hline Lucas & $9(28)$ & $35(52)$ & \\
\hline Erie & $5(16)$ & $3(5)$ & \\
\hline Wood & $5(16)$ & $8(12)$ & \\
\hline Sandusky & $4(13)$ & $7(10)$ & \\
\hline Ottawa & $3(9)$ & $1(2)$ & \\
\hline Henry & $3(9)$ & $1(2)$ & \\
\hline Fulton & $1(3)$ & $4(6)$ & \\
\hline Paulding & $1(3)$ & $1(2)$ & \\
\hline Williams & $1(3)$ & $3(5)$ & \\
\hline Defiance & $0(0)$ & $4(6)$ & \\
\hline
\end{tabular}

Note: Percentages may not equal $100 \%$ due to rounding and/or nonreported answers. ${ }^{\mathrm{a}} \mathrm{N}=953$

${ }^{\mathrm{b}} \mathrm{RN}$ staffing rating is based on a 1-5 point scale that rates the number of adjusted RN hours per resident per day. The lower the rating, the fewer RN hours per resident per day. 
As a whole, nurses were supportive of talking with residents about their sexual health. The majority of nurses agreed they should provide education to residents on the risks of engaging in sex $(85 \%)$, talk with their residents about their sexual health needs (84\%), and support sexual intimacy among residents (75\%). When asked about sexual desire among residents, $72 \%$ of nurses agreed sexuality was a lifelong need among residents, and only $44 \%$ of nurses agreed residents in their facility desired sexual intimacy. Nurses did not perceive residents as being open to discussions on sex, however, with only $9 \%$ agreeing residents would want to talk about sexual intimacy with staff.

\section{Perceived Barriers and Benefits to Providing STD Education}

The most commonly reported perceived barriers to STD education were family opposition (63\%), resident embarrassment (56\%), lack of education regarding the prevalence of STDs in older adults (53\%), and not having enough time to provide education to residents $(50 \%)$ (Table 3 ). The most commonly reported perceived benefits to STD education were being seen as a leading facility for healthy initiatives $(66 \%)$, promotion of healthy sexual relationships among residents (56\%), improved overall health among residents $(47 \%)$, and improved resident knowledge of STDs (47\%) (Table 4).

\section{Perceived Support and Opposition to STD Education}

The vast majority of nurses agreed they are personally supportive of STD education for residents (97\%), and 75\% also believed residents would be supportive. In terms of other health care professionals, most believed LTCF administrators (78\%), physicians (78\%), and nurses (56\%) would all be supportive individuals, while fewer (50\%) agreed nursing assistants would be supportive. Of the responses listed, family members of residents were the only group noted as being opposed to STD education by the majority of respondents $(66 \%)$.

\section{Comfort with Sexual Health Discussions}

The respondents were asked how comfortable they would be discussing certain sexual health topics with residents. Most stated they were comfortable discussing STD risk (84\%), HIV/AIDs risk (84\%), erectile dysfunction (75\%), sexual desire and intimacy (72\%), and pain with sexual intercourse (72\%). Slightly fewer stated they were comfortable discussing lubricant use (69\%) and correct condom use (66\%). Notably, only half (50\%) stated they were comfortable discussing consent to sex for residents with dementia.

\section{Additional Comments}

Participants were asked for any additional insights regarding STDs in LTCFs. Five respondents provided comments, with 3 highlighting the need for more education in this area. One respondent commented, "This has opened my eyes to a potential need for education at this facility." Another stated, "In my opinion, if the center leaders approach this with residents and staff we may be able to decrease STDs in the entire community." An additional respondent said, "It is the residents right to engage in sexual activity if they want. Sometimes nurses and family members oppose their resident or family engaging in sexual activities-that's our highest barrier. STD education would be a good program for residents, staff, and family."

\section{Table 3. Perceived Barriers to Providing STD Education}

\begin{tabular}{|c|c|c|}
\hline Barrier & $\begin{array}{l}\text { Not a barrier or minor barrier } \\
\mathrm{N}(\%)\end{array}$ & $\begin{array}{l}\text { Moderate or major barrier } \\
\text { N (\%) }\end{array}$ \\
\hline Family opposition to sex among residents & $11(34)$ & $20(63)$ \\
\hline $\begin{array}{l}\text { Lack of education among LTCF nurses regarding the prevalence of STDs in } \\
\text { older adults }\end{array}$ & $14(44)$ & $17(53)$ \\
\hline Negative nurse attitudes towards sex among residents & $16(50)$ & $14(44)$ \\
\hline Lack of training on how to address STDs among residents & $17(53)$ & $13(41)$ \\
\hline Lack of funding for STD education programming & $18(56)$ & $13(41)$ \\
\hline Nurse embarrassment regarding talking about sex with residents & $20(63)$ & $10(31)$ \\
\hline
\end{tabular}

Note: Percentages may not equal $100 \%$ due to rounding and/or nonreported answers. 
Table 4. Perceived Benefits to Providing STD Education

\begin{tabular}{|lll|}
\hline Benefit & Not a benefit or minor benefit & $\begin{array}{l}\text { Moderate or major benefit } \\
\text { N (\%) }\end{array}$ \\
\hline Being a leading LTCF for healthy initiatives & $8(25)$ & $21(66)$ \\
Promotion of healthy sexual relationships among residents & $11(34)$ & $18(56)$ \\
Improved overall health among residents & $14(44)$ & $15(47)$ \\
Improved knowledge of STDs among residents & $14(44)$ & $15(47)$ \\
Decreased STD rates in my facility & $27(85)$ & $1(3)$ \\
Other & $1(3)$ & $0(0)$ \\
\hline
\end{tabular}

Note: Percentages may not equal $100 \%$ due to rounding and/or nonreported answers.

Two additional nurses commented on the need for consent among residents by remarking the following: "Must be consensual and residents must have a high BIMS [brief interview for mental status] score" and "this topic is under spoken about in LTC especially considering the dementia population is unable to knowingly give consent to participate in sexual activity. Married couples and those able to safely consent are spoken to by social workers to ensure safety and privacy."

\section{DISCUSSION}

Nurses in our study were nearly unanimous in disagreeing STDs and HIV are problems among their residents. While there was stronger agreement that STDs and HIV are problems among older adults in the general population, this still represents a disconnect between what the nurses are perceiving as health problems in their residents and what the literature shows are growing health concerns among older adults.1-3 This corroborates previous research findings which showed that while LTCF staff consider privacy, consent, and appropriateness of sexual intimacy among residents, STDs may not be a significant concern. ${ }^{9}$ Since nurses are typically the ones assessing and triaging patients in a nursing home, perceptions could be driven by personal experience such that nurses are not observing STDs in their residents and thus do not consider such diseases a problem. Given that our study did not ask about STD screening procedures, it is unknown how nurses in nursing homes would be made aware of an STD other than patient signs and symptoms. Many STDs such as chlamydia and gonorrhea are asymptomatic, however, and thus would not be obvious without systematic screening.

Our findings also show that STD education for nursing home residents remains a rare occurrence. Just 2 respondents (6\%) stated their facility provides some sort of STD education. This should not be surprising given that previous research has demonstrated a reluctance of health care providers to discuss sexual health in older adults coupled with complex or nonexistent intimate partner policies in LTCFs. ${ }^{9-19}$ Respondents in our study also stated perceived family opposition would be the most significant barrier to providing STD education, which means decisions of care are not happening based on patient need alone. Decisions to educate residents on STDs and healthy sexual relationships are clearly a complex decision that combines nurse comfortableness, previous training, facility policies, perceptions of resident embarrassment, and perceptions of family opposition.

Surprisingly, the most significant perceived benefit to providing STD education to residents noted by respondents was the ability to be seen as a leading LTCF for healthy initiatives. Respondents in our study did not perceive a reduction in STDs to be a significant benefit, most likely due to the perception that STDs are not a problem among residents. These responses could be driven by the supervisory role of our respondents, since directors of nursing typically have responsibilities that go beyond direct patient care. ${ }^{12}$ Highlighting this benefit to nurse administrators may encourage more facilities to adopt an STD education program.

In terms of consent to sexual intimacy, dementia is often overlooked as an increasingly common diagnosis that impacts sexual expression and consent.26-29 Only half of respondents in our study said they were comfortable talking about consent to sex for residents with dementia. In any case involving sexual expression and intimacy, the individual's autonomy, privacy, and safety are the most important considerations for LTCFs. ${ }^{28}$ A person's ability to make decisions regarding their sexuality typically comes from being deemed an autonomous individual by a facility staff member conducting an assessment evaluating their cognitive abilities, known as the mini mental status exam (MMSE). ${ }^{26,28}$ Research suggests that in order for an individual with dementia to have sex without the capacity for consent, the resident, staff, and family should be involved in making decisions to keep the resident's best interest in mind. ${ }^{27}$ While these patients may have diminished thinking capabilities, it does not mean that every scenario is the same and should follow the same guidelines. ${ }^{26}$ As previous research has noted, directors of nursing in LTCFs prefer a top-down approach to addressing sexual expression, with more direction on consent and intimacy policies coming from national organizations such as CMS. ${ }^{12}$ 
Furthermore, at least 1 respondent in our study made a comment regarding how practices may differ between assisted living facilities and nursing homes since independence differs greatly based on the type of facility. Individuals living in resident communities, where they are essentially autonomous residents, have less mobility limitations and more independence in terms of day-to-day activities. As previously noted, program and service offerings in assisted living facility services can vary greatly and are not welldefined in Ohio. Since our study did not seek out responses from nurses working in assisted living facilities, findings do not represent the full spectrum of nurse perceptions in LTCFs. Future research should compare differences in nurse perception based on the type of facility.

Our study was limited by several factors. First, since this was a pilot study, the small sample size does not allow for generalizability to a broader population. Homogeneity in responses to our survey items also limited variation and comparison among study variables. A larger sample inclusive of all LTCFs, including assisted living facilities, would aid in comparison of facility demographic variables, nurse demographic variables, and perceptions of STD education. Survey items were also monothematic in nature and somewhat controversial which can influence response bias.

\section{PUBLIC HEALTH IMPLICATIONS}

Among nurses in our study, there was clear support for STD education and facilitation of healthy sexual relationships, yet implementation of STD education remains rare. Nurses report lacking the training necessary to talk with residents about STD prevalence and prevention but feel overwhelmingly comfortable talking about many sexual health concerns. While perceptions of barriers and benefits do not always translate into practice, this study expands our understanding of the hesitancy among medical professionals to discuss STD risk with residents in LTCFs.

\section{REFERENCES}

1. American Association of Retired People. National poll on healthy aging. Accessed November 15, 2019. https://www.healthyagingpoll.org

2. Syme ML, Cohn J, Barnack-Tavalaris J. A comparison of actual and perceived sexual risk among older adults. J Sex Res. 2017;54(2):149-160. https://doi.org/10.1080/00224499.2015.1124379

3. Athena health. Published May 16, 2018. Accessed November 11, 2019. https://www.athenahealth.com/insight/over-60-stis-may-not-bedone-you

4. Villar F, Celdran M, Faba J, Serrat R. Barriers to sexual expression in residential aged care facilities (RACFs): comparison of staff and residents' views. JAdv Nurs. 2014;70(11):2518-2527. https://doi.org/10.1111/jan.12398

5. Bauer M, Fetherstonhaugh D, Tarzia L, Nay R, Wellman D, Beattie E. "I always look under the bed for a man." Needs and barriers to the expression of sexuality in residential aged care: The views of residents with and without dementia. Psychol Sex. 2013;4(3):296-309. https://doi.org/10.1080/19419899.2012.713869
6. Mathieu L, Gastmans C. Older residents' perspectives on aged sexuality in institutionalized elderly care: A systematic review. Int J Nurs Stud. 2015;52:1891-1905.

https://doi.org/10.1016/j.ijnurstu.2015.07.007

7. Centers for Disease Control and Prevention (2017). Nursing home care. Accessed October 30, 2019.

https://www.cdc.gov/nchs/fastats/nursing-home-care.htm

8. Lindau ST, Schumm LP, Laumann EO, Levinson W, O'Muirchesartaigh CA, Waite LJ. A study of sexuality and health among older adults in the United States. N Engl J Med. 2007,357:762-774. https://doi.org/10.1056/NEJMoa067423

9. Gilmer MJ, Meyer A, Davidson J, Koziol-McLain J. Staff beliefs about sexuality in aged residential care. Nurs Prax N Z. 2010;26(3):17-24.

10. Penwell-Waines L, Wilson CK, Macapagal KR, et al. Student perspectives on sexual health: implications for interprofessional education. $J$ Interprof Care. 2014;28(4):317-322. https://doi.org/10.3109/13561820.2014.884553

11. Benoot C, Enzlin P, Peremans L, Bilsen J. Addressing sexual issues in palliative care: A qualitative study on nurses' attitudes, roles and experiences. JAdv Nurs. 2018;74(7):1583-1594. https://doi.org/10.1111/jan.13572

12. Syme ML, Lichtenberg P, Moye J. Recommendations for sexual expression management in long-term care: a qualitative needs assessment. $J$ Adv Nurs. 2016;72(10):2457-2467. https://doi.org/10.1111/jan.13005

13. Slinkard MS, Kazer MW. Older adults and HIV and STI screening: the patient perspective. Geriatr Nurs. 2011;5(32):341-349. https://doi.org/10.1016/j.gerinurse.2011.05.002

14. Syme ML, Yelland E, Cornelison L, Poey JL, Krajicek R, Doll G. Content analysis of public opinion on sexual expression and dementia: implications for nursing home policy development. Health Expect. 2016;20 (4):705-713. https://doi.org/10.1111/hex.12509

15. Ports KA, Barnack-Tavalaris JL, Syme ML, Perera RA, Lafata JE. Sexual health discussions with older adult patients during periodic health exams. J Sex Med. 2014;11:901-908. https://doi.org/10.1111/jsm.12448

16. Hughes AK. HIV knowledge and attitudes among providers in aging: results from a national survey. AIDS Patient Care STDS. 2011;25 (9):539-545.

https://doi.org/10.1089/apc.2011.0026

17. Villar F, Celdran M, Faba J, Serrat R. Staff members' perceived training needs regarding sexuality in residential aged care facilities. Gerontol Geriatr Educ. 2017;38(4):443-452. https://doi.org/10.1080/02701960.2015.1127811

18. Di Napoli EA, Breland GL, Allen RS. Staff knowledge and perceptions of sexuality and dementia of older adults in nursing homes. J Aging Health. 2013;25(7): 1087-1105. https://doi.org/10.1177/0898264313494802

19. American Medical Directors Association. Elder care sex survey. Published October 28, 2013. Accessed August 10, 2020. https://www.bloomberg.com/graphics/infographics/elder-care-sexsurvey-results.html

20. Bauer M, McAuliffe L, Nay R, Chenco C. Sexuality in older adults: effect of an education intervention on attitudes and beliefs of residential 
aged care staff. Educ Gerontol. 2013;39(2):82-91.

https://doi.org/10.1080/03601277.2012.682953

21. Rosenstock IM. The health belief model and preventive health behavior. Health Educ Monogr. 1974;2(4):354-386.

22. Hochbaum GM. Public Participation in Medical Screen Programs: A Socio-psychological Study. US Department of Health, Education, and Welfare: Washington, DC; 1958.

23. Maziarz LN, Dake JA, Glassman T, Telljohann SK, Beekley C. Superintendents perceptions of condom availability in US high schools. Health Behav Policy Rev. 2017;4(4):389-398.

24. Reindl D, Glassman T, Price J, Dake J, Yingling F. Perceptions of college and university presidents regarding tobacco-free campus policies. Jof Am Coll Health, 2014.62(3):193-202.

https://doi.org/10.1080/07448481.2013.877019

25. Centers for Medicare and Medicaid Services (CMS) Skilled Nursing Facilities Report. Published February 2, 2021. Accessed March 30, 2021.

https://data.cms.gov/provider-data/dataset/4pq5-n9py

26. Victor E, Guidry-Grimes L. Relational autonomy in action: rethinking dementia and sexuality in care facilities. Nurs Ethics. 2019;26(6):16541664.

https://doi.org/10.1177/0969733018780527

27. Wilkins JM. More than capacity: alternatives for sexual decision making for individuals with dementia. Gerontologist. 2015;55(5):716-723. https://doi.org/10.1093/geront/gnv098

28. Hillman J. Sexual consent capacity: ethical issues and challenges in long-term care. Clin Gerontol. 2016;40(1):43-50.

https://doi.org/10.1080/07317115.2016.1185488

29. Cornelison LJ, Doll GM. Management of sexual expression in long-term care: ombudsmen's perspectives. Gerontologist. 2012;53(5):

780-789.

https://doi.org/10.1093/geront/gns162 


\title{
A Geographic Perspective on Opioid Misuse: Substance Abuse Treatment Deserts in Southwestern Ohio
}

\author{
Linnea Lowe ${ }^{1}$; Cole Brokamp ${ }^{2,3}$; Erika Rasnick ${ }^{3}$; Eric S. Hall ${ }^{4}$; Shauna Acquavita ${ }^{1,5}$
}

${ }^{1}$ School of Social Work, University of Cincinnati, Cincinnati, $\mathrm{OH}$

${ }^{2}$ College of Medicine, University of Cincinnati, Cincinnati, $\mathrm{OH}$

${ }^{3}$ Cincinnati Children's Hospital Medical Center, Cincinnati, $\mathrm{OH}$

${ }^{4}$ Geisinger, Danville, PA

${ }^{5}$ Center for Addiction Research, University of Cincinnati, Cincinnati, $\mathrm{OH}$

Corresponding Author: Linnea Lowe, School of Social Work, University of Cincinnati, PO Box 670108, Cincinnati, OH 45267-0108, lowela@mail.uc.edu Submitted November 22, 2020 Accepted April 6, 2021 Published June 21, 2021 https://doi.org/10.18061/ojph.v4i1.8075

\section{ABSTRACT}

Background: The opioid crisis is one of the most pressing public health issues facing Ohio, with an impact unevenly distributed across the state. This work examined geographical barriers to substance abuse treatment in southwestern Ohio through examining geographical areas with limited access to substance abuse treatment services and identifying substance abuse treatment deserts.

Methods: The study domain included the 13 counties in the Ohio Mental Health and Addiction Service's Cincinnati region. Publicly available substance use disorders treatment data were collected from government agency resources, pharmaceutical websites, and web searches. Substance abuse treatment deserts were defined as areas in the 13-county study area that were not within a 15-minute drive from a treatment center.

Results: We found large portions of the study region that were considered a substance abuse treatment desert for methadone and naltrexone/buprenorphine clinics, behavioral health treatment centers, and both medicated assisted treatment (MAT) and behavioral health treatment combined. Out of the 2017337 total persons living in the 13-county study area, $17 \%(n=342872)$ live in a desert for all MAT and behavioral treatment. Similarly, $19.7 \%(n=396581)$ live in a desert for naltrexone/buprenorphine treatment, $60.9 \%(n=1227560)$ live in a desert for methadone treatment, and $19.7 \%(n=396581)$ live in a desert for behavioral health treatment.

Conclusion: We successfully defined substance abuse treatment deserts in southwestern Ohio, which will be useful for future research to determine its association with opioid-related health outcomes. This resource is publicly available online (https://doi.org/10.5281/zenodo.4011051).

Keywords: Opioid abuse; Treatment desert; Medicated assisted treatment; Behavioral health treatment; Geospatial

\section{INTRODUCTION}

In recent decades, an opioid epidemic has gripped the United States resulting in an unprecedented public health crisis. ${ }^{1}$ Between 1999 and 2019, the number of opioid-involved overdose deaths increased almost 6 -fold, with opioids involved in nearly $70 \%$ of the over 67000 overdose deaths in 2019.2,3 That same year, an estimated 2 million people were diagnosed with an opioid use disorder; of those, only about $20 \%$ received substance use treatment in the previous year. ${ }^{3}$ The necessity of access and availability to specialty drug treatments for opioid dependence is highlighted by studies that have demonstrated that these types of treatments 
reduce the risk of overdose mortality. ${ }^{4}$ While affordability of treatment increased in recent years for many low-income individuals due to Medicaid expansion under the Patient Protection and Affordable Care Act of 2010,5 geographic accessibility continues to be an area of concern. Cummings and colleagues ${ }^{6}$ found that while approximately $60 \%$ of counties in the United States have at least 1 outpatient substance abuse treatment facility that accepts Medicaid, this rate was lower in many southern and midwestern states. Furthermore, counties with a higher percentage of Black, rural, and/or uninsured residents were less likely to have a facility that accepted Medicaid. Other studies suggest that primary care providers who practice in rural areas and/or communities with larger Black and Latinx populations have fewer, geographically, behavioral health professionals providing mental health and substance use services. ${ }^{7}$

Ohio has been hit especially hard by the epidemic, with opioid overdoses resulting in over 500000 total years of lost life from 2010 to $2016 . .^{8}$ In 2007, unintentional drug poisoning became the leading cause of injury death in Ohio and, unfortunately, this remains true as of this writing. As an epicenter of the crisis, the opioid mortality rate doubled every 3 years from 1999 to $2016 .{ }^{9}$ As in much of the country, there has been an uneven distribution of opioid overdose mortality throughout Ohio. A geospatial analysis using data from 2010 through 2017 found that the increasing rates of the opioid overdose epidemic in Ohio were driven by 12 epidemic hotspot areas, 5 of which are part of the Greater Cincinnati area. ${ }^{10}$ Of these, 3 were in the Appalachian Region, a cultural, social, and economic region that spans the Appalachian Mountains. ${ }^{11}$ Rural Appalachian counties have the highest mortality rates in the region with $65 \%$ higher overdose mortality compared to nonAppalachian counties. ${ }^{12}$

The concept of deserts to describe geographical areas with limited access to goods and services has been used in popular discourse in recent decades. The term food desert was initially used to describe geographic areas where people experienced physical and economic barriers to accessing healthy food.13 Older studies utilized the former Food Desert Atlas from the United States Department of Agriculture Economic Research Service, which provided a food desert measure for each census tract. A census tract was classified as low access if at least 500 residents, or $33 \%$ of the tract population, lived over 10 miles from a supermarket, based on Euclidean distance. ${ }^{14}$ In more recent literature, the term food desert is used to imply the inability to easily acquire food with high nutritional content, rather than a lack of access to food per se.15,16 This has led researchers to consider other factors that could impact food desert status. Potential factors include explicit and implicit travel costs for consumers in addition to food costs ${ }^{15}$ and perceptions of the acceptability of food stores and shopping locations. ${ }^{17}$

The term health care desert has also been applied to areas where residents of an area or region must travel significant distances to obtain health care services. ${ }^{18}$ Specifically, areas where disparities in access to pharmacy, hospital, trauma, and medical services exist have been identified as deserts.19-21 Additionally, treatment deserts have been used to conceptualize restricted access to treatment in rural areas. A scoping review of opioid misuse in rural America found a theme of treatment deserts in 2 key areas: 1) areas where a small proportion of primary care physicians received buprenorphine waivers and 2) areas where treatment facility types were further for Appalachian versus non-Appalachian and rural versus micropolitan/metropolitan patients. ${ }^{21}$

These examinations of food and health care deserts have been modes through which to identify and explore barriers to goods and services, vital to the health and well-being of vulnerable individuals and communities. Applying a similar paradigm as the original use of the term food desert, this project examined geographical barriers to substance abuse treatment in a greater Cincinnati, Ohio, region, and explored the existence of substance abuse treatment deserts, as defined by individuals living more than a 15minute drive from a treatment center.

\section{METHODS}

\section{Setting and Design}

Included counties were part of the Ohio Department of Mental Health and Addiction Services (OMHAS) Cincinnati region: Adams, Butler, Brown, Clermont, Clinton, Fayette, Hamilton, Highland, Lawrence, Pike, Ross, Scioto, and Warren. ${ }^{22}$ See Figure 1.

\section{Procedures}

Publicly available substance abuse treatment data were obtained from the Substance Abuse Mental Health Services Administration (SAMHSA) website (https://findtreatment.samhsa.gov/), the OMHAS Emerald Jenny Treatment Finder tool (https:// www.emeraldjennyfoundation.org), the Commission on Accreditation of Rehabilitation Facilities (CARF) website (http:// www.carf.org/providerSearch.aspx), the Ohio Behavioral Health Directory (https://prod.ada.ohio.gov/directory/), and the Find a Treatment Provider tool on the Vivitrol website (https:// www.vivitrol.com/find-a-treatment-provider) between August 2019 and February 2020. Additional facilities were found by using Google (www.google.com) to search substance+abuse+treatment and the respective county. Discrepancies between websites for contact information and services were reconciled by calling the facility to confirm the correct address and available services.

\section{Measures/Outcomes}

The street addresses of treatment facilities were geocoded using a standalone, validated geocoder based on Census TIGER/Line street range address files. ${ }^{23,24}$ A geocode is considered accurate if coordinates are placed on the correct street or within the correct street segment, and the input address text and resulting geocoded address text are at least a 50\% match. The current study excluded treatment facilities that could not be accurately geocoded. Out of 260 treatment centers, 250 were able to be accurately geocoded. 


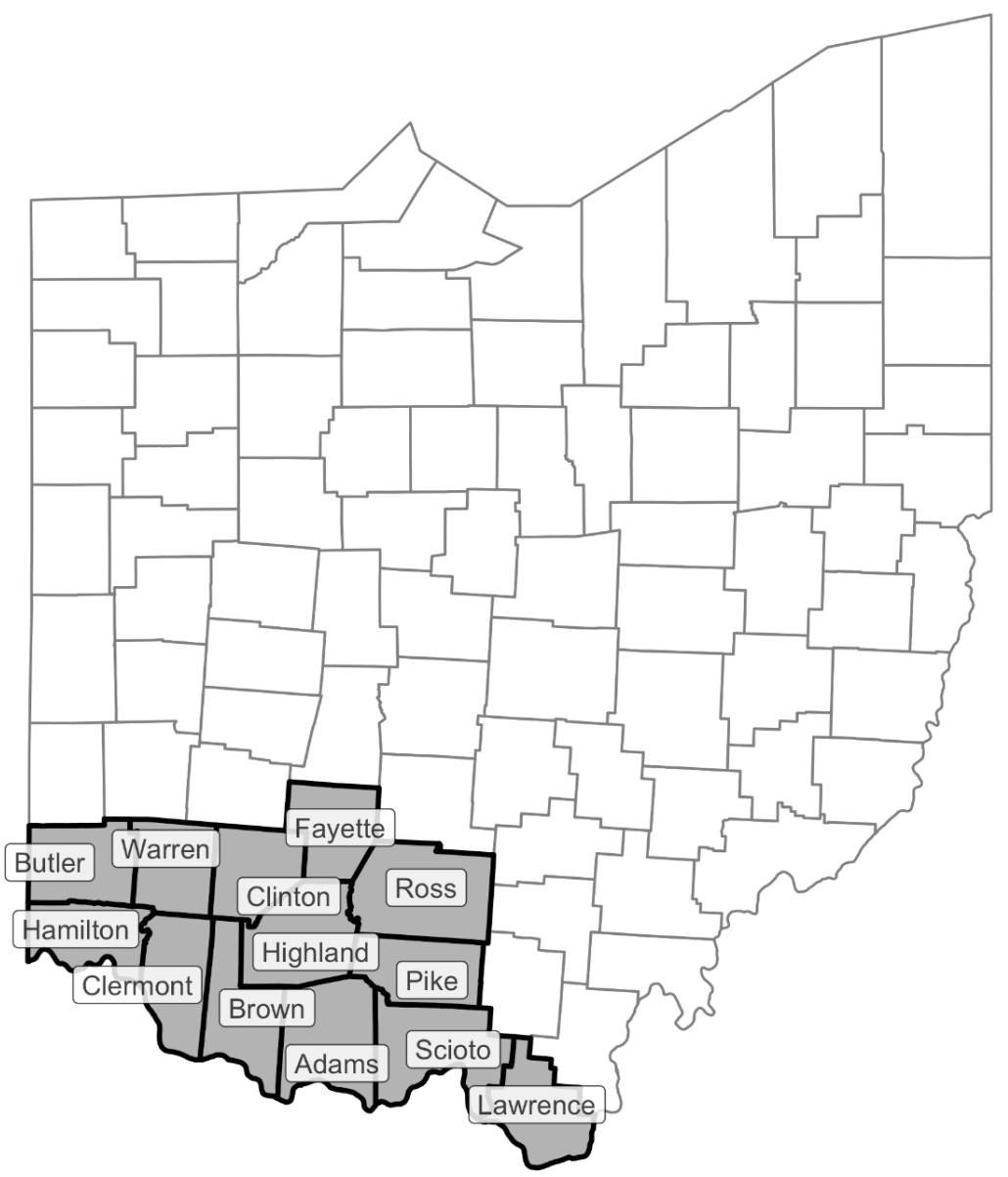

Figure 1. Map of the Study Regions, the OMHAS Cincinnati Region

Polygons consisting of 15-minute drive times from each treatment center were generated using the openroute service API. ${ }^{25}$ We defined 4 types of deserts based on the 3 treatment types and access to any of the treatment types (naltrexone/buprenorphine, methadone, behavioral, and overall). The union of these individual access polygons for each treatment facility was used to define areas of treatment access for each desert type. Substance abuse treatment deserts were defined as areas in the 13-county study area not covered by the treatment access areas. To estimate the number and percentage of people living in substance abuse treatment desert areas, population estimates for the 13-county study area were obtained from the 2010 US Census at the census block level. Each census block was classified as a substance abuse treatment desert if it overlapped with the defined desert area. Geospatial and statistical computing was done using $\mathrm{R}$, version 3.6.3. ${ }^{26}$ Specifically, we used the sf package for all geospatial calculations. ${ }^{27}$

\section{RESULTS}

Figure 2 shows maps of the 13-county study area with substance abuse treatment desert regions highlighted in colors for each respective treatment type. The upper left map panel combines deserts for all substance abuse pharmacological and behavioral treatment deserts, meaning that these areas lack access to all 3 types of treatments.

Overall, out of the 2017337 total persons living in the 13-county study area, $17 \%(n=342872)$ live in a desert for all MAT and outpatient behavioral treatment. Similarly, 19.7\% $(n=396581)$ live in a desert for naltrexone/buprenorphine treatment, $60.9 \%$ $(n=1227560)$ live in a desert for methadone treatment, and $19.7 \%(n=396581)$ live in a desert for behavioral treatment. When considering the fraction of population living in a substance abuse treatment desert by county, the percentages ranged from $5 \%$ to $57 \%$. Table 1 presents the population and percentage of total population living in a substance abuse treatment desert for each county in the study region. The table presents the data substance abuse treatment desert percentage for all counties in the study region. For the 13-county study area region, the largest desert centered on methadone (61\%), with many counties not having access to any methadone treatment. Naltrexone/buprenorphine followed (20\%), and outpatient behavioral treatment was next (18\%).

The counties fell into 2 subregions. The first is a 3-county subregion where the substance abuse treatment desert was $7 \%$ or less 
All MAT and Behavioral

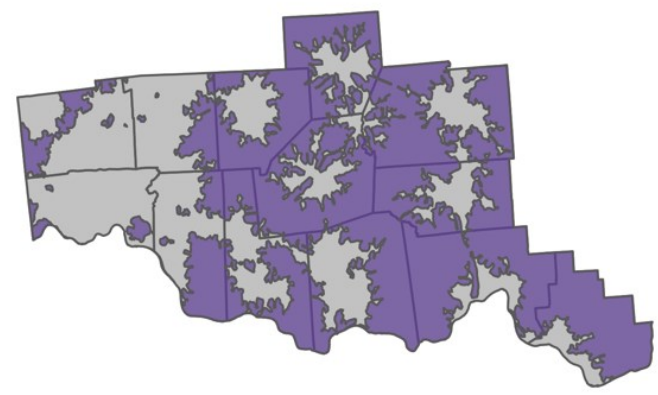

Methadone

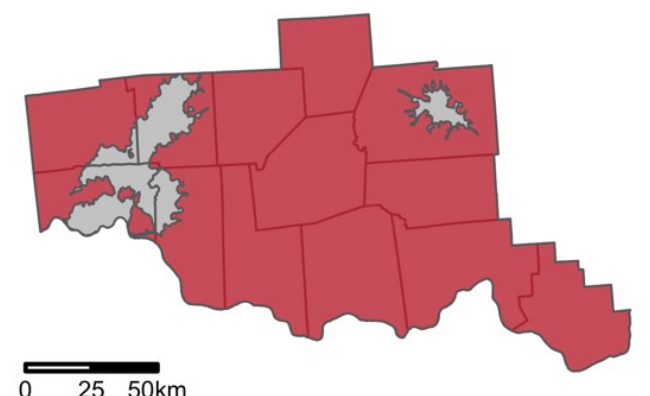

Naltrexone/Buprenorphine

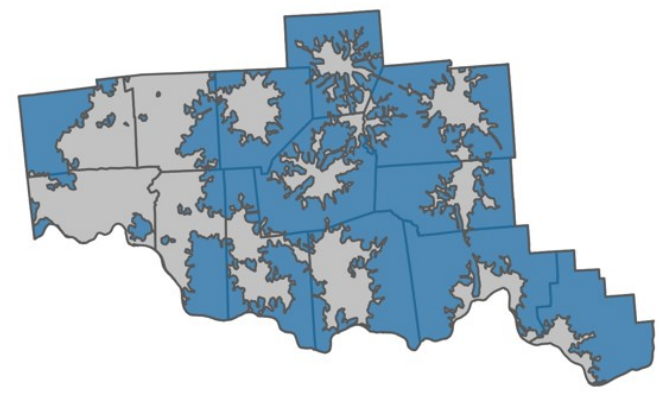

Behavioral

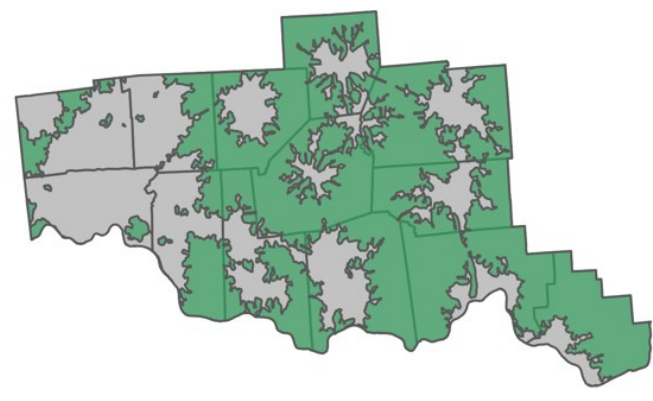

Figure 2. Maps of the 13-County Study Region with Substance Abuse Treatment Deserts Highlighted in Color for Each Type of Treatment

of the individual county's population, indicating a greater availability for substance use disorder treatment (5\% to $7 \%$ ). The second is a 10-county region where the substance abuse treatment desert was greater than $22 \%$ of the individual county's population (22\% to $57 \%$ ), indicating a dearth of treatment.

\section{DISCUSSION}

In this project, we identified substance abuse treatment deserts in a 13-county region in southwestern Ohio. Substance abuse treatment deserts were defined as areas that were not within a 15minute drive from a treatment center, including methadone and naltrexone/buprenorphine clinics, behavioral health treatment centers, and both medicated assisted treatment (MAT) and behavioral health treatment combined.

Further examination of subregional differences in the identified regions looked at differences in Appalachian status, overdose mortality rates, opioid dispensing rates, and poverty rates. Although no counties within the first subregion overlapped with the Appalachian region, 8 of the 10 counties in subregion 2 were part of the Appalachian region. This second subregion also contained the largest substance abuse treatment desert area. In the substance abuse treatment desert subregion where treatment was more available, the average opioid dispensing rate per 100 residents was lower (51.6\% versus $70.9 \%)$, as was the poverty rate $(11.7 \%$ versus
18.6\%). ${ }^{28,29}$ While differences in the poverty and opioid dispensing rates were found between the 2 regions, delineation between the 2 regions in terms of accidental drug overdose rates is unclear. This may be related to specific classes of opioid mortality on the county level. Monnat and colleagues found that while drug mortality rates overall were higher in counties with higher economic disadvantage and opioid dispensing rates, counties with higher heroin mortality and very high and rapidly growing mortality rates from all types of opioids were more urban and less economically disadvantaged. ${ }^{30}$

Butler and Hamilton counties were categorized into the first subregion. While residents had more access to treatment, the number and age-adjusted accidental drug overdose rates for 2013 through 2018 had ranges corresponding with regions that have a dearth of treatment. ${ }^{31}$ Butler and Hamilton counties are more urban with the first and second highest proportion of urban population in the study region. ${ }^{32}$ These counties also had the second and fourth lowest poverty rates of the study region. ${ }^{29}$ Monnat and colleagues classified these counties as 2 with a very high and rapidly growing mortality rate from all types of opioids with data from 2014 to $2016 .{ }^{30}$ This aligns with their conclusion that higher overdose rates cannot be fully explained by the rate of opioid prescriptions dispensed and availability of substance abuse treatment. ${ }^{30}$ 
The third county in the first subregion, Warren County, had the lowest overdose mortality rate of any of the counties in the study region, the lowest dispensing rate, and the lowest poverty rate. ${ }^{28,29,31}$ The data from this county and the other subregion, aside from 1 outlier county, coincided with the main finding of Monnat and colleagues, ${ }^{30}$ that overall mortality rates were lower in those counties with less economic disadvantage and lower opioid dispensing rates.

The outlier in the second subregion, Highland County, had the largest substance abuse treatment desert, the highest opioid dispensing rate, and a poverty rate comparable to the other counties, yet the number and age-adjusted accidental drug overdose rate for 2013 to 2018 was 23.6, the 48th highest rating in the state. ${ }^{31}$ The other 9 counties in the second group ( 7 of which enclose Highland County) had ratings ranging from 2nd to 19th. Despite the lower accidental drug overdose rate, substance abuse is still a significant concern in Highland County. Not only was illegal drug use listed as the number one health issue by the general public and health professionals in 2016,33 but the Centers for Disease Control and Prevention has identified Highland County as 1 of 220 counties in the United States particularly vulnerable for significant increases in HIV and hepatitis $\mathrm{C}$ infections due to injection drug use. ${ }^{34} \mathrm{~A}$ further examination of this county is warranted to identify how other county-level protective factors could be mobilized by communities when medical and behavioral health substance abuse interventions are more limited. A case study may find that factors such as social capital ${ }^{35}$ or local initiatives, such as the implementation of the Byrne Criminal Justice Innovation program, ${ }^{36}$ may be driving forces in preventing overdose deaths.

A strength of our analysis was that we utilized driving time, rather than "as the crow flies" distance to define proximity to treatment facilities. Currently, there is little evidence on the impact of total travel time for treatment adherence among substance use disorder patients. We chose 15 minutes as our threshold for the accessibility of treatment because regular access to treatment is more similar to regular access to health food retailers (which usually use 15 minutes) rather than to acute care (which usually use 60 minutes), which is required much less often and regularly. Regardless, the threshold of accessibility as a driving time likely differs among patients based on their personal behaviors and beliefs, as well as on how much they usually travel daily, their access to a vehicle, and whether or not they live in a rural or urban area.

A limitation of this project is that we only considered transportation by car, which misrepresents patients that may lack access to a car. Patients that walk or utilize public transportation systems, such as a bus, are not represented in our calculation of these treatment deserts. Future work should extend the definition of treatment deserts to include travel time related to other modes of transportation. Our existing treatment deserts could be combined

Table 1. Population (and percent of total population) Living in Substance Abuse Treatment Deserts Overall and by County in the Study Region

\begin{tabular}{|c|c|c|c|c|}
\hline County & All & Naltrexone/Buprenorphine & Methadone & Outpatient behavioral \\
\hline Entire study region & 342872 (17\%) & 396581 (20\%) & 1227560 (61\%) & 360275 (18\%) \\
\hline \multicolumn{5}{|l|}{ Subregion 1} \\
\hline Butler & $17281(5 \%)$ & 53145 (14\%) & $303086(82 \%)$ & $17281(5 \%)$ \\
\hline Hamilton & $50060(6 \%)$ & $58814(7 \%)$ & 299016 (37\%) & $50060(6 \%)$ \\
\hline Warren & $14994(7 \%)$ & $15019(7 \%)$ & $112501(53 \%)$ & $28076(13 \%)$ \\
\hline \multicolumn{5}{|l|}{ Subregion 2} \\
\hline Clermont & $43018(22 \%)$ & $43018(22 \%)$ & $111454(56 \%)$ & $43018(22 \%)$ \\
\hline Fayette & $9792(34 \%)$ & 10895 (38\%) & 29030 (100\%) & $10120(35 \%)$ \\
\hline Ross & 34170 (44\%) & $36158(46 \%)$ & 42790 (55\%) & 34170 (44\%) \\
\hline Scioto & 36426 (46\%) & 36937 (46\%) & 79499 (100\%) & $36426(46 \%)$ \\
\hline Adams & 14008 (49\%) & 14008 (49\%) & 28550 (100\%) & $14008(49 \%)$ \\
\hline Clinton & 22600 (54\%) & 22600 (54\%) & 42040 (100\%) & $22611(54 \%)$ \\
\hline Brown & $24576(55 \%)$ & $24576(55 \%)$ & 44846 (100\%) & 24576 (55\%) \\
\hline Lawrence & 35060 (56\%) & 38708 (62\%) & $62450(100 \%)$ & 35060 (56\%) \\
\hline Pike & $16050(56 \%)$ & 17866 (62\%) & 28709 (100\%) & 16050 (56\%) \\
\hline Highland & 24837 (57\%) & 24837 (57\%) & 43589 (100\%) & 28819 (66\%) \\
\hline
\end{tabular}

Percentages were calculated as the fraction of the total population. 
with census survey data on the number of vehicles per household to estimate where this limitation would be the greatest.

\section{PUBLIC HEALTH IMPLICATIONS}

The geographically-defined regions identified in this study could be useful to study their impact on substance use disorder diagnosis and treatment outcomes. The geographically-defined substance abuse treatment desert locations are available to the public online as GeoPackage data files (https://doi.org/10.5281/ zenodo.4011051). Approximately 1 in 6 of the individuals residing within the study area lived more than a 15-minute drive from any type of MAT or behavioral treatment facility. Consistent with findings of other researchers, ${ }^{37}$ we found treatment deserts disproportionally distributed across rural communities. Furthermore, if there are substance abuse treatment centers in rural areas, those living in rural communities face transportation barriers due to distance and limited public transportation options. ${ }^{38}$ These transportation and distance barriers may contribute to inadequate substance abuse treatment or relapse. As has been proposed, offering MAT through primary care providers or expanding transportation services through substance abuse treatment programs are potential ways to improve access and utilization for those living in substance abuse treatment deserts. ${ }^{39,40}$

\section{ACKNOWLEDGMENTS}

Acknowledgements and Funding: There is no funding to declare.

\section{REFERENCES}

1. Kaufman R, Durkin, K. Impact of emotional distress on prescription opioid abuse in a rural juvenile drug court sample. Ohio J Public Health. 2019;2:37-43. Accessed September 8, 2020. https://ohiopha.org/wp-content/uploads/2020/04/7-0JPH-2019-201 -Kauffman-FINAL-11-01-19.pdf

2. Centers for Disease Control and Prevention. Opioid data analysis and resources. Accessed February 19, 2021. https://www.cdc.gov/drugoverdose/data/analysis.html

3. Substance Abuse and Mental Health Services Administration. Key substance use and mental health indicators in the United States: Results from the 2018 national survey on drug use and health. 2019; No. PEP19-5068, NSDUH Series H-54. Rockville, MD: Center for Behavioral Health Statistics and Quality, Substance Abuse and Mental Health Services Administration.

4. Davoli M, Bargagli AM, Perucci CA, et al. Risk of fatal overdose during and after specialist drug treatment: the VEdeTTE study, a national multi-site prospective cohort study. Addiction. 2007;102(12):19541959.

https://doi.org/10.1111/j.1360-0443.2007.02025.x

5. Wen H, Hockenberry JM, Borders TF, Druss BG. Impact of Medicaid expansion on Medicaid-covered utilization of buprenorphine for opioid use disorder treatment. Med Care. 2017;55(4):336-341. https://doi.org/10.1097/MLR.0000000000000703

6. Cummings JR, Wen H, Ko M, Druss BG. Race/ethnicity and geographic access to Medicaid substance use disorder treatment facilities in the United States. JAMA Psychiatry. 2014;71(2):190-196 https://doi.org/10.1001/jamapsychiatry.2013.3575
7. Wielen LM, Gilchrist EC, Nowels MA, Petterson SM, Rust G, Miller BF. Not Near Enough: Racial and Ethnic Disparities in Access to Nearby Behavioral Health Care and Primary Care. J Health Care Poor Underserved. 2015;26(3):1032-1047. https://doi.org/10.1353/hpu.2015.0083

8. Hall OT, Hall OE, McGrath RP, Haile ZT. Years of life lost due to opioid overdose in Ohio: Temporal and geographic patterns of excess mortality. J Addict Med. 2020;14(2) https://doi.org/10.1097/ADM.0000000000000554

9. Kiang MV, Basu S, Chen J, Alexander MJ. Assessment of changes in the geographical distribution of opioid-related mortality across the United States by opioid type, 1999-2016. JAMA Netw Open. 2019;2

(2):e190040

https://doi.org/10.1001/jamanetworkopen.2019.0040

10. Hernandez A, Branscum AJ, Li J, MacKinnon NJ, Hincapie AL, Cuadros DF. Epidemiological and geospatial profile of the prescription opioid crisis in Ohio, United States. Sci Rep. 2020;10(1):4341-10. https://doi.org/10.1038/s41598-020-61281-y

11. Pollard KM. A "New Diversity": Race and Ethnicity in the Appalachian region. Washington DC: Appalachian Regional Commission and Population Reference Bureau; 2004.

12. Meit M, Heffernan M, Tanenbaum E. Investigating the impact of the diseases of despair in Appalachia. J Appalach Health. 2019;1(2):7-18. https://doi.org/10.13023/jah.0102.02

13. Reisig V, Hobbiss A. Food deserts and how to tackle them: a study of one city's approach. Health Educ J. 2000;59(2):137-149. https://doi.org/10.1177/001789690005900203

14. Ver Ploeg, M., Dutko, P., Breneman, V. (2014;2015;). Measuring food access and food deserts for policy purposes. Appl Econ Perspect Policy. $37(2): 205-225$ https://doi.org/10.1093/aepp/ppu035

15. LeClair MS, Aksan A. Redefining the food desert: combining GIS with direct observation to measure food access. Agric Hum Values. 2014;31 (4):537-547. https://doi.org/10.1007/s10460-014-9501-y

16. Sadler RC, Gilliland JA, Arku G. Theoretical issues in the 'food desert' debate and ways forward. GeoJournal. 2016;81(3):443-455. https://doi.org/10.1007/s10708-015-9634-6

17. Sadler RC, Sanders-Jackson AN, Introne J, Adams R. A method for assessing links between objectively measured food store scores and store \& neighborhood favorability. Int J Health Geogr. 2019;18(1):31. https://doi.org/10.1186/s12942-019-0195-7

18. Sanders SR, Erickson LD, Call VRA, Rugh JS, McKnight ML. Healthcare use in the heartland: How health care selection varies between rural, retirement-Age migrants and long-term residents. Rural Sociol. 2016;81(1):66-98. https://doi.org/10.1111/ruso.12088

19. Harant P. Hospital cooperation across French Borders. In Rosenmoeller M, McKee M, Baeten R, ed. Patient Mobility in the European Union: Learning from Experience. Copenhagen, DK: WHO Regional Office for Europe; 2006:157-177. Accessed September 8, 2020. https://www.euro.who.int/_data/assets/pdf_file/0005/98420/ Patient_Mobility.pdf

20. Qato DM, Daviglus ML, Wilder J, Lee T, Qato D, Lambert B. 'Pharmacy deserts' are prevalent in Chicago's predominantly minority communities, raising medication access concerns. Health Aff. 2014;33(11):1958- 
1965.

https://doi.org/10.1377/hlthaff.2013.1397

21. Palombi LC, St Hill CA, Lipsky MS, Swanoski MT, Lutfiyya MN. A scoping review of opioid misuse in the rural United States. Ann Epidemiol. 2018;28:641-652.

https://doi.org/10.1016/j.annepidem.2018.05.008

22. Ohio Substance Abuse Monitoring (OSAM). Ohio Department of Mental Health and Addiction Services website. Access September 20, 2020.

23. Brokamp C, Wolfe C, Lingren T, Harley J, Ryan P. Decentralized and reproducible geocoding and characterization of community and environmental exposures for multisite studies. J Am Med Inform Assoc. 2018;25:309-314.

https://doi.org/10.1093/jamia/ocx128

24. Brokamp C. DeGAUSS: Decentralized Geomarker Assessment for MultiSite Studies. J Open Source Softw. 2018;3:812.

https://doi.org/10.21105/joss.00812

25. Openrouteservice. Accessed June 25, 2020. https://openrouteservice.org/

26. $\mathrm{R}$ Core Team. $R$ : A language and environment for statistical computing. R Foundation for Statistical Computing. 2020. Accessed June 25, 2020. https://www.R-project.org/

27. Pebesma E. Simple features for R: Standardized support for spatial vector data. $R J .2018 ; 10: 439-446$. https://doi.org/10.32614/RJ-2018-009

28. Centers for Disease Control and Prevention. U.S. County Opioid Dispensing Rates, 2018. Accessed on February 7, 2021. https://www.cdc.gov/drugoverdose/maps/rxcounty2018.html

29. Ohio Development Services Agency. The Ohio poverty report: February 2017. Accessed on September 20, 2020. https://www.development.ohio.gov/files/research/p7005.pdf

30. Monnat SM, Peters DJ, Berg MT, Hochstetler A. Using Census data to understand county-level differences in overall drug mortality and opioid-related mortality by opioid type. Am J Public Health (1971). 2019;109:1084-1091. https://doi.org/10.2105/AJPH.2019.305136

31. Ohio Public Health Information Warehouse. Ohio Resident Mortality Data, 2018. Accessed June 25, 2020. http://publicapps.odh.ohio.gov/EDW/DataCatalog

32. United States Census Bureau. 2010 census urban and rural classification and urban area criteria. Accessed on May 2, 2021. https://www.census.gov/programs-surveys/geography/guidance/geo -areas/urban-rural/2010-urban-rural.html

33. Highland County Community Action Organization. Highland County Community Health Report: Summary of Findings. Columbus, OH: The Ohio State University; 2016. Accessed February 18, 2021. https://comdev.osu.edu/sites/comdev/files/imce/Highland\% 20County\%20Community\%20Health\%20Report $\% 20 \% 20-\% 20$ April $\%$ 202016.pdf

34. Van Handel MM, Rose CE, Hallisey EJ, et. al. County-level vulnerability assessment for rapid dissemination of HIV or HCV infections among persons who inject drugs, United States. J Acquir Immune Defic Syndr. 2016;73(3): 323-331. https://doi.org/10.1097/QAI.0000000000001098

35. Zoorob MJ, Salemi JL. Bowling alone, dying together: The role of social capital in mitigating the drug overdose epidemic in the United
States. Drug Alcohol Depend. 2017;173:1-9.

https://doi.org/10.1016/j.drugalcdep.2016.12.011

36. Local Initiatives Support Corporation. CBCR in Action. Accessed February 18, 2021.

https://www.lisc.org/our-initiatives/safety-justice/cbcr/where-ithappening/sites/highland-county-ohio/

37. Joudrey PJ, Edelman EJ, Wang EA. Drive times to opioid treatment programs in urban and rural counties in 5 US states. JAMA. 2019;322:1310-1312. https://doi.org/10.1001/jama.2019.12562

38. Pullen E, Oser C. Barriers to substance abuse treatment in rural and urban communities: Counselor perspectives. Subst Use Misuse. 2014;49(7):891-901. https://doi.org/10.3109/10826084.2014.891615

39. Samet JH, Botticelli M, Bharel M. Methadone in primary care - one small step for Congress, one giant leap for addiction treatment. $N$ EnglJ Med. 2018;379:7-8. https://doi.org/10.1056/NEJMp1803982

40. Whetten R, Whetten K, Pence BW, Reif S, Conover C, Bouis S. Does distance affect utilization of substance abuse and mental health services in the presence of transportation services? AIDS Care. 2007;2006;18:27-34. https://doi.org/10.1080/09540120600839397 


\title{
Using Social Determinants Screening/Mapping Tools to Identify Needs and Resources for Student-Run Free Clinic Patients
}

\author{
Akanksha Dadlani'; Cooper T. Johnson'; Rebecca Fischbein ${ }^{1}$; Stacey L. Gardner- \\ Buckshaw ${ }^{1}$; Amy Lee ${ }^{1}$; John M. Boltri ${ }^{1}$ \\ ${ }^{1}$ Department of Family and Community Medicine, Northeast Ohio Medical University, Rootstown, $\mathrm{OH}$ \\ Corresponding Author: Akanksha Dadlani, 4209 State Route 44, PO Box 95, Rootstown, OH 44272, (925) 518-6394, adadlani@neomed.edu \\ Submitted November 21, 2020 Accepted April 6, 2021 Published June 21, 2021 https://doi.org/10.18061/ojph.v4i1.8073
}

\section{ABSTRACT}

Background: Social determinants of health have been well accepted as contributing to health outcomes. They are a vital aspect of health care delivery and must be a consideration, especially among free clinic populations. Social determinants of health have also become a required element of medical school curricula. The Student Outreach to Area Residents Student-Run Free Clinic based out of Northeast Ohio Medical University piloted a student-led program that implemented social determinants of health screening and community resource referral as a part of integrated health care delivery for all its patients.

Methods: We described the development of a screening tool, protocol, and creation of community resource referral materials. We also described the tracking of patient-reported needs and mapping of location and accessibility of community resources. One hundred patients were surveyed through convenience sampling, and results were used for program improvement.

Results/Conclusion: After collecting and analyzing survey results, it was found that the 2 most frequently requested determinants were mental health and utilities services, and the most available community resource was emergency food services. We also mapped these results by zip code and found gaps between need and distribution of services. We demonstrated the utility of mapping to identify points of improvement for the future. We also provided lessons learned related to effective social determinants of health screening, community resource referral, and overall program implementation in student-run free clinics. We further explained the benefits of including similar student-led programs as a way for students to gain practical experience related to social determinants of health.

Keywords: Social determinants of health; Mapping; Student-run free clinic

\section{INTRODUCTION}

Social determinants of health (SDOH), or an individual's social situation related to life and work such as income, education, access to health care, and housing, have a strong influence on health. ${ }^{1}$ While these SDOH have a large impact on health status, they are often ignored in medicine: $60 \%$ of the preventable deaths in the United States (US) have been shown to be caused by modifiable behaviors and exposures in the community, yet more than $95 \%$ of the money spent on health care in the US is for direct medical services. ${ }^{2}$
In recognition of the critical impact of SDOH, in primary care settings increasing attention is paid to screening for SDOH such as inequalities/variances in income, education, employment, selfreport of disease, social environment, and housing.3,4 Benefits of screening and referral include providing whole-person care, increasing cost effectiveness, and reducing utilization of services downstream. ${ }^{3}$

Despite increased interest and attention regarding SDOH screening and referral in primary care, many providers report concerns 
about conducting screens with patients. ${ }^{5,6}$ Structural barriers to SDOH screening include lack of reimbursement for screening ${ }^{7}$ as well as insufficient time to implement this activity with patients. ${ }^{8}$ Other provider concerns are related to training such as lack of skills and knowledge to perform screens and uncertainty of how to adequately perform referrals.5,6 Because this gap in medical education has been identified, efforts have been made to alleviate it in future physician training. Current medical school curricula require education related to SDOH. Specifically, the Liaison Committee on Medical Education (LCME) accreditation standards 7.5 and 7.6 require education related to "societal problems," and "recognition of the impact of disparities in health care on medically underserved populations and potential solutions to eliminate health care disparities," respectively. ${ }^{9}$

One way to enhance student exposure to and experience with SDOH screening and referral is through integration of these services into student-run free clinics. For more than a decade, the number of student-run free clinics has been increasing across the US.10 Early research has shown that medical students and patients believe free clinics are valuable for education and care quality. ${ }^{11}$ Student-run free clinics provide free, high quality services to vulnerable patients, most of whom are uninsured or underinsured. ${ }^{11-13}$ Given the demographics of patients at student-run free clinics and the need to incorporate SDOH in medical education, both patients and students could benefit from enhanced SDOH screening and referral in student-run free clinics. For example, education programs at free clinics led by medical students have facilitated clinical improvements among patients with diabetes who also experience economic and social disadvantage. ${ }^{14}$ Additionally, there is evidence that early-career first-year medical students develop comfort with diverse patients under the mentorship of fourth-year medical students. ${ }^{15}$ And physicians who receive training in community-based and underserved settings are more likely to practice in similar settings, such as health centers. ${ }^{16}$

Despite the potential benefits of incorporating SDOH screening student-run free clinics, the integration of such services in student-run free clinics may be lacking. ${ }^{17}$ Only limited published research exists regarding the implementation of SDOH screening and referral services into student-run free clinic settings and how to assess the match between patient needs and the availability of local services surrounding student-run free clinics. ${ }^{18}$ Consequently, the primary goal of this work is to describe an SDOH screening and referral process designed and implemented by medical students at a rural student-run free clinic. Specifically, this work describes: 1) the process used to develop and implement the screening protocol, 2) screening results from a convenience sample of 100 patients, and 3) how screening results were analyzed using mapping software and needs assessment of community resources to match needs to referral resources. We conclude with lessons learned and how similar processes can assist with both health professions student education as well as patients' needs.

\section{METHODS}

\section{Setting}

The Student Outreach to Area Residents (SOAR) student-run free clinic is based at Northeast Ohio Medical University (NEOMED) in a rural portion of Portage County, where $10 \%$ of the population is uninsured. Additionally, in Portage County, 45\% of adults reported cost as an issue with their health coverage, $8 \%$ opted out of some coverage because they could not afford it, and $17 \%$ of adults did not fill prescriptions from their doctor. ${ }^{19}$ The US Census Bureau does not explicitly define the term "rural." Rootstown, Ohio, is categorized as an urban cluster on rural land. On the US Census Bureau website, however, Rootstown, Ohio, is mapped as a rural area. ${ }^{20}$

Founded in 2017, SOAR offers primary care, chronic disease management, physical exams, basic labs, prescription for medications, dietician services, diabetes education, and medication therapy management. Since its inception, SOAR has had over 920 patient visits with roughly 280 unique patients and approximately 700 follow-up visits. The clinic operated 3 Saturdays a month from 2019 to winter 2020. Roughly 12 patients are seen on an average clinic date. Twenty-five students work an average clinic day with 355 medicine and pharmacy student volunteers, 29 physicians, and 16 pharmacists working at the clinic every year. Eighty percent of the patients are native to Portage County, with $73 \%$ of the patients uninsured and $89 \%$ living below the 200 percent federal poverty level line. Based on informal observation of patients' needs, it was determined that patients could benefit from more formal SDOH screening and referral process.

\section{Community, participant characteristics, recruitment}

Starting in September 2019, attempts were made to screen every new and returning SOAR patient. One hundred patients completed the screening form on their own while in the waiting room. The only inclusion criterion was that participants had to be patients of the clinic. No compensation was provided. The results were reviewed by student volunteers who then did the following: 1) entered patient's room with completed survey and requested permission to discuss results with patient, 2) upon consent, reviewed with the patient potential matching resources including hours of operation, location and services, and 3) wrote down and provided information about the suggested resource(s) for the patient to take home.

To launch screening and referral in SOAR, a community resource team of 22 medical student volunteers were selected and trained to administer screening and provide referrals. Training included didactic orientation, observation of the authors performing screenings and referrals, and practice performing activities while being observed by the authors.

\section{Procedures/Program description}

The lead author conducted a literature review of existing SDOH screening tools and toolkits. Google Scholar and PubMed were the 
primary resources used for the literature review. Keywords included, "social determinants of health," "student run free clinic," "PDSA," "program implementation," "community asset inventory," "community asset," and "rural." The goal was to see if other similar programs existed and, if they did, how they were implemented into the clinic's workflow. The organization Health Leads was selected as a model for our program as it has a preexisting infrastructure for a similar screening survey and workflow. ${ }^{21}$ The Health Leads tool requires patients to complete a screening tool so their provider could identify adverse social determinants of health to be addressed by multidisciplinary care teams. The screening tool includes food insecurity, housing, utility needs, financial resources strain, transportation, exposure to violence, demographic information with options to add childcare, education, employment, health behaviors, social support and mental health as determined by the health system and/or program initiative. ${ }^{22}$

The Health Leads screening tool was adapted for use in Portage County. The decision to include specific screening items was guided by a review of the resources available in the community. A starting point for this process included examination of preexisting student-developed lists of community resources. Community resources were defined as any local resource that would provide aid for the given categories at either no cost, prorated cost, or sliding scale. Other factors taken into account include hours of operation, availability, and eligibility criteria. Each resource was individually audited for hours of operation, location, payment, and services offered. This process resulted in the creation of an organized list of resources labeled based on categories matching the screening tool (eg, food, housing, transport). Upon finalization of the list of available resources, items from the corresponding Health Leads categories were selected. For this analysis, services that provided childcare include psychiatric services, counseling, case management, social skills groups, daycare, and development services. Pet care includes providing food, low-cost clinics, neutering, and adoption programs. Utility services assist with paying bills and connecting clients with attorneys. Clothing services include gently used clothing at no cost, clothing for interviews, and clothing for children.

\section{Measures/Outcomes}

The measures for this study are common SOAR patient needs. If a patient indicated "yes" to a particular need, we classified that as a need, and it was recorded in a deidentified, secure document. The current project uses this survey's data and compares it to deidentified patient zip code data/demographic information. These data were combined with publicly available data related to community resources and bus lines in Portage County, provided by the Portage Area Transit Authority (PARTA).

\section{Statistical analysis}

Analyses included descriptive statistics of the common patient needs and maps using ArcGIS Online. ${ }^{19}$ Esri ArcGIS Online was used to create maps for this analysis. Patient home zip codes were spatially joined to zip code shape files from the US Census Bureau. A choropleth map was created to depict areas with high and low density of patients compared to areas with high and low density of services. A second choropleth map of patient zip codes was created which added addresses of resources. Additionally, local bus routes were overlaid on the addresses of organizations to highlight possible public transportation barriers. General transportation barriers were defined as any difficulty in getting to the clinic as perceived by the patient. This can include, but is not limited to, lack of access to a vehicle, lack of access to a bus route, or inability to drive a vehicle.

\section{RESULTS}

One hundred patients were screened using the SDOH instrument between September 2019 and December 2019. Patients were mostly female (57\%), White (90\%), and with an average age of approximately 48 years. Most patients were uninsured (80\%) with the remainder covered by a private insurer $(12 \%)$ and Medicare (7\%); no patient was billed. Medicaid is not as prevalent in this population because patients with Medicaid have $\$ 0$ copay to see primary care physicians. They also have $\$ 0$ copay for emergency and urgent care visits. Because they have access to medical care otherwise, they are not our primary source of patients.

Responses were tallied across the 100 participants and patientidentified needs were compared to corresponding community resources (Table 1).

Table 1. Frequency of Reported Patient Needs $(n=100)$ and Available Community Resources $(n=55)$

\begin{tabular}{|lll|}
\hline Patient need & $\begin{array}{l}\text { Frequency of patients reporting a need } \\
(\mathbf{n}=\mathbf{1 0 0} \text { patients)* }\end{array}$ & $\begin{array}{l}\text { Count of available community resources } \\
\mathbf{( n = 5 5} \text { resources) }\end{array}$ \\
Mental health & $18(18 \%)$ & $9(16 \%)$ \\
Utilities & $18(18 \%)$ & $4(7 \%)$ \\
Transportation & $15(15 \%)$ & $3(5 \%)$ \\
Emergency food & $11(11 \%)$ & $16(29 \%)$ \\
Substance abuse & $11(11 \%)$ & $5(9 \%)$ \\
Legal & $9(9 \%)$ & $4(7 \%)$ \\
Children care & $5(5 \%)$ & $3(5 \%)$ \\
Clothing & $5(5 \%)$ & $2(4 \%)$ \\
Housing & $4(4 \%)$ & $6(11 \%)$ \\
Pet care & $3(3 \%)$ & $2(4 \%)$ \\
Hygiene & $2(2 \%)$ & $1(2 \%)$ \\
*Patients could report more than 1 need, therefore sum of total needs is greater than 100
\end{tabular}

*Patients could report more than 1 need, therefore sum of total needs is greater than 100 . 
Twenty-one percent of patients reported having more than 1 need, for a mean of 4 needs. Among all patients, the most frequently reported needs were mental health and utilities (both 18\%) followed by transportation (15\%). Only $2 \%$ and $3 \%$ of patient needs were identified to be hygiene and pet needs, respectively. The most commonly available community resource within and near Portage County is emergency food assistance (29\%) followed by mental health resources (16\%) and then housing (11\%). Despite being frequently reported needs among patients, resources in the community for utilities and transportation were limited $(7 \%$ and $5 \%$, respectively).

To better understand the proximity of community resources relative to the SOAR patient population, patient zip codes were mapped against the location of community resources; specifically, we plotted the proportion of patients to community resources per zip code (Figure 1).

Areas in Figure 1 that are dark pink have a high number of patients and services. Dark grey areas have a low number of patients and a high number of services. Areas that are peach have a high number of patients and a low number of services.
In Figure 2, patient population is depicted with darker shades corresponding to a high number of patients, and lighter zip codes indicate few patients. The median number of patients per zip code was 20 .

Each type of service is represented by colored dots. Location and clustering of services are useful for comparing patient needs against resource availability. For example, all emergency food services are red dots and are located in 6 unique zip codes. These resources are not located in town centers but are often located at faith-based organizations which are more widespread. Mental health services, the second most requested resource, are primarily located in 2 areas (Akron, Ohio, and Kent, Ohio). This illustrates a potential gap in services since the majority of mental health services are concentrated in Akron, Ohio, which is approximately a 25 -minute drive from the zip code with the highest number of patients. While the local bus routes connect many of the available resources, many of the peripheral zip codes are not serviced by the local bus authority. The SOAR facility is not serviced by PARTA routes during SOAR's operating hours. Depending on the route, PARTA operates Monday through Friday or Monday through Sat-

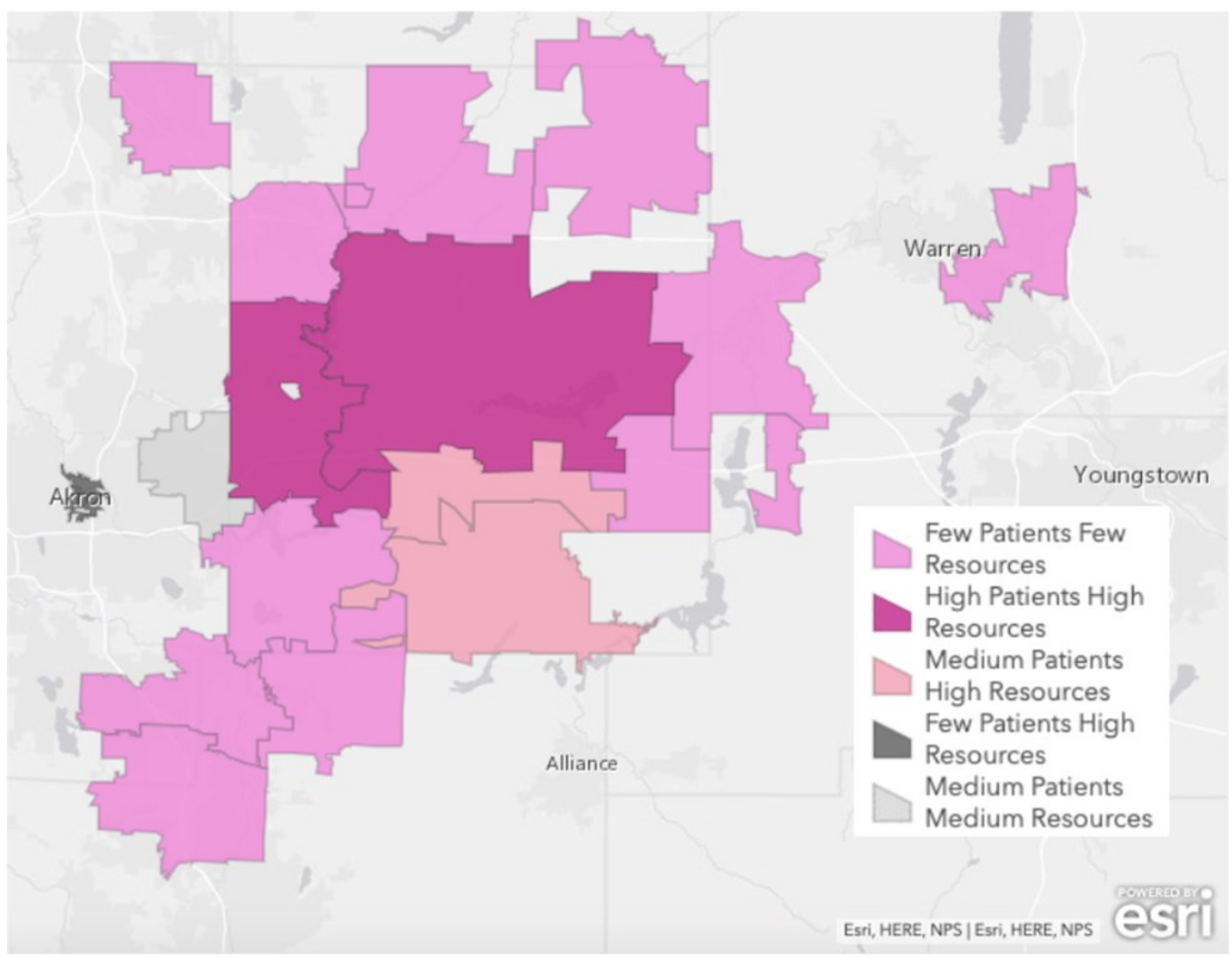

The light pink zip codes represent areas that have few patients and few community resources. The dark pink areas represent areas that have a high density of patients and resources. 


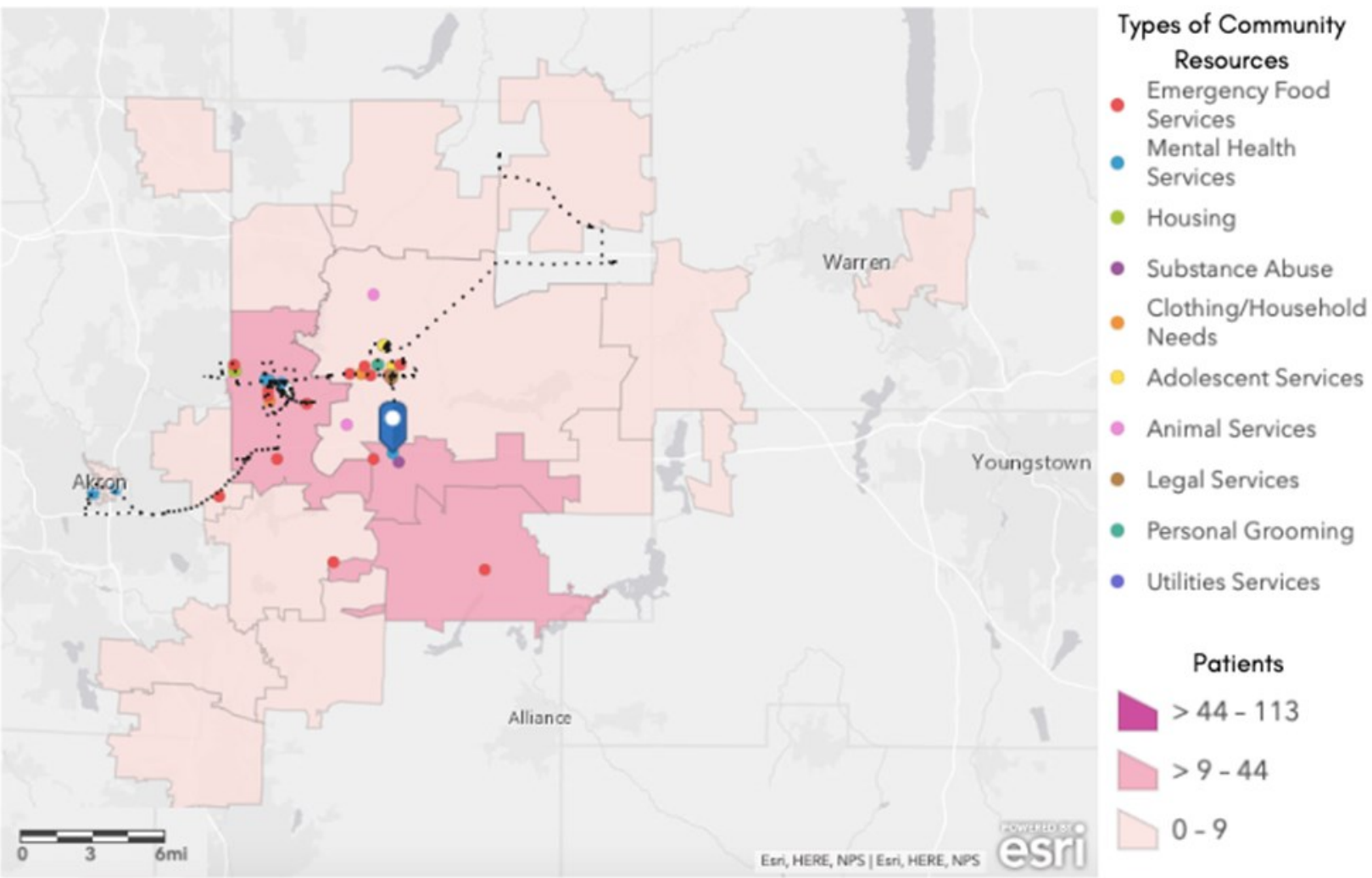

The blue point in the center of the map represents the SOAR Clinic location. The individual type of services are identified by the colored dots with each color representing a different type of service. The dark lines correspond to bus routes across Summit County and Portage County.

\section{Figure 2. Comparison of SOAR Patient Zip Codes to Location of Specific Community Resources and Bus Routes}

urday. While the major bus route has 9 stops and circulates about every 30 minutes, the closest bus stop to SOAR stops approximately 4 miles away, with no additional local public transportation.

\section{DISCUSSION}

In this study we describe the development of a community free clinic-specific screening tool, an implementation protocol, and the creation of community resource referral materials. However, resources are useless if they cannot be accessed by patients in need. Therefore, we visually presented patient-reported needs of 100 patients utilizing the free clinic for primary care and mapped the location and accessibility of community resources. This project provides an example and lessons learned when depicting SDOH screening and referral integration into a student-run free clinic. We have described the information that can be gathered by conducting social needs screening among patients at a student-run free clinic and then using tools like mapping software to compare that information against resources available in the community. We have demonstrated how this activity can reveal a disparity in terms of diversity and geographic distribution of resources.

Beyond our own clinic, we hope that this data collection method can serve as a model for other student-run free clinics conducting needs assessment and gap analysis. Because SOAR is in a rural area, community resources are sparse and there are many barriers in connecting patients to appropriate resources. While limited research exists about conducting needs analysis and mapping in urban settings, ${ }^{18}$ we were unable to find literature on these topics related to rural areas.

In only 2 zip codes, there are a high number of both services and patients. Figure 2 also details the service area the SOAR Clinic covers; the farthest zip code is roughly 30 miles away, confirming that more resources are available for patients who live in urban/ suburban areas while less is available for our many patients who live in rural locations. ${ }^{23}$ This lack of distribution could be a challenge for some patients who lack adequate transportation, especially given that many of the rural areas where our patients reside are not served by the local bus authority.

Our analysis clarifies the need for mental health and substance abuse services for many SOAR patients. In response, our clinic recently expanded to include a behavioral health consultant who can conduct, and guide SOAR students with, behavioral health screening, brief intervention, and referral to treatment. This project also demonstrates the prevalence and significance of social needs in this free clinic population. Of the patients surveyed, 21\% had more than 1 need, with an average of 4 needs. 


\section{Limitations and lessons learned}

Our implementation of SDOH screening and referral in the SOAR clinic was not without limitations. First, when choosing which SDOH to include in the screening, more formal data collection and inclusion of patients as part of the development of the screening tool using a community-based participatory method would have been highly beneficial. This would have likely avoided inclusion of some of the less critical needs (eg, pet and hygiene) as well as inclusion of women's health care, a missed need. Additionally, we were limited in the needs we could include in the screener. For example, based on anecdotal reports from patients and staff, we suspected our patients had unmet dental needs; yet Portage County had no available dental resources for patients without insurance at the time of screening. Therefore, we did not include this need in our screener as screening without provision of appropriate resources could be considered wasteful and unethical.8,24 However, after the collection of this pilot data, we found a dentist willing to take patients with little or no insurance and included this need in our screening.

Further, despite the physical geographic distance, some services could be provided remotely, with the potential to reduce geographic disparities. We did not include in our screening whether patients would or would be able to remotely access services for these needs (eg, by telephone or virtually). Further, we did not break down our scan of available community resources in this manner. However, with the onset of coronavirus disease 2019 (COVID-19), the ability for patients to have remote access to services has become more relevant than ever. ${ }^{25}$ In fact, the SOAR Clinic quickly adapted to provide telephone-based and virtual services for patients. Moving forward, future revisions of screeners and community asset inventory will include information related to remote access for services.

While the community resource team did not address remote access for services, it has updated the community asset inventory to include current and relevant COVID-19 resources. Correspondingly, community resources should always be added and subtracted based on availability and quality of the local resources. Teams should periodically check on resources to determine if all the provided information is still valid and applicable. Establishing a strong community resource network involves time and effort including online research, cold calling, and seeking out partners within the community that can help navigate resources.

Finally, we also recognize that even if only a few resources are available to address a high demand need, this does not necessarily indicate patients will be underserved by those resources. For example, there are only 3 community resources for transportation, but it is the third most indicated concern for patients at the clinic. However, we tend to recommend only a single transportation resource because it works well for patients and is a high-quality service. In other words, quantity cannot be equated with quality.
For potential future projects, it would be beneficial to include other methods of assessing of resource distribution. For example, as indicated above, adding an element which objectively captures quality of the resources would help when determining what referrals to provide and which services to consider adding internally to the clinic. Similarly, following up with patients over time would permit us to gauge the efficacy of resources and whether patients are benefiting from our recommendations. This long-term tracking of SDOH, use of resources, and interaction with the patient education team will be facilitated by the clinic's recent transformation to electronic health records (EHR). The SDOH screen will become part of the patient record in the EHR. Eventually, we would like for it to be added to the patient's problem list to ensure that it is regularly revisited and addressed. Additionally, comparing the home address of patients (rather than just zip codes) to the addresses of social services would allow for a more detailed location-based examination of needs. For example, there may be an area that has a high need for emergency food services that does not have a food pantry nearby. Currently, we do not know if that level of disparity exists. Also importantly, as indicated above, future screening and referral will take into account patients' interest and ability to remotely access services as well as the ability of community resources to provide remote services.

Based on mapping analysis, there are large disparities in how patients and social services are distributed. Spatial segregation and clustering of poverty are both present issues in our community. While we do not have a mobile clinic, we have recently started doing telemedicine visits. Using telemedicine comes with unique barriers, but we hope that some of the disparities can be addressed with this new method of patient contact. There is no current plan to do a "clinic on wheels" or expand the clinic to have multiple locations, though it is a consideration given the difficulty to access. There are local "clinics on wheels" services that we have contacted, and we are waiting to hear back from them.

\section{PUBLIC HEALTH IMPLICATIONS}

Nearly one-fourth of our patients surveyed are facing multiple needs, highlighting the importance of providing SDOH screening and referral for our patient population. The significance of SDOH in health care delivery and student medical education is clear.1,9 The next step in providing necessary care for patients involves implementation of SDOH screening and referral programs, ${ }^{3}$ as well as continuous improvement of this process. This project has not only added value to the quality of care provided at SOAR, but also allowed students to experience provision of health care in a way that is often beyond the scope of traditional medical school curriculum. As SDOH becomes a more integral part of health care delivery and medical school curriculum, ${ }^{9}$ projects like these provide students with an opportunity to learn by doing; students gained exposure to the significance of social determinants of health in a clinical setting. ${ }^{13,15}$ 


\section{ACKNOWLEDGMENTS}

The authors received no financial support for the research, authorship, and/or publication of this article.

Conflict of interest statement. The authors declare that they have no conflict of interest.

Compliance with ethical standards. The NEOMED University institutional review board determined that the project did not constitute human subjects research

\section{REFERENCES}

1. WHO Commission on Social Determinants of Health, World Health Organization, eds. Closing the Gap in a Generation: Health Equity through Action on the Social Determinants of Health: Commission on Social Determinants of Health Final Report. World Health Organization, Commission on Social Determinants of Health; 2008.

2. Alley DE, Asomugha CN, Conway PH, Sanghavi DM. Accountable health communities-addressing social needs through Medicare and Medicaid. $N$ Engl J Med. 2016;374(1):8-11.

https://doi.org/10.1056/NEJMp1512532

3. Andermann A. Screening for social determinants of health in clinical care: moving from the margins to the mainstream. Public Health Rev. 2018;39:19.

https://doi.org/10.1186/s40985-018-0094-7

4. Cadzow RB, Servoss TJ, Fox CH. The health status of patients of a student-run free medical clinic in inner-city Buffalo, NY. J Am Board Fam Med. 2007;20(6):572-580.

https://doi.org/10.3122/jabfm.2007.06.070036

5. British Medical Association. Social Determinants of Health: What Can Doctors Do? British Medical Association; 6455. Accessed March 66, 6464. https://www.paho.org/hq/dmdocuments/2012/Social-DeterminantsDoctors-Eng.pdf

6. Fenton M. Health Care's Blind Side: The Overlooked Connection between Social Needs and Good Health. The Robert Wood Johnson Foundation Accessed March 22, 2020.

https://sirenetwork.ucsf.edu/tools-resources/resources/health-caresblind-side-overlooked-connection-between-social-needs-and

7. Chisolm DJ, Brook DL, Applegate MS, Kelleher KJ. Social determinants of health priorities of state Medicaid programs. BMC Health Serv Res. 2019;19(1):167. https://doi.org/10.1186/s12913-019-3977-5

8. O'Gurek DT, Henke C. A Practical Approach to Screening for Social Determinants of Health. Fam Pract Manag. 2018;25(3):7-12.

9. Liaison Committee on Medical Education. Functions and Structure of a Medical School: Standards for Accreditation of Medical Education Programs Leading to the MD Degree. Association of American Medical Colleges and American Medical Association; 2019. Accessed March 22, 2020.

https://lcme.org/publications/

10. Smith S, Thomas R, Cruz M, Griggs R, Moscato B, Ferrara A. Presence and Characteristics of Student-Run Free Clinics in Medical Schools. JAMA. 2014;312(22):2407. https://doi.org/10.1001/jama.2014.16066

11. Simpson SA, Long JA. Medical Student-Run Health Clinics: Important Contributors to Patient Care and Medical Education. J Gen Intern Med. 2007;22(3):352-356.

https://doi.org/10.1007/s11606-006-0073-4
12. Swartz MK. The contributions of student-run free clinics. JPediatr Health Care. 2012;26(6):397.

https://doi.org/10.1016/j.pedhc.2012.07.015

13. Smith SD, Johnson ML, Rodriguez N, Moutier C, Beck E. Medical student perceptions of the educational value of a student-run free clinic. Fam Med. 2012;44(9):646-649.

14. Gorrindo P, Peltz A, Ladner TR, et al. Medical students as health educators at a student-run free clinic: improving the clinical outcomes of diabetic patients. Acad Med. 2014;89(4):625-631. https://doi.org/10.1097/ACM.0000000000000164

15. Choudhury N, Khanwalkar A, Kraninger J, Vohra A, Jones K, Reddy S. Peer mentorship in student-run free clinics: the impact on preclinical education. Fam Med. 2014;46(3):204-208.

16. Phillips RL, Petterson S, Bazemore A. Do residents who train in safety net settings return for practice?: Acad Med. 2013;88(12):1934-1940. https://doi.org/10.1097/ACM.0000000000000025

17. Warren S, Puryear E, Chapman M, Barnett TM, White LS. The role of social work in free healthcare clinics and student-run clinics. Soc Work Health Care. 2017;56(10):884-896. https://doi.org/10.1080/00981389.2017.1371097

18. Lefer TB, Anderson MR, Fornari A, Lambert A, Fletcher J, Baquero M. Using Google Earth as an innovative tool for community mapping. Public Health Rep. 2008;123(4):474-480. https://doi.org/10.1177/003335490812300408

19. Portage County Community Health Partners. 2019 Portage County Community Health Needs Assessment;; 2019. Accessed June 5, 2020. https://www.hcno.org/wp-content/uploads/2019/12/FINAL-2019. Portage-County-CHNA-12-6-19.pdf

20. United States Census Bureau. How does the census bureau define rural? Rural America. Accessed March 30, 2021.

https://mtgis-portal.geo.census.gov/arcgis/apps/MapSeries/ index.html? appid=49cd4bc9c8eb444ab51218c1d5001ef6\#: :text=The\% 20Census\%20Bureau\%20defines\%20rural,rural\%20based\%20on\% 20this\%20definition

21. Health Leads. Social Needs Screening Toolkit. Published online 2018. Accessed March 23, 2020.

https://healthleadsusa.org/resources/the-health-leads-screeningtoolkit/

22. National Alliance to Impact Social Determinants of Health. Screening Tools and Tool Kits. Helpful Screening Tools and Tool Kits. Published 2019. Accessed February 25, 2021.

https://www.nasdoh.org/screening-tools-and-tool-kits/

23. Douthit N, Kiv S, Dwolatzky T, Biswas S. Exposing some important barriers to health care access in the rural USA. Public Health. 2015;129 (6):611-620. https://doi.org/10.1016/j.puhe.2015.04.001

24. Perrin EC. Ethical questions about screening. J Dev Behav Pediatr. 1998;19(5):350-352. https://doi.org/10.1097/00004703-199810000-00006

25. Kronenfeld JP, Penedo FJ. Novel coronavirus (COVID-19): telemedicine and remote care delivery in a time of medical crisis, implementation, and challenges. Transl Behav Med. Published online October 24, 2020:ibaa105.

https://doi.org/10.1093/tbm/ibaa105 


\section{Leveraging Local and Regional Partners to Imple- ment Hospital Closed Point of Dispensing Sites}

\section{Daniel Baker ${ }^{1}$; Sara Paton ${ }^{2}$}

${ }^{1}$ Ohio Emergency Management Agency, Columbus, $\mathrm{OH}$

${ }^{2}$ Wright State University, Dayton, $\mathrm{OH}$

Corresponding Author: Daniel Baker, 2855 W. Dublin Granville Road, Columbus, OH 43235, (614) 799-3689, dabaker@dps.ohio.gov

Submitted December 15, 2020 Accepted April 7, 2021 Published June 21, 2021 https://doi.org/10.18061/ojph.v4i1.8078

\section{ABSTRACT}

Background: Point of dispensing (POD) sites are critical to local public health agencies (LPHA) when an emergency occurs requiring medications or vaccinations. Delivering medical countermeasures (MCM) ensures community support mechanisms and the general public are provided with a pharmaceutical intervention to limit untoward outcomes caused by the emergency. While LPHAs are required to have an MCM response plan, these plans vary based on jurisdictional size and geographical location in Ohio. This study evaluated the implementation potential of an MCM toolkit developed for LPHAs and hospitals across Ohio.

Methods: An MCM toolkit was created consisting of planning resources, training modules, sample exercises, and custom graphics. The toolkit was evaluated using Consolidated Framework for Implementation Research constructs by public health, hospital, hospital association, and emergency management professionals across Ohio by an electronic survey and phone interview. Qualitative and quantitative data were collected to determine overall implementation potential.

Results: Thirty-eight $(n=38)$ respondents with jurisdictional influence over 44 Ohio counties participated. Electronic survey results demonstrated high implementation potential for the MCM toolkit (weighted average 4.71/5.00). Phone interviews highlighted: (1) jurisdictional and regionalized planning approaches were necessary for MCM delivery, and (2) hospitals should function as closed POD sites for jurisdictional LPHAs.

Conclusion: This work demonstrates the importance of MCM response planning for LPHAs and hospitals. Implementation and planning materials for this work could be adopted into practice by LPHAs and hospitals across the United States to further assist in emergency preparedness planning.

Keywords: Public health; Emergency preparedness; Hospital preparedness; Point of dispensing; Medical countermeasures

\section{INTRODUCTION}

Local public health agencies (LPHA) play a pivotal role in the health and well-being of the communities they serve. Key pieces of public health service delivery have grown and evolved since LPHAs were formed in the late 1800 s. ${ }^{1}$ Providing services such as adult and pediatric immunizations, sexually transmitted infection testing, personal and family planning services, and breastfeeding counseling have been staples to LPHAs and the overall public health mission. ${ }^{2}$ Changing global dynamics and integration of a systems-thinking approach have greatly enhanced the roles, re- sponsibilities, and expectations of LPHAs' other core functions including emergency and disaster preparedness, epidemiological surveillance, and regional public health collaboration. ${ }^{3}$

A key component of this public health infrastructure is point of dispensing (POD) sites. The POD sites are utilized by LPHAs to rapidly dispense medical countermeasures (MCMs), medications or vaccinations, to the public before or immediately following a public health emergency. ${ }^{4}$ While the concept of POD sites is simple, the logistical need for credentialed staff, proper working environments, and community support is pronounced for LPHAs. The Cen-

(c) 2021 Daniel Baker; Sara Paton. Originally published in the Ohio Journal of Public Health (http://ojph.org) June 2021. This article is published under a Creative Commons Attribution 4.0 International License (http://creativecommons.org/licenses/by/4.0/). 
ters for Disease Control and Prevention (CDC) and the Assistant Secretary of Preparedness and Response have a joint agreement to house, maintain, and deliver MCMs to any public health jurisdiction in the United States within 12 hours of request, when available. ${ }^{4}$ The overall POD framework was then subdivided into open and closed PODs. Open PODs serve the general public, are managed by LPHA staff, and are located at large facilities (eg, arenas, schools, and community centers). ${ }^{5}$ Closed PODs are staffed and managed by individuals of a specific organization (private or public) and would only distribute MCMs to individuals who have a direct relationship to that organization (staff, immediate family of staff, and inpatient residents when applicable). ${ }^{5}$ Both open and closed PODs utilize the same planning and implementation strategy. Targeting specific populations (socially vulnerable minorities, refugees, non-English speaking populations, etc) for MCM distribution would need to be taken into account for open POD operations or as a separate initiative by the LPHA.

While the concept and planning for PODs started soon after September 2001, the first example of LPHA mobilizing PODs postSeptember 11, 2001, for a nationwide public health emergency, was in 2009 for the H1N1 influenza strain. ${ }^{3}$ H1N1 was the first post-September 11, 2001, instance where public health as a discipline was catapulted into the national spotlight for emergency response and the first opportunity POD plans were tested for a real-world emergency. ${ }^{3}$ The H1N1 outbreak of 2009 yielded several lessons learned about POD site logistics at the local government level including improved POD plans and procedures, recruitment of additional closed POD sites for LPHAs, and LPHAs integrating with hospitals and health care facilities. ${ }^{6}$ Focusing collaboration with hospitals can allow LPHA staff to leverage interventions for a large portion of the jurisdictional population through the health care system. Providing hospital staff with MCMs allows the hospital to continue critical operations during a public health emergency. The coronavirus disease 2019 (COVID-19) pandemic has shined a light on the importance and need for POD planning, training, and exercise across the public health enterprise.

While the concept of utilizing hospitals as closed POD sites is practical in theory, implementation of public health programming within the scope of a hospital is not a regularly ventured concept. Health care systems are complex and require coordination by several administrators to begin implementation of a new program. ${ }^{7}$ Even though the aforementioned challenges exist, several public health initiatives have been successfully initiated within the hospital setting in the past (eg, breastfeeding coaches, smoking cessation). ${ }^{8}$ Several organizational factors that gave rise to public health program success within the hospital setting include hospital culture and engagement, identifying where programming would fit into mission/vision, integration into organization structures, and program buy-in by administration. ${ }^{7}$

Local public health agencies are often stretched thin on staff, time, and finances to successfully implement a large-scale program within their respective field. This study focused on creating a comprehensive MCM toolkit and determining its implementation potential for LPHAs and hospitals within a jurisdiction. Additionally, the study looked at the feasibility of the MCM toolkit across urban and rural areas of Ohio. By creating a common MCM planning procedure, which the toolkit may provide, across LPHAs and hospitals, a unique opportunity exists for hospitals and LPHAs to work more in tandem and ensure continuity of health care across a community during a public health emergency.

\section{METHODS}

\section{Setting}

Local public health agencies, hospitals, regional hospital associations, and emergency management agencies (EMA) across southwest, west central, northwest, northeast, and central Ohio participated.

\section{Community, Participant Characteristics, Recruitment}

The project leader identified individuals involved in emergency preparedness activities from LPHAs, hospitals, regional hospital associations, and EMAs across 44 Ohio counties to participate. These individuals were recruited by the project leader based on professional contacts established through current and previous employment opportunities. Inclusion criteria included (1) employment in the field of public health emergency preparedness, emergency management, or health care; (2) working in the state of Ohio; and (3) being known by the project leader. No formal exclusion criteria were established.

\section{Design}

A mixed methods study was conducted using qualitative and quantitative data analysis from May 2020 to July 2020. Cross-sectional surveys were conducted electronically and by phone to identified participants from public health, emergency management, and health care to capture MCM toolkit feedback.

\section{Procedures/Program Description}

Various POD procedures, grant standards, and guidance materials from state of Ohio and CDC resources were consolidated to form the MCM toolkit. Toolkit documents were categorized into 4 primary sections: planning resources, training modules, sample exercise, and custom graphics. All documents were uploaded electronically into a cloud storage account. A document outlining all toolkit contents and potential implementation instructions accompanied the toolkit.

An electronic survey was created utilizing Microsoft Forms through Microsoft 365. The form collected reviewer information (name, contact information, jurisdiction, agency/profession, and date completed) as well as feedback on the toolkit. Toolkit document review information was ascertained based on Likert scale and open-ended questions. All open-ended questions were structured as strengths, areas of improvement, and additional com- 
ments for each section. Online survey questions were created by the project leader based on the Homeland Security Exercise and Evaluation Program (HSEEP). The HSEEP provides a common approach to exercise program design and development, evaluation, and improvement planning. ${ }^{9}$

Following the completion of the online survey, the project leader conducted a structured, 30-minute follow-up phone interview with toolkit reviewers. The project leader facilitated the discussion to determine information specific to POD implementation potential. The project leader developed follow-up questions focused on 4 Consolidated Framework for Implementation Research (CFIR) constructs: intervention characteristics, inner settings, outer settings, and process. ${ }^{10} \mathrm{~A}$ thematic analysis of all open-ended questions was conducted to determine frequency of common responses from each respondent.

\section{Measures/Outcomes}

The online survey contained quantitative and qualitative (openended) questions on MCM toolkit documents. Quantitative questions were structured on a scale from 1 to 5 where 1 represented a 'poor' rating and a 5 represented an 'excellent' rating. Open-ended questions were used to determine general strengths, areas of improvement, and general comments for each section within the online survey. All questions were to be completed to ensure uniformity in survey results and a full data comparison. Implementation potential was based on the combined weighted average (out of 5.00) from quantitative survey data. Implementation potential was categorized as either low (less than 3.00), likely (3.00-4.00), or high (greater than 4.00).

Qualitative data from the online survey were used to determine applicability of toolkit documents and identify possible implementation barriers. A thematic analysis of all open-ended questions was conducted to determine frequency of common responses from each respondent. Follow-up phone interviews provided qualitative data that identified individual agency issues to MCM planning and POD site mobilization. A thematic analysis was also conducted on phone interview responses.

\section{Statistical Analysis}

Two primary analysis techniques were used for this study, weighted average and thematic analysis. A weighted average was conducted on all quantitative survey elements using Microsoft Excel. The weighted average was conducted rather than a normal average to ensure the importance of the scale values is reflected in the results. No data points were missing from the electronic survey as all questions were deemed 'required' by the project leader. A thematic analysis was conducted on open-ended questions from both the electronic survey and the follow-up phone interviews. All thematic analyses were conducted by finding similar themes from respondents in open-ended questions and then counting frequency of those occurrences. Additionally, no data points were missing from the follow-up phone interview questions as they were also all required by the project leader.

\section{RESULTS}

A total of $38(n=38)$ surveys were completed and obtained by the project leader with Table 1 showing respondents by organization. All survey respondents comprised emergency preparedness planners for public health, hospitals, hospital associations, and EMA personnel. A 59\% participation rate can be attributed to other priorities faced by respondents for the COVID-19 pandemic response.

Table 2 provides the weighted averages (out of 5.00) of each document in each section of the toolkit. A combined weighted average for the toolkit was $4.71 / 5.00$. Because this value is greater than 4.00, this demonstrates the MCM toolkit's high implementation potential across public health, health care, and emergency management. Tables 3 and 4 show results from the qualitative thematic analysis of toolkit strengths and areas of improvement. This analysis was conducted by finding like-themes across all respondents $(n=38)$ and counting their frequency. The thematic analysis data reflect the concise nature of the toolkit as a whole by combining procedures and grant guidance materials into a single product, ability to implement, and scalability. While all toolkit materials were collected based on current state of Ohio and federal guid-

\section{Table 1. Toolkit Respondents by Organizational Area for Participation Request and Provided}

\begin{tabular}{|lll|}
\hline Organizational area & Participation request & Participation provided \\
\hline LPHA & 37 & 20 \\
Hospital & 15 & 8 \\
EMA & 7 & 6 \\
Regional hospital associations & 5 & 4 \\
\hline
\end{tabular}


Table 2. Likert Scale (out of five) Weighted Averages Results by Toolkit Review Element $(n=38)$

\begin{tabular}{|c|c|}
\hline \multicolumn{2}{|l|}{ Planning resources } \\
\hline Closed point of dispensing (POD) mobilization and response guide & 4.70 \\
\hline Memorandum of understanding (MOU) and training agreements & 4.70 \\
\hline POD staff roster template & 4.76 \\
\hline Hospital closed POD planning guide & 4.65 \\
\hline Public health cold chain management standard operating procedure (SOP) & 4.81 \\
\hline \multicolumn{2}{|l|}{ Training modules } \\
\hline POD access and functional needs training & 4.59 \\
\hline Organization chart & 4.86 \\
\hline Job action sheets & 4.84 \\
\hline Medication registration form template & 4.59 \\
\hline Vaccine registration form template & 4.68 \\
\hline POD overview training PowerPoint & 4.89 \\
\hline \multicolumn{2}{|l|}{ Sample exercise } \\
\hline Exercise evaluation guide (hospital) & 4.54 \\
\hline Exercise evaluation guide (public health) & 4.59 \\
\hline Exercise player scenarios & 4.73 \\
\hline Sample exercise - medication & 4.65 \\
\hline Sample exercise - vaccine & 4.68 \\
\hline Training evaluation (pre and post) & 4.65 \\
\hline \multicolumn{2}{|l|}{ Custom graphics } \\
\hline Registration section look and design & 4.70 \\
\hline Screening section look and design & 4.70 \\
\hline Treatment section look and design & 4.73 \\
\hline Support section look and design & 4.62 \\
\hline Exit section look and design & 4.73 \\
\hline Average (across all sections) & 4.71 \\
\hline
\end{tabular}

Table 3. Thematic Analysis of Qualitative Electronic Survey Results by Observed Theme-General Toolkit Comments-Strengths ( $\mathrm{n=38)}$

\begin{tabular}{|ll|}
\hline Theme & Frequency \\
Well organized; clear and concise information & 19 \\
Ability to implement; ease of use & 13 \\
Modular and scalable & 4 \\
Customizable & 3 \\
Graphics & 2 \\
\hline
\end{tabular}

Table 4. Thematic Analysis of Qualitative Electronic Survey Results by Observed Theme-General Toolkit Comments-Areas of Improvement $(\mathbf{n}=38)$

\begin{tabular}{|lc|}
\hline Theme & Frequency \\
None & 20 \\
Spelling and/or grammatical revisions & 4 \\
Customization (graphics, PowerPoints) & 3 \\
Exercise scenario modification & 3 \\
Document length (longer than preferred) & 2 \\
\hline
\end{tabular}


ance, few respondents felt the toolkit was customizable enough to fit the needs of their organization.

During the follow-up interview, reviewers identified the POD toolkit as an item that will be integrated into current POD planning activities for internal and external partners. Comments supporting this finding included

"This toolkit will be utilized by my entire hospital system. Everything laid out provides enough information for our hospitals to quickly become a closed POD site. Additionally, we can easily work with the health department to get up to speed on what is needed to be an official POD site for them." (hospital planner);

"We can add to what is already in place for POD planning with the addition of this toolkit. Everything is laid out very nicely and can be very easy for patients who would be moving through a POD using this model." (LPHA planner); and

"The toolkit really brings home the point of engaging public/ private partnerships. We have never had to do so much with the health department until the COVID-19 pandemic - we now realize how much more we have to rely on the private sector," (EMA director).

These comments highlighted both the implementation potential for the toolkit and the need to engage public-private partnerships. Emergency management directors discussed the complexity of public health emergencies and the need to have a coordinated response with the private sector. Both hospital and LPHA planners cited the ease of implementation for new or existing MCM plans. While the concept of establishing a closed POD within the hospital is new, both LPHAs and hospitals agreed that it is not only attainable but that it would be beneficial to each agency during an emergency.

When asked about potential internal implementation barriers, respondents unanimously agreed that coordination of POD plans between LPHAs and hospitals should occur at the jurisdictional and regional levels. Comments that support this finding included

"Regional and local planning needs to happen with the POD toolkit - even without. Our plans are all different and we each do things a little different in each county. This should be done with all of our plans, honestly," (LPHA planner); and

"Regional planning allows hospitals and LPHA to have better handle on resources and move resources around as needed - it provides a more coordinated response. That is critically important for a POD and movement of life saving resources. We need to have better coordination in our regions," (hospital association coordinator).

The comments cited above underscore the importance of jurisdictional and regional planning. While these comments only capture an LPHA planner and hospital association coordinator, the sentiments were shared by a majority of respondents. Ensuring prepar- edness planning efforts encompass all relevant partners is paramount when a real-world incident occurs.

\section{DISCUSSION}

This work provides a foundational baseline for other practitioners and academicians to better understand an integral piece of public health practice and public health infrastructure. The significance of public health emergency preparedness has never been more understood given the COVID-19 pandemic. The MCM toolkit provides a mechanism for practitioners in public health, health care, and emergency management to implement and evaluate their overall preparedness planning for a public health emergency.

Findings from follow-up phone interviews with LPHAs and hospitals suggest that hospitals can be leveraged by LPHAs to serve as a closed POD for the community. As evidenced by the COVID-19 pandemic, LPHAs and hospitals are both tasked with a myriad of responsibilities to safeguard the public's health. The introduction of hospital closed POD sites not only expedites the MCM distribution process within a jurisdiction, but it will allow for better continuity of operations for both entities. This concept reinforces the notion of utilizing systems-based approaches to complete public health services.11,12 Funding for this initiative would be a joint partnership between the LPHA's and hospital's respective general revenue funds or preparedness grants.

Systems thinking can also include leveraging public-private partnerships. Leveraging public-private partnerships was cited by toolkit reviewers in follow-up interviews as a need for LPHAs moving forward. DeSalvo and colleagues point out improved partnerships throughout the community are necessary to sustain public health services. ${ }^{13}$ The Federal Emergency Management Agency's (FEMA) revised emergency support function (ESF) 14 also outlines a new approach for public-private partnership integrating into emergency response for local, state, and federal emergency management. ${ }^{14}$ Revised ESF 14 can assist LPHAs to recruit hospitals as closed POD sites, as well as other private organizations in the future, by providing a planning framework for local EMA directors to coordinate the process.

Findings from the electronic survey (Table 3) suggested that the MCM toolkit is modular, scalable, and can easily be implemented. While establishing hospital closed POD sites was shown to be a vital component for LPHAs in the follow-up phone interviews, the widespread dissemination of an MCM toolkit must show itself to be scalable, modular, and customizable to best fit the needs of a jurisdiction. The prepared MCM toolkit provided a method to incorporate these differences by integrating HSEEP principles. The HSEEP has been used as a methodology to conduct planning, training, and exercises as modular and scalable units. ${ }^{9}$ This method has been shown to be the most effective for adult learning and applicability to various sized jurisdictions. ${ }^{9,15}$ The HSEEP provides a means to underscore general lecture style training that is capped off with a discussion-based or action-based exercise. Because of 
the various types of emergency response partners within a community (public health, hospitals, emergency management, hospital associations, law enforcement, etc), scalability is needed to encompass the strengths of different sized response agencies. This concept is also true for understanding the roles and responsibilities of these agencies.

The CDC's public health emergency preparedness capabilities have been utilized to demonstrate the applicability of concepts to both urban and rural jurisdictions and were shown to be an effective metric for preparedness performance. ${ }^{16}$ Counties across Ohio vary in size from over 1 million individuals in urban areas to less than 14 thousand in rural areas. ${ }^{17}$ Each jurisdiction is also vastly different in resources, political structure, and staffing capability. The respondents for this study encompassed both urban and rural counties across Ohio. Based on the results in Table 3 and the follow-up phone interview quotes, this study demonstrated that the MCM toolkit allows for scalability and customization by LPHAs and hospitals regardless of jurisdictional size or geographical location through the state of Ohio. Additionally, the modular nature of the materials allows for LPHAs to conduct planning, training, and exercise that fits into a cycle that best fits their needs. Scalability is imperative because it allows individuals to utilize the toolkit to the fullest extent necessary for their respective jurisdiction. This ensures that the basic principles of MCM response are maintained from the toolkit while allowing for flexibility during implementation.

Finally, this work provided evidence to highlight the importance of regional planning efforts within the state of Ohio. As evidenced by the implementation barriers in the results, regionalized planning is a concept that had not been well received by local jurisdictions in the past and can be seen as loss of control or a means of political conflict. Planners within public health and hospitals often use their social networks to collaborate on different projects, deliverables, and grant requirements within regions. Individual jurisdictions may implement a common planning structure (eg, MCM toolkit) and the structure is then used with LPHAs and hospitals within their respective jurisdiction. This conceptualization could then graduate to being adopted by other counties within a region. Progression from individual jurisdictional planning to a regionalized approach could be a possible framework to be considered by LPHA and hospital planners to address concerns outlined in toolkit implementation barriers.

Harris and Clements highlighted the need for information exchange between public health practitioners through their social networks. ${ }^{18}$ Loss of experience based on personnel turnover within public health increases the need for these social networks and other unique approaches to ensure public health services are maintained at the local level.3,13,18 Sharing of resources and personnel, as well as the ability to save on costs and general overhead, were cited as major benefits to regional planning. ${ }^{3}$ This concept was also shown to provide a foundational approach to allow POD planning for all jurisdictions to ensure continuity among all
LPHAs and hospitals. This allows for a unified approach between LPHAs and hospitals to expedite the MCM distribution process to residents within jurisdictions.

A limitation to this study was generalization of results. Because study participants were obtained through a convenience sample, external validity may not account for the larger public health system.

\section{PUBLIC HEALTH IMPLICATIONS}

The implication of MCM toolkit dissemination would substantially benefit the public health community across Ohio and the United States. Toolkit reviewers determined that the scalability and implementation potential is applicable for both rural and urban areas. While not explicitly reviewed for this study, exurban and suburban areas would need to be considered as part of the primary jurisdiction. The MCM toolkit has implementation potential for jurisdictions across Ohio and the United States. Additionally, the use of regionalized planning can be utilized by local-level partners for other planning considerations outside of MCM response (eg, epidemiological outbreak, environmental health emergency, etc). Leveraging regional planning efforts streamlines processes and allows for a shared area of responsibility among similar partner agencies.

Revised ESF 14 guidance produced by FEMA encourages the coordination and utilization of private partners when responding to an emergency. While hospitals are the first step toward leveraging the public-private partnership for MCM distribution in communities, revised ESF 14 will better equip local EMA and emergency operation centers to identify additional private partnerships by designating specific planning considerations for partnership integration. Private pharmacies, grocery stores, and biotech companies have been leveraged and engaged during the COVID-19 response for testing purposes. The same principle of resource identification and integration may be utilized by LPHAs and local EMAs to cultivate additional public-private partnerships.

\section{ACKNOWLEDGMENTS}

The project leader would like to thank the many professionals across Ohio who provided their input and time into this research. This support demonstrates their commitment to establishing more evidence-based public health practices in Ohio. The project leader would also like to thank Ishmael Hoare, PhD, University of South Florida for his support.

\section{REFERENCES}

1. State of Ohio. Ohio Revised Code $§ 3709.01$ - Health districts. Ohio Revised Code $\$ 3709.01$ - Health districts. Ohio Revised Code $\$ 3709.01$ Health districts. Published 2013.

2. Sellers K, Leider JP, Gould E, et al. The state of the US governmental public health workforce, 2014-2017. Am J Public Health. 2019;109 (5):674-680. https://doi.org/10.2105/AJPH.2019.305011

3. Lurie N, Wasserman J, Nelson CD. Public health preparedness: evolution or revolution? Health Aff. 2006;25(4):935-945. https://doi.org/10.1377/hlthaff.25.4.935 
4. Centers for Disease Control and Prevention. Division of Strategic National Stockpile Program Review. 2012.

https://www.cdc.gov/cpr/science/documents/dsns_program_review_ workgroup_report_final2.pdf

5. Centers for Disease Control and Prevention. Health Care Closed Points of Dispensing. Published 2018.

https://www.cdc.gov/cpr/readiness/healthcare/closedPODtoolkit.htm

6. Department of Homeland Security. 2009 H1N1 After Action Report; 2010. https://www.hsdl.org/?view\&did=783079

7. Sligo J, Gauld R, Roberts V, Villa L. A literature review for large-scale health information system project planning, implementation and evaluation. Int J Med Inform. 2017;97(2017):86-97.

https://doi.org/10.1016/j.ijmedinf.2016.09.007

8. Vanderkruik R, McPherson ME. A contextual factors framework to inform implementation and evaluation of public health initiatives. $\mathrm{Am} \mathrm{J}$ Eval. 2017;38(3):348-359. https://doi.org/10.1177/1098214016670029

9. Federal Emergency Management Agency. Homeland Security Exercise and Evaluation Program.

10. Consolidated Framework for Implementation Research. What is the Consolidated Framework for Implementation Research?Published 2019.

https://cfirguide.org/

11. Institute of Medicine. The Future of Public Health. The National Academies Press. 1988.

https://doi.org/10.17226/1091

12. Pickett G. The future of public health. J Public Health Policy. 1989;10

(3):397.

https://doi.org/10.2307/3342799

13. DeSalvo KB, Claire Wang Y, Harris A, Auerbach J, Koo D, O'Carroll P. Public health 3.0: A call to action for public health to meet the challenges of the 21st century. Prev Chronic Dis. 2017;14(9):1-9.

https://doi.org/10.5888/pcd14.170017

14. Federal Emergency Management Agency. Emergency Support Function \# 14 - Cross-Sector Business and Infrastructure. 2019;(October):1-15. https://www.fema.gov/media-library-data/1572358162675d2c7af34a5b5063e582ae1798b038351/ESF14AnnexFINAL508 C_20191028.pdf

15. Hites LS, Granillo BS, Garrison ER, et al. Emergency preparedness training of tribal Community Health Representatives. J Immigr Minor Heal. 2012;14(2):323-329. https://doi.org/10.1007/s10903-011-9438-9

16. Hunter JC, Yang JE, Crawley AW, Biesiadecki L, Aragón TJ. Public health response systems in-action: Learning from local health departments' experiences with acute and emergency incidents. PLoS One. 2013;8 (11). https://doi.org/10.1371/journal.pone.0079457

17. United State Census Bureau. Population and Housing Unit Estimates Datasets. Published 2018. https://www.census.gov/programs-surveys/popest/data/datasets.html

18. Harris JK, Clements B. Using social network analysis to understand Missouri's system of public health emergency planners. Public Health Rep. 2007;122(4):488-498.

https://doi.org/10.1177/003335490712200410 


\section{APPENDIX. Electronic Survey Template POD/MCM Online Survey}

1. What organization do you represent?

Local public health agency

Hospital

Regional hospital association (eg, HCNO, GDAHA, etc)

Local emergency management agency

2. What is your name?

3. Name of your organization's county of residence.

4. What is your email address?

5. What is the best phone number to reach you for follow-up questions?

6. When reviewing the PLANNING RESOURCES folder, please provide your feedback to each of the following items. One (1) reflect a rating of "poor" while a five (5) reflects a rating of "great."

Closed Point of Dispensing (POD) Mobilization and Response Guide

1 (Poor) $2 \quad 3 \quad 4 \quad 5$ (Great)

MOU and Training Agreements

1 (Poor) 2345 (Great)

POD Staff Roster Template

1 (Poor) $2 \quad 345$ (Great)

Hospital Closed POD Planning Guide

1 (Poor) $2 \quad 345$ (Great)

Public Health Cold Chain Management SOP

1 (Poor) $2 \quad 3 \quad 45$ (Great)

7. Please describe notable strengths for the PLANNING RESOURCES materials.

8. Please describe notable areas of improvement for the PLANNING RESOURCES materials.

9. Please include any additional comments for the PLANNING RESOURCES materials.

10. When reviewing the TRAINING MODULES folder, please provide your feedback to each of the following items. One (1) reflect a rating of "poor" while a five (5) reflects a rating of "great."

POD Access and Functional Needs Training

1 (Poor) $23 \quad 3 \quad 4 \quad 5$ (Great)

Organization Chart

1 (Poor) $22 \quad 3 \quad 4 \quad 5$ (Great)

Job Action Sheets

1 (Poor) $23 \quad 3 \quad 5$ (Great)

Medication Registration Form Template

1 (Poor) $23 \quad 345$ (Great)

Vaccine Registration Form Template

1 (Poor) $23 \quad 345$ (Great)

POD Overview Training PowerPoint

1 (Poor) $23 \quad 345$ (Great)

11. Please describe notable strengths for the TRAINING MODULES materials.

12. Please describe notable areas of improvement for the TRAINING MODULES materials.

13. Please include any additional comments for the TRAINING MODULES materials.

14. When reviewing the SAMPLE EXERCISE folder, please provide your feedback to each of the following items. One (1) reflect a rating of "poor" while a five (5) reflects a rating of "great."

Exercise Evaluation Guide (Hospital)

1 (Poor) 22345 (Great)

Exercise Evaluation Guide (Public Health)

1 (Poor) 22345 (Great)

Exercise Player Scenarios
1 (Poor) 2345 (Great)

Sample Exercise - Medication

1 (Poor) $2 \quad 3 \quad 4 \quad 5$ (Great)

Sample Exercise - Vaccine

1 (Poor) 2345 (Great)

Training Evaluation (Pre and Post)

1 (Poor) $2 \begin{array}{llll}3 & 4 & 5 \text { (Great) }\end{array}$

15. Please describe notable strengths for the SAMPLE EXERCISE materials.

16. Please describe notable areas of improvement for the SAMPLE EXERCISE materials.

17. Please include any additional comments for the SAMPLE EXERCISE materials.

18. When reviewing the CUSTOM GRAPHICS folder, please provide your feedback to each of the following items. One (1) reflect a rating of "poor" while a five (5) reflects a rating of "great."

Registration Section Look and Design

1 (Poor) 2345 (Great)

Screening Section Look and Design

1 (Poor) 23345 (Great)

Treatment Section Look and Design

1 (Poor) 2345 (Great)

Support Section Look and Design

1 (Poor) $2 \quad 3 \quad 4 \quad 5$ (Great)

Exit Section Look and Design

1 (Poor) $23 \quad 3 \quad 4 \quad 5$ (Great)

19. Please describe notable strengths for the CUSTOM GRAPHICS materials.

20. Please describe notable areas of improvement for the CUSTOM GRAPHICS materials.

21. Please include any additional comments for the CUSTOM GRAPHICS materials.

22. Given the OVERALL TOOLKIT, please describe notable strengths for all the materials presented to you.

23. Given the OVERALL TOOLKIT, please describe notable areas of improvement for all the materials presented to you. 


\title{
Toledo Naloxone Outreach Program: Patient and Health Care Professional Student Education
}

\author{
Alex Petrak'; Luke Zona ${ }^{1}$; Jeni Ten Eyck'; Manish Karamchandani²; Tanvir Singh ${ }^{1}$ \\ ${ }^{1}$ College of Medicine and Life Sciences, University of Toledo, Toledo, $\mathrm{OH}$ \\ ${ }^{2}$ Department of Psychiatry and Behavioral Sciences, Medical University of South Carolina, Charleston, SC \\ Corresponding Author: Alex Petrak, 5859 Spring Hollow Drive, Toledo, OH 43615, (614) 716-9741, petrak.alex@gmail.com \\ Submitted October 28, 2020 Accepted April 7, 2021 Published June 21, 2021 https://doi.org/10.18061/ojph.v4i1.8072
}

\begin{abstract}
Background: In 2016, Ohio was home to 2 of the top 10 cities with opioid overdoses in the United States. Dayton ranked first, and Toledo held the tenth slot. In response to the opioid epidemic, the Toledo Naloxone Outreach Program (TNOP) was developed to provide naloxone to underserved patients at a student-run free clinic.

Methods: The TNOP takes place weekly at 2 locations in the greater Toledo area. Patients are asked to fill out an anonymous survey and given a brief training session by a health care professional student. Patients are then sent home with a free naloxone kit. Additionally, health care professional students were surveyed on their confidence of acquiring a substance use history and knowledge of local services for patients and family members of those experiencing addiction during the "train the trainer" event. The health care professional student survey utilized a 1-5 Likert scale and was analyzed using paired student $t$ tests.
\end{abstract}

Results: Survey results from patients indicate that a majority had not received naloxone prior to the training, indicating the service was expanding access to an otherwise underserved population. Results from the survey administered before and after health care professional student training sessions reflect a significant increase in confidence eliciting a substance abuse history and providing patients and/or family members with addiction resources in the community.

Conclusion: The TNOP has provided the community of Toledo with 2 additional outreach locations for receiving free naloxone kits with proper education. Currently, TNOP is in the process of expanding the outreach program to additional student-run free clinics in Ohio.

Keywords: Interdisciplinary teams; Pharmacy; Community health/engagement; Naloxone

\section{INTRODUCTION}

In 2018, Ohio ranked fifth in rates of age-adjusted drug overdose deaths. ${ }^{1}$ Within Ohio, Lucas County has experienced a steady rise in opioid overdose deaths from 2014-2019.2 Lucas County ranks seventh of 88 counties in Ohio regarding total drug overdoses from 2012-2020.3 If uninsured, the public can procure naloxone for $\$ 75$ from a variety of pharmacies and at no cost from the Toledo Lucas County Department of Health. The cost for naloxone can be covered depending on the individual's insurance. However, the need for readily available access to naloxone in underserved populations remains high. The American Society of Addiction Medicine
(ASAM) published a public statement supporting broadened community access to naloxone in populations with high risk for opioid overdose. ${ }^{4}$ Given the significant detrimental impact of opioid overdoses on the local community, the Addiction Medicine Club at the University of Toledo College of Medicine (UTCOM) created the Toledo Naloxone Outreach Program (TNOP) in August 2018. The TNOP was formed to combat the opioid epidemic at a local level by providing free naloxone training and kits to vulnerable populations. Additionally, the program aims to provide health care professional student education early on in training to prepare students to care for a population significantly affected by the opioid epidemic. 
The TNOP works in conjunction with the Lucas County Department of Health and Project DAWN (Deaths Avoided With Naloxone) through the Ohio Department of Health which provides grant funding for naloxone kits. Project DAWN is an Ohio-based nonprofit dedicated to providing naloxone training and distribution. To implement the program, TNOP partnered with Community Care Clinics (CCC), a student-run free clinic for the uninsured and unemployed in the greater Toledo area. As of September 2020, TNOP has aided in the training of over 1200 health care professional students on the signs of opioid overdose and how to act in the event of an overdose, including administering naloxone. This paper aims to show the impact of a student-run naloxone service on both professional health care student education and patient access to naloxone.

\section{METHODS}

\section{Setting}

The TNOP's naloxone service is provided each Thursday at Community Care Clinics' (CCC) main site and Mondays during CCC's Labre Traveling Clinic which operates at 2 street corners in downtown Toledo. An estimated 50 patients are screened per week for naloxone needs.

Health care professional student trainings took place in person on the campus of University of Toledo College of Medicine.

\section{Design}

The research utilized surveys for both the patient training and the health care professional student "train the trainer" event to determine outcomes of the naloxone service provided. For the patient survey, information was utilized to determine the need for a naloxone service in an underserved patient population.

From the "train the trainer" event, pre- and post-training surveys were utilized to determine if the event provided a significant increase in professional student knowledge of taking a substance use history and awareness of local addiction recovery resources.

For this analysis, data were collected between August 2018 and December 2019. The University of Toledo Institutional Review Board has granted exemption for this research.

\section{Participants}

During CCC's intake process, patients are asked if they or a family/ friend use opioids and are provided examples of opioids. If indicated, they are offered free naloxone training and kits during their clinic visit.

Interprofessional students, including students from the schools of social work, college of medicine, college of pharmacy, and college of nursing are eligible to receive training. Selection criteria were limited to students who had never received formal training on naloxone administration or education.

\section{Procedures}

The research was performed using information from 2 separate training protocols. The patient training process consisted of a 15minute private interactive session with a trained health care professional student regarding naloxone and its administration during an overdose as well as signs and symptoms of an opioid overdose. Prior to the training the patient was required to fill out the Project DAWN survey. After the training, patients were then sent home with a free naloxone kit. The kit contains 2 doses of $4 \mathrm{mg}$ intranasal naloxone, gloves, a face shield, and a card with rescue directions and local recovery service numbers. Patients with smartphones were encouraged to download the "NARCAN Now" smartphone app in case of emergency for rapid review of the materials.

Additionally, 2 types of health care professional training events were conducted. The first, "train the trainer," included details about pharmacokinetics, pharmacodynamics, and prescriber information. This is a standardized 1-hour in-person training session created by TNOP in conjunction with the local health department. Students were then eligible to train patients via the naloxone outreach program. The other type of student training was conducted through the Interprofessional Education Program (IPE) in conjunction with the Lucas County Health Department. This 20minute in-person training educated IPE students to personally respond to an opioid overdose situation using naloxone but did not qualify them to train patients. No survey was utilized during the IPE training and, therefore, is not included in data analysis.

Both types of training covered topics including trends in opioid usage and overdose in the Toledo area, signs and symptoms of narcotic overdose, the pharmacology of naloxone, and the appropriate steps to navigate a rescue scenario. Additionally, both types of training highlighted addiction recovery resources available locally and how to contact them.

\section{Measures/Outcomes}

Patients are required to fill out an anonymous 1-page survey from Project DAWN which includes 14 questions. This covers patient demographics, past overdose history, and naloxone use history. A copy of the survey can also be found in Appendix A. This valuable information is periodically returned to the Ohio Department of Health to evaluate the local need for naloxone and titrate funding.

Before and after the "train the trainer" session, students were asked to fill out a survey assessing their confidence in eliciting a substance use history from a patient or family member as well as their knowledge of local addiction recovery resources. Of the 100 students in attendance in the "train the trainer" session, 70 participants completed the pre-training survey and 35 completed the post-training survey. The discrepancy of pre- and post-training survey participation is due to some students leaving the event before filling out the post-training survey. 
A 1-5 Likert scale (1 = strongly disagree, 5 = strongly agree) was used for the health care professional student pre- and post-survey questions. The survey included 4 questions assessing confidence in eliciting a substance use history from patients and family members as well as their familiarity with addiction recovery resources in the Northwest Ohio area. A copy of this survey can be found in Appendix B.

\section{Statistical analysis}

Results were entered into a Microsoft Excel spreadsheet. Twotailed paired student $t$ tests were performed on the health care professional student survey responses. The Likert scale averages of pre- and post-training questions were compared. The data points from the 35 students that completed the pre-training survey but did not complete the post-training survey were not included in data analysis to allow for paired student $t$ tests to be conducted.

\section{RESULTS}

Project DAWN survey results were collected during the intake process from 35 participants after a patient expressed interest in naloxone training. While patients were required to fill out the survey to the best of their ability, not all patients answered each question in the Project DAWN survey. Many of the questions had a low response rate of less than 5 responses. The following 3 questions are included for discussion. When asked whether an individual has witnessed an overdose in the past, there was an equal distribution that answered yes $(11 / 22,50 \%)$, and no $(11 / 22,50 \%)$. Additionally, when asked the gender of the person who overdosed there was again an almost equal distribution (male: $12 / 26,46 \%$, female: $14 / 26,54 \%)$. For the vast majority, this was the first time patients received naloxone (yes: $27 / 30,90 \%$, no: 3/30, 10\%) (Table 1).

Approximately 550 IPE students attended a training session in 2018, and 550 IPE students attended in 2019. In 2018, 100 health care professional students participated in the "train the trainer" session.

Regarding the health care professional student survey, statistical significance was achieved when comparing pre-training question responses with their respective post-training responses. When asked about their confidence level to elicit a substance abuse history from someone experiencing addiction, there was an increase in the mean from 3.1 to $3.6(P<.05)$. Students reported an increase in the mean from 3.2 to 3.7 when asked about their confidence in eliciting this same abuse history from a family member of someone experiencing addiction $(P<.05)$. When asked about their confidence in relaying contact information of recovery services in the local area to those with a substance use disorder, students reported an increase in the mean of 2.6 to $4.2(P<.01)$ and to family members an increase of the mean from 2.5 to 4.4 post training $(P<.01)$ (Figure 1).

\section{DISCUSSION}

Through the efforts of TNOP, over 1200 health care professional students have been trained to administer naloxone. Over 100 of these students received further training to be eligible to train patients on the use of naloxone in an opioid overdose situation. Surveys indicate the training provided students with greater confidence to elicit a substance use history from patients and family members, as well as increased their knowledge of recovery resources available in the local community. This education aids the trainers during their interactions with patients at the free clinics and also during clinical rotations when encountering patients with a substance use disorder.

From mid-2018 through 2019, approximately 35 patients were trained on the use of naloxone and received free training kits. Data gathered from the Project DAWN surveys indicate that most patients received naloxone for the first time at these locations with 27 of 30 responding their first time receiving naloxone was at CCC while 11 of 22 reported witnessing an opioid overdose in the past. This suggests the services provided patients with naloxone when they otherwise would not have had it to prevent an overdose death. Reviewing data from Lucas County comparing June 2019 to June 2020 there has been a $64 \%$ increase in opioid overdoses (105 in June 2019 and 204 in June 2020) with a 32\% increase in fatalities (16 in June 2019 and 22 in June 2020). However, there has been a 62\% increase in naloxone given (95 in June 2019 and 180 in June 2020). ${ }^{5}$ We suspect that programs such as the TNOP may have played a role in preventing an increase in opioid overdose deaths relative to the increase in total overdoses.

The distribution of naloxone is of increasing importance in Lucas County and surrounding areas as detection of fentanyl was reported in $83 \%$ of opioid deaths (376/452 deaths) in 2019,3 a trend

Table 1. Patient Responses from Project DAWN Survey

\begin{tabular}{|llc|}
\hline $\begin{array}{l}\text { Have you witnessed an overdose in the past? } \\
\text { Gender of the individual who overdosed? }\end{array}$ & Male (12/26), 46\% & Female (14/26), 54\% \\
Is this the first time receiving naloxone? & Yes (27/30), $90 \%$ & No (3/30), 10\% \\
\hline
\end{tabular}




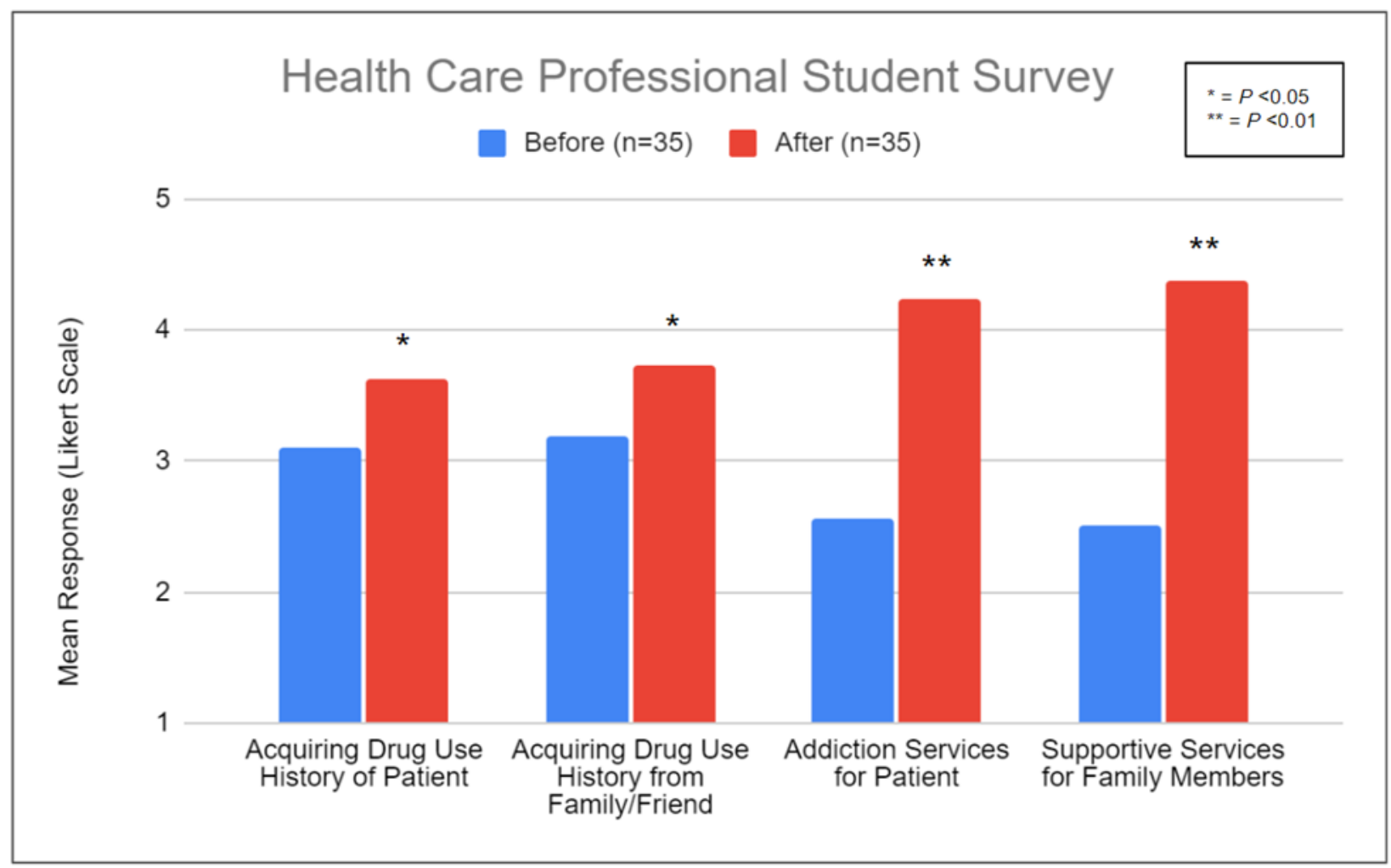

Figure 1. Health Care Professional Student Survey Outcomes

seen throughout the state of Ohio. ${ }^{6}$ Fentanyl is 50 to 100 times more potent than morphine or heroin, and early naloxone use is one of the most critical steps to prevent death in a fentanylinvolved overdose. ${ }^{7}$ Data from 2020 in Lucas County reveal that $74 \%$ of fatal overdoses occur in the person's home, and an additional $14 \%$ of deaths occur in a family/friend's house. ${ }^{8}$ With such a high percentage of fentanyl-involved opioid deaths, it is crucial to continue distributing naloxone to those at risk so that it is readily available in their home.

Limitations of this research include small sample sizes of students and patients surveyed. Some surveys were not filled out in their entirety by patients, thus the amount of people who answered each question varies compared to total patients surveyed. Additionally, there is a lack of follow-up data from patients after they received naloxone. Therefore, it is unknown if the patients went on to use their naloxone kit to prevent an opioid overdose death.

Future directions of the program include expanding TNOP to more locations within Toledo to allow a more diverse population of patients to have the opportunity to receive naloxone with highquality training, implementing an outcome survey to patients assessing their confidence in responding to an opioid overdose event pre- and post-training using a Likert scale, a formal analysis to confirm if a relationship exists between programs offering naloxone and a decrease in overdose fatalities, and creation of a replicable naloxone service for other health care professional schools in Ohio to use at their own institution in conjunction with their local health department and Project DAWN sites.

\section{PUBLIC HEALTH IMPLICATIONS}

The opioid epidemic has affected communities throughout the United States. While efforts have been put in place to mitigate the damage, opioids accounted for $83.7 \%$ of all unintentional drug overdoses in 2019 within Ohio. ${ }^{1}$ A 2017 report from the White House explains that this epidemic has cost the country $2.8 \%$ of the total GDP, which is roughly $\$ 500$ billion in $2015.9^{9}$ This epidemic is unique in that all demographics are affected. It is therefore imperative that all health care team workers in the United States are equipped with the knowledge to identify, support, and treat patients who are affected. When properly executed, health care professional student programs can combat the opioid epidemic at a local level. This study highlights the need for the service in the community and the augmentation of professional student education of addiction to aid in providing high quality patient care. An extra emphasis here is placed on all members of the health care team, as stigma in seeking help remains one of the greatest barriers in this fight.

\section{ACKNOWLEDGMENTS}

We would like to thank the University of Toledo College of Medicine and Life Sciences, Community Care Clinic, Lucas County Health Department, Ohio Department of Health, and Project DAWN. 


\section{REFERENCES}

1. Hedegaard H, Miniño AM, Warner M. Drug overdose deaths in the United States, 1999-2018. NCHS Data Brief, no 356. Hyattsville, MD: National Center for Health Statistics; 2020. Accessed October 2020.

https://www.cdc.gov/nchs/products/databriefs/db356.htm

2. Forney RB, Shinaver R. 2014-2019 Opioid Deaths. Lucas County Coroner Toxicology Laboratory: Lucas County; 2020. Accessed October 2020.

3. Summit County Public Health. Estimated Drug Overdoses, State of Ohio, Counties, and Zip Codes, 2012-2020. Columbus, Ohio: Ohio Department of Health; 2020. Accessed October 2020.

https://app.powerbi.com/view?r=eyJrIjoiZTkxZDAwOGQtNjYyMS00 ZTQ5LTg0OTctOTNiMzMwMGE0MTE2IiwidCI6ImJiMWI0YjU2LTQ 4N2EtNGIyMy04YTI0LWEzYWVmNjVlMTFmZiIsImMiOjF9

4. American Society of Addiction Medicine. Public Policy Statement on the Use of Naloxone for the Prevention of Opioid Overdose Deaths. Chevy Chase, MD; 2016. Accessed October 2020. https://www.asam.org/docs/default-source/public-policystatements/use-of-naloxone-for-the-prevention-of-opioid-overdosedeaths-final.pdf

5. Toledo Fire and Rescue. OD Response. Toledo, Ohio: Lucas County Health Department; 2020. Accessed October 2020.

6. Ohio Department of Health. Drug Overdose. Columbus, Ohio: Ohio Department of Health; 2021; Accessed January 2021 https://odh.ohio.gov/wps/portal/gov/odh/know-our-programs/ violence-injury-prevention-program/Drug-overdose/

7. Center for Disease Control. Occupational Exposure to Emergency Responders - NIOSH Workplace Safety \& Health Topics. Atlanta, GA: CDC; 2016. Accessed October 2020.

https://www.cdc.gov/niosh/topics/fentanyl/

8. Lucas County Health Department. Lucas County Drug Overdose Fatality Quarter 4. Toledo, OH: Lucas County Health Department; 2020. Accessed October 2020.

9. The Council of Economic Advisers. The Underestimated Cost of the Opioid Crisis. Washington D.C; 2017. Accessed February 2021. https://trumpwhitehouse.archives.gov/sites/whitehouse.gov/files/ images/The $\% 20$ Underestimated $\% 20$ Cost $\% 20$ of $\% 20$ the $\% 200$ pioid $\%$ 20Crisis.pdf 


\section{NALOXONE INTAKE FORM}

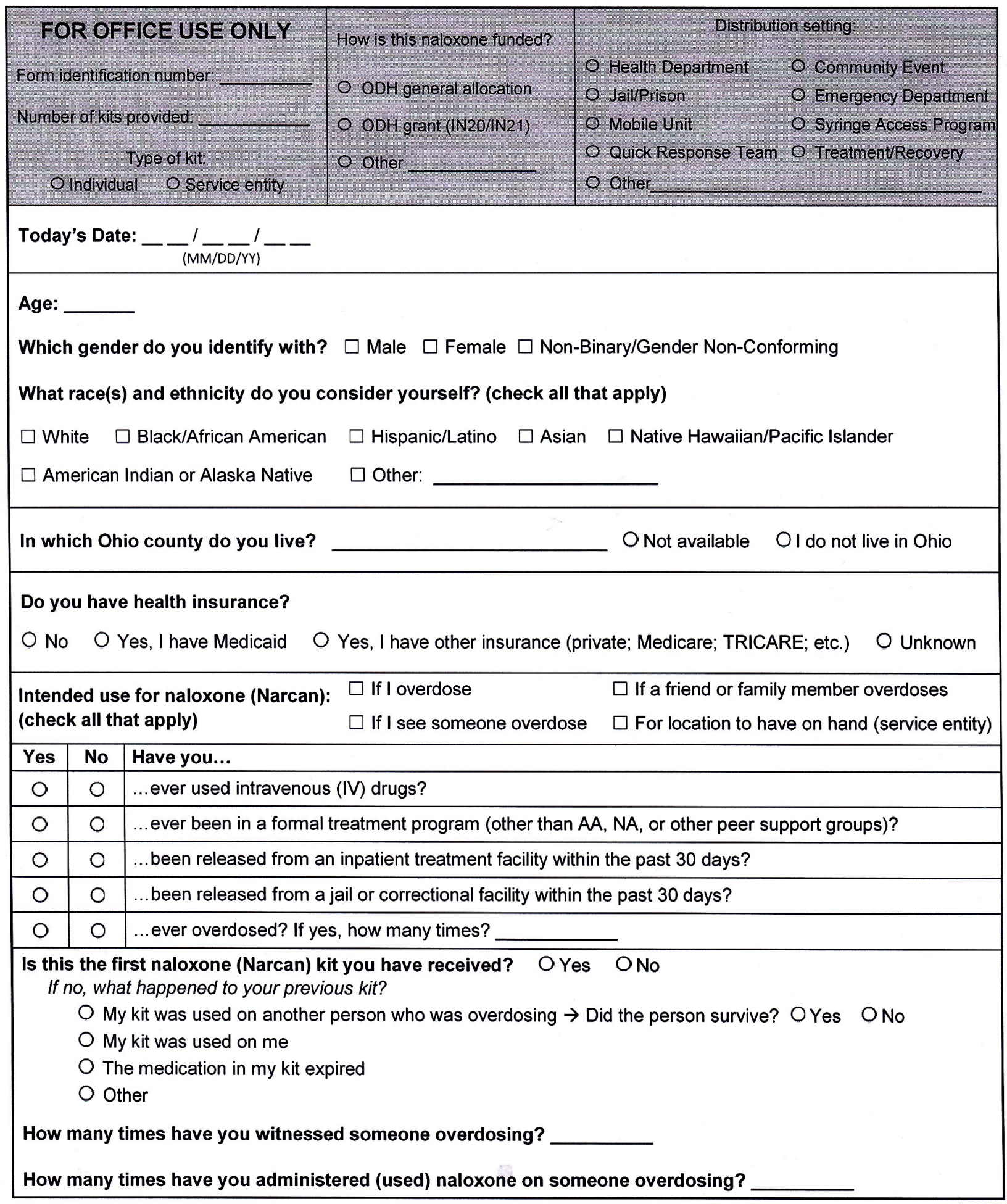


Date:

\section{Naloxone Outreach Program Healthcare Professional Student Survey}

1. I am confident I could elicit a substance abuse history from someone with addiction (Circle One)

\section{Strongly Disagree}

Disagree

Neither agree nor disagree

Agree

Strongly Agree

2. I am confident I could eliciting a substance abuse history from a family member or friend of someone with addiction (Circle One)

Strongly Disagree

Disagree

Neither agree nor disagree

Agree

Strongly Agree

3. I am confident I could provide contact information to those seeking addiction recovery programs in northwest ohio (Circle One)

Strongly Disagree

Disagree

Neither agree nor disagree

Agree

Strongly Agree

4. I am confident I could provide contact information to family members of those suffering from addiction in northwest ohio (Circle One)

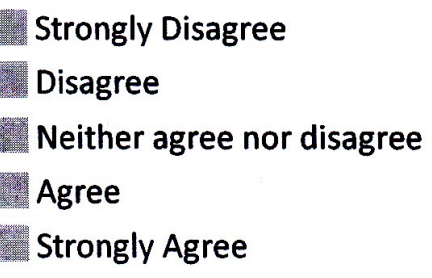




\title{
Sight for All United: Five Year Impact of a Vision Foundation on its Community
}

\author{
Ankur Parikh ${ }^{1}$; Meredith Spitz; ${ }^{1}$ Cooper T. Johnson ${ }^{1}$; S.A. Erzurum ${ }^{1,2}$ \\ ${ }^{1}$ Northeast Ohio Medical University, Rootstown, $\mathrm{OH}$ \\ ${ }^{2}$ Eye Care Associates, Youngstown, $\mathrm{OH}$ \\ Corresponding Author: Sergul Erzurum, 1075 W Western Reserve Road, Poland, OH 44514, (330) 565-0569, erzurum2020@gmail.com \\ Submitted December 14, 2020 Accepted April 12, 2021 Published June 21, 2021 https://doi.org/10.18061/ojph.v4i1.8074
}

\section{ABSTRACT}

Background: In 2016, Sight for All United (SFAU) was founded in the Mahoning Valley of Ohio with the mission of improving access to care and maximizing the visual potential of the underserved.

Methods: A retrospective chart review was conducted on patients served by SFAU from January 2016 through August 2020. Socioeconomic information, type of service, cost, and dollar amount paid were collected for patients. The data were analyzed with descriptive statistics and mapped with Esri ArcGIS.

Results: A total of 1327 patients received assistance through the medical assistance and school vision programs. In the medical assistance program, 222 patients (mean age 50 years, 57\% female) completed applications and $37 \%$ ( 83 patients) were in a household of 3 or more people. Median yearly income was $\$ 18504,134 \%$ above the federal poverty level by household size. The most common surgical services were cataract surgery (101) and vitreoretinal care (17). The most common medical services were eye exams (79) and spectacles (76). Estimated value of medical services provided was $\$ 367249$; actual cost was $\$ 93746$. The school vision program provided 1105 eye exams, 1514 pairs of spectacles, and 1 cataract surgery with an estimated value of $\$ 133692$.

Conclusion: Sight for All United provided \$500 941 of vision services to its patients since 2016 while dispersing less than $\$ 100000$ of donated dollars through collaboration with eye care providers, community resources, and national foundations. This study demonstrates the impact vision foundations managed by local eye care providers can have on the needs in their community in a cost-effective and efficient way.

Keywords: Nonprofit; Vision; Ophthalmology; Mahoning Valley

\section{INTRODUCTION}

In 1999, the World Health Organization (WHO), in collaboration with over 20 nongovernmental organizations, created the VISION 2020 Global Initiative. Its goal was to eliminate preventable causes of blindness by the year 2020. From 1990 to 2010, the global prevalence of moderate to severe visual impairment in adults over 50 years of age decreased from $3 \%$ to $1.9 \%{ }^{1}$

However, access to vision care remains challenging, even in the United States. Eight million Americans above the age of 40 have vision impairment due to uncorrected refractive error, and over 4 million Americans above the age of 40 have uncorrectable vision impairment, a number that is expected to double by $2050 . .^{2}$
One in 4, or close to 12 million, school-age children in the United States have some form of vision impairment. ${ }^{3}$ The total annual economic burden of eye disorders among the entire United States population is estimated to be over $\$ 138$ billion. ${ }^{4}$

Vision loss is a notable public health crisis in the United States and abroad, and conditions causing vision loss can lead to substantial deterioration in quality of life. ${ }^{5}$ The medical, behavioral, and social consequences of significant vision loss cannot be overstated. Myriad studies have shown the potential consequences of vision loss on independence, mobility, mental health, cognition, and, ultimately, mortality. ${ }^{6}$ 
As a society, we are still dependent on the work of charitable organizations to address the visual needs of our most vulnerable. Their programs are diverse in nature, ranging from comprehensive school vision initiatives to free surgical procedures and complex medical care for adults with vision-threatening disease. ${ }^{7}$ These organizations have an immense proclivity for collaboration. In fact, it is this collaboration that makes charitable vision organizations so unique and effective. Ophthalmologists, optometrists, optical laboratories, and industry corporations have united in an unprecedented way. Vision care providers can identify and treat at-risk or in-need patients while optical laboratories and industry corporations help provide lenses and frames. ${ }^{7}$

The purpose of this study is to describe the experiences on 3 counties in northeast Ohio of a single charitable vision organization, Sight for All United (SFAU), since its inception in 2015.

\section{METHODS}

\section{Setting}

Sight for All United is a 501c3 nonprofit organization based in Youngstown, Ohio, that aims to provide vision services for all members in its community in the tri-county area of Trumbull, Mahoning, and Columbiana, regardless of their ability to pay. This is primarily accomplished through 2 major programs, a medical assistance program and a school vision program. A retrospective chart review was conducted on all patients who received services via these 2 programs from January 2016 through August 2020.

\section{Medical Assistance Program}

\section{Program Design and Participant Characteristics}

When an eye care provider identifies a patient with medical and financial need, a formal medical necessity form is submitted to SFAU on behalf of the patient describing the pathology and services needed. The patient in turn completes a financial application to determine if they qualify for services. The patient provides demographic information, documentation of monthly income and expenses, government benefits (if any), and insurance status. Patients falling below $200 \%$ of the federal poverty level qualify for services.

Once an application is complete with all necessary information, it is reviewed by the executive director. If the medical necessity is solely for spectacles, the application can be reviewed and processed immediately. Via a partnership with a local optical laboratory, SFAU can fill the eye care providers' prescriptions for these patients. If the request involves medical or surgical services, the application is reviewed by the board of directors comprised of eye care practitioners and community leaders.

Patients without insurance can be approved for medical or surgical services up to $\$ 4000$. Often, requests are for assistance paying for high co-pays or deductibles. Treatment is provided by community eye care providers who have agreed to be part of this care network. There are currently 43 eye care providers who work with SFAU, including 21 ophthalmologists and 22 optometrists.

\section{Measures}

For participants in the medical assistance program, socioeconomic information including age, gender, household size, yearly income, zip code, type of service and estimated typical cost, and actual dollar amount paid were collected. For inactive patients or patients who did not ultimately receive services, reasons for inactivity were documented. The estimated value of services provided was calculated using Medicare rates. Percentage of the federal poverty level was calculated using published thresholds from 2020 for participants for which both income data and household size were available. ${ }^{8}$ The value was calculated for each participant and the median of these values was reported.

\section{School Vision Program}

\section{Program Design and Participant Characteristics}

Enrollment in the school vision program is initiated by the school administration and/or nurse. School districts participating included Youngstown City Schools, Liberty Local Schools, Warren City Schools, and Crestview Local Schools.

Students enrolled in kindergarten through eighth grade participate in the screening and subsequent school vision program. Per the vision screening requirements set forth by the Ohio Department of Health, students enrolled in kindergarten or first grade must receive a vision screening. The guideline also requires subsequent screenings in third, fifth, seventh, ninth, and eleventh grades. ${ }^{9}$ School nurses along with community volunteers conduct standardized vision screenings evaluating visual acuity, color vision, and stereoacuity at the participating schools each fall. Parents or guardians of students who fail the screening are educated about the importance of a complete eye examination and given the option to individually seek a medical examination for their child or to participate in the school vision program. If parents choose the school vision program, they complete a consent form for the child to receive an eye examination including pupillary dilation by one of the providers at their school during a designated week.

During the school-based eye exams, any student found to have a refractive error is fit for spectacles the same day. Each child receives 2 pairs of spectacles (a pair for home and a pair for school). These spectacles are dispensed and adjusted at the school. If a child is found to have medical pathology, consultation is recommended, and a form is sent home to the parents. School nurses are expected to follow up on the medical referrals, and SFAU provides assistance with locating a provider or transportation for the children if needed.

\section{Measures}

For participants in the school vision program, aggregate data including number of comprehensive exams and numbers of specta- 
cles dispensed were collected. The estimated value of services provided was calculated using Medicaid rates.

\section{Statistical Analysis}

The data were analyzed using Excel (Microsoft, 2019) and ArcGIS (Esri, 2019). Descriptive statistics, numbers, rates, and proportions were reported for the available data. Provider addresses were plotted against the zip codes of active and inactive patients. Provider addresses were also plotted against the school districts based on the number of students who participated in the program. Providers were coded either as MD (Doctor of Medicine), OD (Doctor of Optometry), or as offices with both types of clinicians. When examining the school district providers, the addresses were coded based on which providers worked with each school district. For example, providers who worked with students from Crestview Schools were grouped together.

\section{RESULTS}

\section{Medical Assistance Program}

Since its inception, 222 patients have been assisted by Sight for All United. Of those, 143 have completed applications, been approved by the board, and received services; 41 have been approved but have not yet received services; and 38 are currently active or at some point in the application process.

Patients who have received or will receive services are on average 50 years of age, $57 \%$ female, $30 \%$ live in a solo household, and
$63 \%$ live in a household with 2 to 4 people. The median income for patients with fully available income data $(\mathrm{n}=145)$ was $\$ 18504$ (on average, $134 \%$ of the federal poverty level).

The most common surgical service provided was cataract surgery ( $n=101$ ). Of note, 16 of these cataract approvals were for co-pay or deductible assistance. Other common surgical services included retinal procedures $(n=17)$ such as laser treatments and intravitreal injections and specialty toric lens implants for patients with severe, monocular astigmatism $(n=11)$. Lower volume surgical services included corneal crosslinking and procedures related to glaucoma and strabismus. The most common medical services included comprehensive eye examinations $(n=79)$ and provision of spectacles $(n=76)$. Patients also received specialty contact lenses for conditions such as keratoconus $(n=7)$, prosthetic eyes $(n=3)$, and medications ( $n=3)$. The total estimated value of these services provided was $\$ 367249$ while the total actual expenditure by SFAU was $\$ 93746$. A summary of the services provided and their estimated value can be seen in Table 1.

There were 126 inactive patients, with the most common reason being an incomplete application ( $n=41,33 \%)$. Other known reasons included denied and withdrawn applications ( $\mathrm{n}=17,14 \%)$, incomplete medical necessity forms $(n=10,8 \%)$, or incomplete income verification $(n=8,6 \%)$.

The zip codes of patients participating in the program along with locations of participating providers can be seen in Figure 1. Zip

\section{Table 1. Services Provided Including Estimated Value}

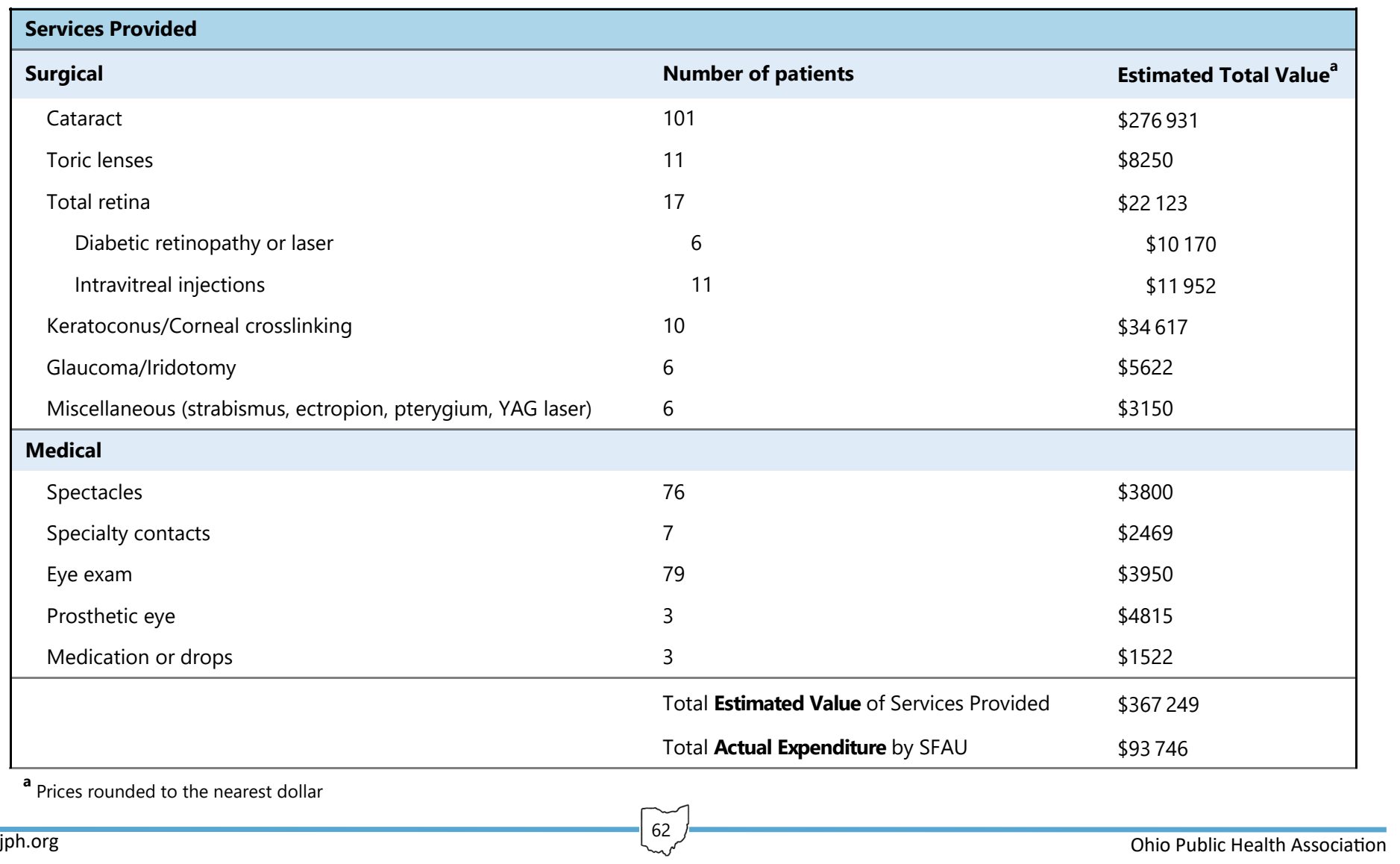




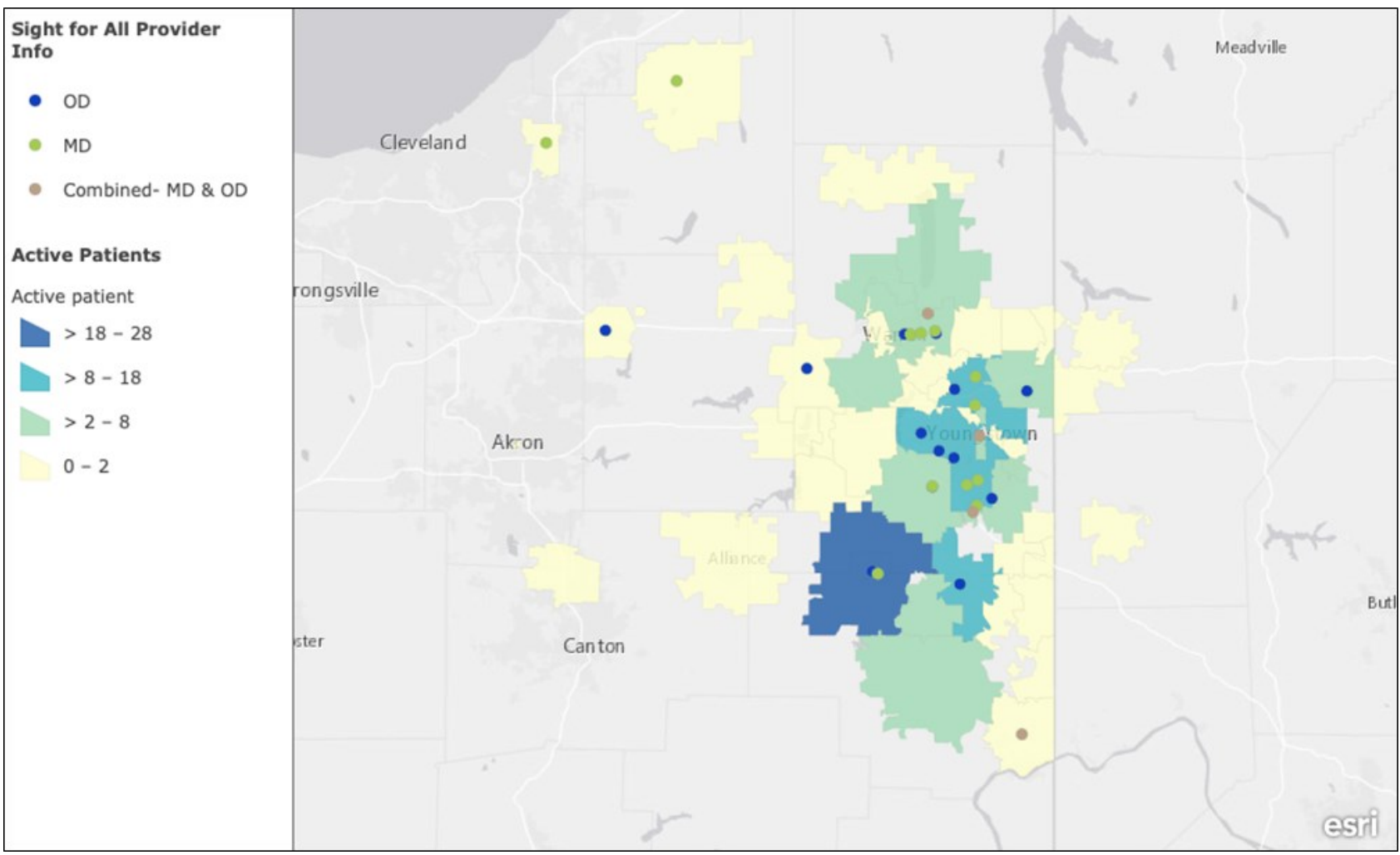

The zip codes with the highest number of patients are dark blue while the zip codes with the fewest patients are cream. Abbreviations: OD, Doctor of Optometry; MD, Doctor of Medicine

Figure 1. Comparison of Active Patient Zip Codes to Provider Zip Addresses

codes with a higher number of patients tended to have providers that are in the same zip code; however, this does not mean that those patients were visiting the nearest provider. There are some outlier zip codes, particularly in the northwest. These zip codes have providers nearby, but few patients. Most of these outlier zip codes were for patients with unusual conditions requiring referral.

\section{$\underline{\text { School Vision Program }}$}

The first school vision program was conducted in 2016 with only 95 students examined. Since that time, 1105 comprehensive eye examinations have been performed with a total estimated value of $\$ 55250$. From these 1105 exams, 378 (34.2\%) children were determined to have a vision impairment correctable with spectacles. In addition, 757 pairs of spectacles have been dispensed with a total estimated value of $\$ 75700$. One child required cataract surgery with an estimated value of $\$ 2742$. The total estimated value of the school vision program over its 4 active years was $\$ 133692$ with a total actual expenditure by SFAU of $\$ 0$ due to collaborations with national vision foundations, local optical laboratories, grants, and school and community organizations. Sight for All United provided and set up all eye examination equipment, eye care providers, oversight of prescriptions ordered, and dispensed all spectacles upon completion. Any spectacles broken or lost were replaced by SFAU's spectacle program at no cost to the student or school. A summary of the number of eye examinations and spectacles provided along with their estimated value can be seen in Table 2 .

A visualization of participating school districts along with the relationship between those school districts and the participating providers can be seen in Figure 2. This displays the providers who work with each school district. While Youngstown City Schools and Liberty Local School District are 2 unique districts, all providers who worked with 1 of these districts also worked with the other district.

\section{Total Value of Services Provided}

In the past 5 years, Sight for All United has served 1476 citizens of the Mahoning Valley community through their medical assistance and school programs by providing services with an estimated total value of $\$ 500941$ and an actual expenditure of $\$ 93746$.

\section{DISCUSSION}

As a result of the programs provided by SFAU, a significant number of patients who otherwise may not have been able to afford or access eye care due to economic or social reasons were provided with medical and surgical services at no cost. It is important to note that 16 patients of the 101 that received cataract surgery had health insurance. However, their significant co-pays or deductibles 


\section{Table 2. School Vision Program Services Provided with Estimated Value}

\begin{tabular}{|lllllll|}
\hline & Number of exams & \$ of exams & $\begin{array}{l}\text { Number of spectacles } \\
\text { (2 pairs per child) }\end{array}$ & \$ of spectacles & Number of misc & \$ of misc \\
\hline 2016 & 95 & $\$ 4750$ & 85 & $\$ 8500$ & 1 (Cataract) \\
2017 & 252 & $\$ 12600$ & 156 & $\$ 15600$ & \\
2018 & 335 & $\$ 16750$ & 232 & $\$ 23200$ & \\
2019 & 423 & $\$ 21150$ & 284 & $\$ 28400$ & \\
\hline Total & $\mathbf{1 1 0 5}$ & $\mathbf{\$ 5 5 2 5 0}$ & $\mathbf{7 5 7}$ & $\mathbf{\$ 7 5 7 0 0}$ & $\mathbf{1}$ & $\mathbf{\$ 2 7 4 2}$ \\
\hline
\end{tabular}

prevented them from receiving the care they needed. The number and range of services provided indicate that there is a large need for vision assistance in this area.

The Mahoning Valley, an area encompassing Mahoning, Trumbull, and Columbiana Counties, is a socioeconomically disadvantaged population. This can often translate to poor health outcomes. Per a report published by the Centers for Disease Control and Prevention (CDC), both Mahoning and Columbiana Counties have a prevalence of vision impairment between $2.4 \%$ and $3.0 \%$. For Trumbull County, the prevalence of vision impairment is between $1.8 \%$ and $2.3 \% .^{10}$ The median household income of these 3 counties, $\$ 48000, \$ 47400$, and $\$ 44900$ respectively, is significantly lower than Ohio's median household income of $\$ 56200.11$ This is especially apparent in the population served by SFAU, whose me- dian household income was just \$18504, or $134 \%$ above the federal poverty level. Age is another indicator that may be correlated to need for vision services, especially cataract surgery. ${ }^{12}$ The proportion of the population over the age of 65 years in these counties, 21\%, 21.6\%, and 20.5\% in Mahoning, Trumbull, and Columbiana respectively, is also significantly higher than the $17.1 \%$ seen throughout the state. ${ }^{11}$

Visual impairment can have a profound impact on a person's quality of life, including their health and wellbeing. ${ }^{6}$ Several factors have been instrumental in the success of the medical assistance program. Sight for All United is in the unique position of being able to operate as a coordinator, negotiator, and payer for services provided by community eye care providers. In its role as coordinator, SFAU can both receive referrals from physicians who have

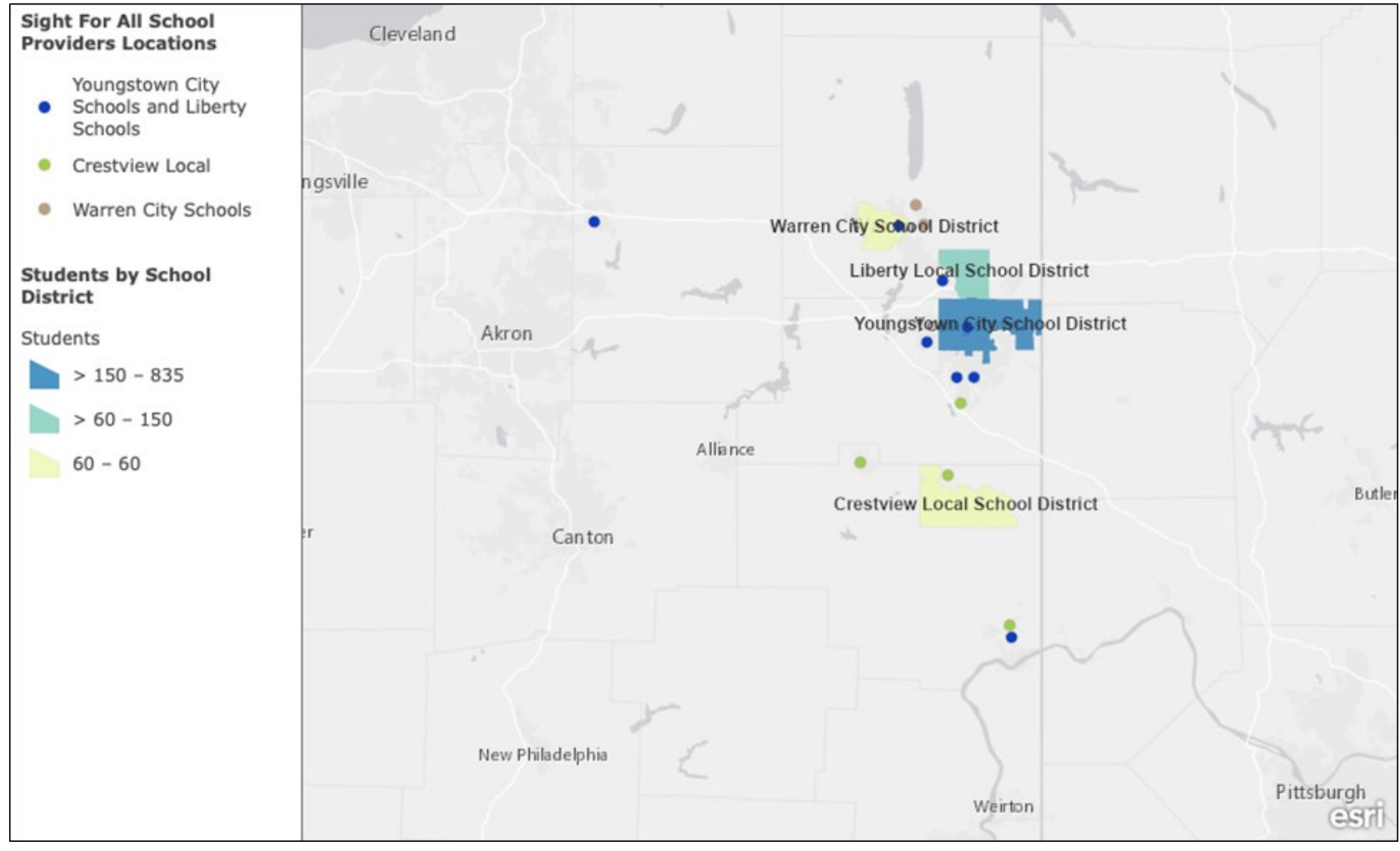

Figure 2. School Districts by Active Students and the Associated Providers 
patients in need and subsequently vet the patients and determine both their economic need and the ultimate cost for the services they require. In its role as a negotiator, SFAU can work with both providers and local and national organizations to deliver the necessary care at reduced costs. Through partnerships with optical laboratories, large vision foundations, and even commercial providers of medical and surgical equipment, they can maximize every dollar received from fundraising and grants. Finally, in their role as payer, they can compensate providers for their service to the community and, as a result, encourage them to continue providing services and advocating for patients in need. Future goals for the medical assistance program include increasing the reach to surrounding communities and increasing the volume of patients served.

While visual impairment has a significant impact on the adult and elderly population, untreated vision impairment also affects children. Prior studies have shown that refractive error and uncorrected visual abnormalities in children can have a significant effect on academic performance and achievement.13-15 Additionally, these visual abnormalities, oftentimes secondary to correctable refractive error, disproportionately affect children from low income and minority families. ${ }^{14}$ While the Ohio Department of Health mandates regular vision screenings for school-age children, one of the biggest roadblocks is optometric and ophthalmic followup care for the children that fail their screenings. ${ }^{9}$ In its vision screening annual report for the 2018-2019 school year, the Ohio Department of Health reported that only $22.5 \%$ of referrals were completed by preschool through twelfth grade students. ${ }^{16}$ It is here that SFAU has been able to have the biggest impact on its community's school-age population. With over four years of implementing and continually improving its school vision program, SFAU has been able to provide eye exams for over 1100 children and provide over 750 pairs of spectacles. Approximately $34 \%$ of children who received an eye examination had a correctable visual deficit and were provided spectacles. As with the medical assistance program, SFAU's relationship with community providers, optical laboratories, and national organizations has been essential to the program's success. Their coordination of these entities along with their on-the-ground knowledge of the Mahoning Valley has allowed the program to be efficiently and effectively executed. In the future, the school vision program will expand to more school districts and include collaboration with school nurses to increase referrals for children with medical issues.

Moving forward, it is critical to continue raising awareness about the effects of visual impairment on health, quality of life, and, for children, academic achievement and future success so that those in need know how and when to reach out for assistance.

\section{PUBLIC HEALTH IMPLICATIONS}

While significant progress in treating vision loss has been made over the past several decades, it remains a significant public health concern. In 2016, the National Academies of Sciences, Engineering, and Medicine (NASEM) issued a report declaring eye health a major public health problem. ${ }^{17}$ The population of Americans with vision loss is expected to increase by nearly 2.5 times by the year 2050, affecting over 7 million people. The projected cost of vision loss is expected to reach nearly $\$ 375$ billion by the year $2050 .^{18}$ However, these are only projections. If we change course and continue supporting and raising awareness about unmet visual needs, the outcome can change. Community organizations will be particularly important in these efforts. By using their specific knowledge and local relationships while building regional and national connections, community organizations can create networks that deliver care to those who need it most.

\section{ACKNOWLEDGMENTS}

Sight for All United would like to thank its partners in sight, especially the Essilor Vision Foundation, Classic Optical Laboratories, United Way of the Mahoning Valley, United Way of Trumbull County, Cafaro Foundation, 00A, and Polena Trust

\section{REFERENCES}

1. Stevens GA, White RA, Flaxman SR, et al. Global prevalence of vision impairment and blindness: magnitude and temporal trends, 19902010. Ophthalmology. 2013;120(12):2377-2384. https://doi.org/10.1016/j.ophtha.2013.05.025

2. Centers for Disease Control and Prevention. Fast facts of common eye disorders. Published June 9, 2020. Accessed August 26, 2020. https://www.cdc.gov/visionhealth/basics/ced/fastfacts.htm

3. Hecker S. New Online Resource to Help Protect Children's Sight Launches from The National Center For Children's Vision And Eye Health at Prevent Blindness and the National Association Of School Nurses. Prevent Blindness; 2016:3. Accessed September 1, 2020. https://preventblindness.org/wp-content/uploads/2016/03/ NASNPBRelease.pdf

4. Wittenborn JS, Zhang X, Feagan CW, et al. The economic burden of vision loss and eye disorders among the United States population younger than 40 years. Ophthalmology. 2013;120(9):1728-1735. https://doi.org/10.1016/j.ophtha.2013.01.068

5. Saaddine JB, Narayan KMV, Vinicor F. Vision loss: a public health problem? Ophthalmology. 2003;110(2):253-254. https://doi.org/10.1016/S0161-6420(02)01839-0

6. National Academies of Sciences E, Division H and M, Practice B on PH and $\mathrm{PH}$, et al. The Impact of Vision Loss. National Academies Press (US); 2016. Accessed December 9, 2020.

http://www.ncbi.nlm.nih.gov/books/NBK402367/

7. United SFA. Sight for All United. Accessed February 20, 2021. https://sightforallunited.com/

8. US Department of Health and Human Services. 2020 Poverty Guidelines. Office of the Assistant Secretary for Planning and Evaluation. Published January 21, 2020. Accessed February 20, 2021.

https://aspe.hhs.gov/2020-poverty-guidelines

9. Ohio Department of Health. Vision Screening Requirements and Guidelines for Preschool and School-aged Children 2017. 2017. Accessed July 30, 2020.

https://odh.ohio.gov/wps/wcm/connect/gov/471c5b34-e547-44fda0a4-f8fbc2190743/Vision-Screening-Requirements-Report-2-18.pdf? 
MOD=AJPERES\&CONVERT_TO $=$ url\&CACHEID=ROOTWORKSPACE.Z1

8_M1HGGIK0N0J000Q09DDDDM3000-471c5b34-e547-44fd-a0a4-

f8fbc2190743-mlCJLCo

10. Centers for Disease Control and Prevention. Vision Health Initiative (VHI) | Ohio State Profile. Published April 25, 2019. Accessed February 20, 2021.

https://www.cdc.gov/visionhealth/data/state-profiles/ohio.htm

11. Compare Counties in Ohio - Mahoning (MH) vs Trumbull (TR) vs Columbiana (CO). County Health Rankings \& Roadmaps. Accessed December 10, 2020.

https://www.countyhealthrankings.org/app/ohio/2020/compare/ additional

12. Hashemi H, Pakzad R, Yekta A, et al. Global and regional prevalence of age-related cataract: a comprehensive systematic review and metaanalysis. Eye. 2020;34(8):1357-1370.

https://doi.org/10.1038/s41433-020-0806-3

13. JBO - Volume 7 - Issue 2 - The vision screening of academically \& behaviorally at-risk pupils | OEP Foundation. Accessed December 11, 2020 .

https://www.oepf.org/journal/pdf/jbo-volume-7-issue-2-visionscreening-academically-behaviorally-risk-pupils

14. Basch CE. Vision and the achievement gap among urban minority youth. J Sch Health. 2011;81(10):599-605.

https://doi.org/10.1111/j.1746-1561.2011.00633.x

15. Maples WC. Visual factors that significantly impact academic performance. Optometry. 2003;74(1):35-49.

16. Ohio Department of Health. ODH Children's Vision Program - Annual Report 2018-2019. Accessed December 6, 2020.

https://odh.ohio.gov/wps/portal/gov/odh/know-our-programs/

children-s-hearing-vision-program/resources/vision-program-annualreport-2018-2019

17. Making Eye Health a Population Health Imperative - NCBI Bookshelf. Accessed December 11, 2020.

https://www.ncbi.nlm.nih.gov/books/NBK385157/

18. Wittenborn JS, Rein D. The Future of Vision: Forecasting the Prevalence and Costs of Vision Problems. NORC at the University of Chicago; 2014. Accessed August 26, 2020.

https://visionimpactinstitute.org/research/the-future-of-visionforecasting-the-prevalence-and-costs-of-vision-problems / 

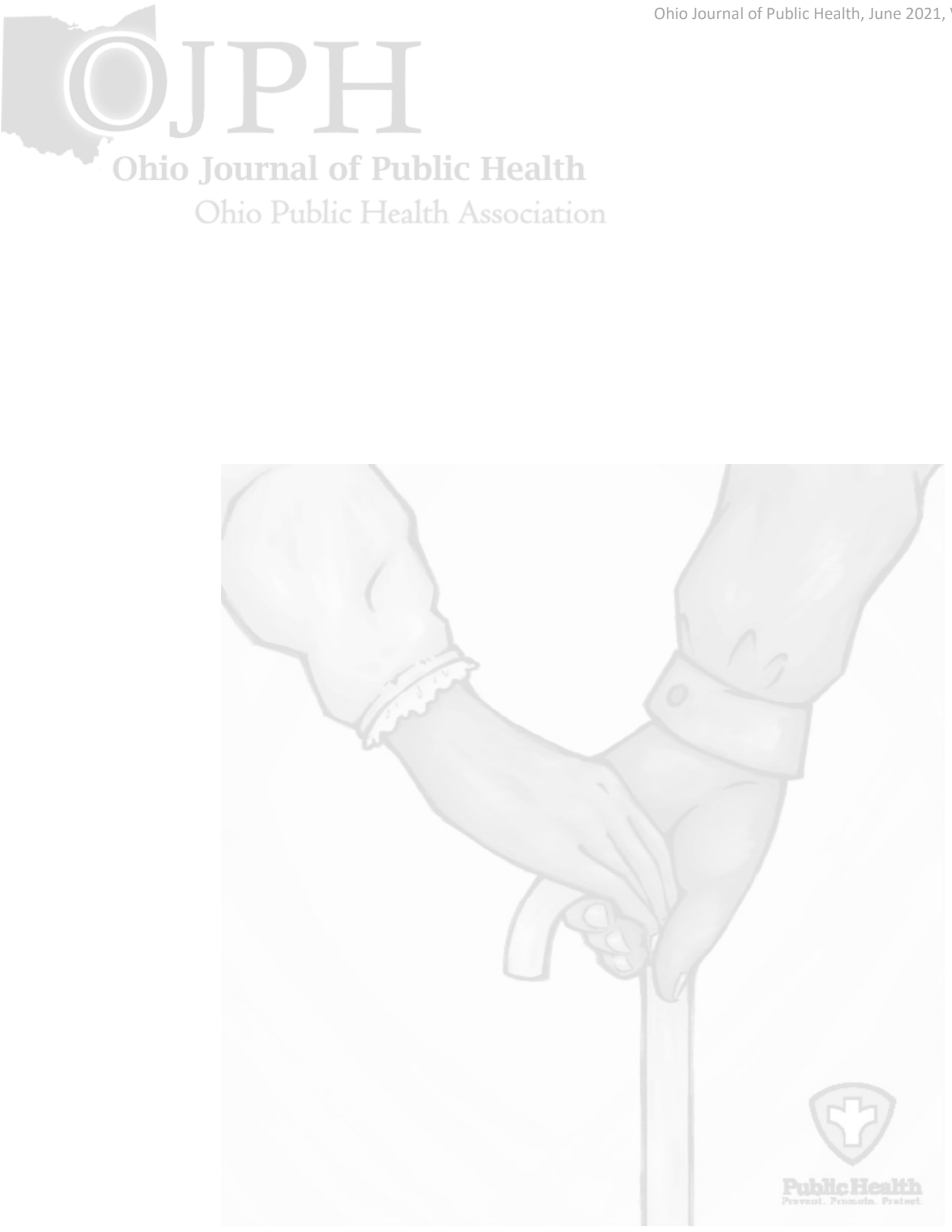